\title{
Sustainability for Whom? \\ The Politics of Imagining Environmental Change in Education
}

\author{
Hanna Sjögren
}

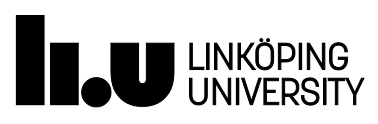

Linköping Studies in Arts and Science No. 678

Faculty of Arts and Sciences

Linköping 2016 
Linköping Studies in Arts and Science • No. 678

At the Faculty of Arts and Sciences at Linköping University, research and doctoral studies are carried out within broad problem areas. Research is organized in interdisciplinary research environments and doctoral studies mainly in graduate schools. Jointly, they publish the series Linköping Studies in arts and Science. This thesis comes from Unit of Technology and Social Change at the Department of Thematic Studies.

Distributed by:

Department of Thematic Studies - Technology and Social Change Linköping University

58183 Linköping SWEDEN

Hanna Sjögren

Sustainability for Whom?

The Politics of Imagining Environmental Change in Education

Edition 1:1

ISBN 978-91-7685-782-3

ISSN 0282-9800

Cover design: Hanna Sjögren, Baki Cakici, and Per Lagman, LiU-Tryck

Cover photo: Hanna Sjögren

(C) Hanna Sjögren

Department of Thematic Studies - Technology and Social Change 2016

Printed by: LiU-Tryck, Linköping 2016 


\section{Abstract}

Global initiatives regarding environmental change have increasingly become part of political agendas and of our collective imagination. In order to form sustainable societies, education is considered crucial by organizations such as the United Nations and the European Union. But how is the notion of sustainability imagined and formed in educational practices? What does sustainability make possible, and whom does it involve? These critical questions are not often asked in educational research on sustainability.

This study suggests that the absence of critical questions in sustainability education is part of a contemporary post-political framing of environmental issues. In order to re-politicize sustainability in education, this study critically explores how education - as an institution and a practice that is supposed to foster humans-responds to environmental change. The aim is to explore how sustainability is formed in education, and to discuss how these formations relate to ideas of what education is, and whom it is for.

This interdisciplinary study uses theories and concepts from cultural studies, feminist theory, political theory, and philosophy of education to study imaginaries of the unknown, nonhuman world in the context of education. The focus of the empirical investigation is on teacher education in Sweden, and more precisely on those responsible for teaching the future generations of teachers - the teacher instructors. With help from empirical findings from focus groups, the study asks questions about the ontological, political, and ethical potential and risk of bringing the unknown Other into education. 



\section{Contents}

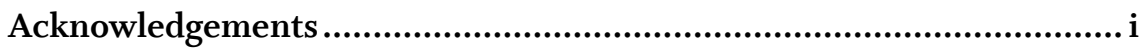

1 Introduction: Sustainability for whom? ..............................................

Sustainability and education .............................................................. 2

The politics of environmental change …………...................................... 4

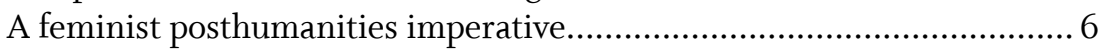

Sustainable development in Swedish education ....................................... 7

An introduction to Swedish teacher education...................................... 9

Research aim and questions ...............................................................11

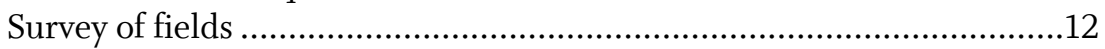

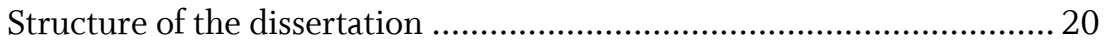

2 Theoretical perspectives: The politics of imagining.......................... 23

The politics of (un)knowing................................................................. 24

The politics of social imagination........................................................... 26

Feminist interventions into what counts as nature ................................ 32

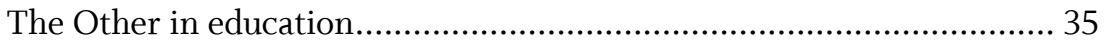

3 Material and methods: How to study social imaginaries................... 39

Focus groups as a methodological strategy ............................................. 40

Interview guide and stimulus material ................................................... 42

Recruiting focus group participants ....................................................... 53

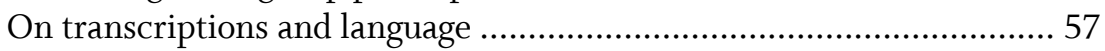

Analytical strategies......................................................................... 57

Situating the researcher by developing themes and chapters.................. 60

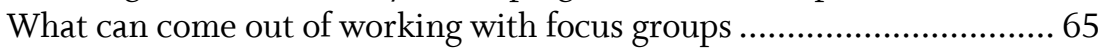

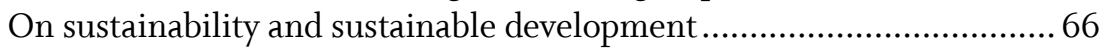

4 Who can become sustainability literate? ............................................69

The student as an active and happy consumer ......................................... 70

Students as irresponsible youth..............................................................77

The knowing student and the purpose of sustainability education ..........80

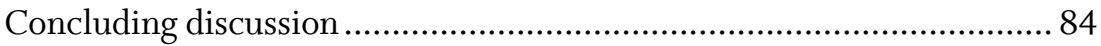


5 The balancing acts of teaching sustainability in a post-political

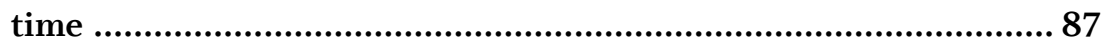

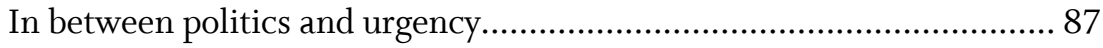

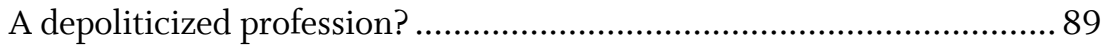

Troublesome knowledge in between facts and values ............................ 98

Concluding discussion ......................................................................104

6 The possibility of nonhuman animal encounters in sustainability

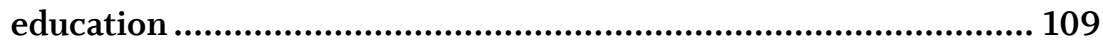

"Meating" animals: Reification of domesticated creatures....................110

A conditioned care for the individual animal........................................115

A moment of care for charismatic animals ..........................................119

The fear of losing control .................................................................123

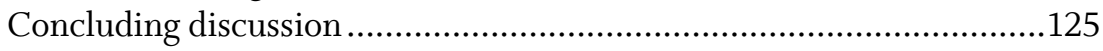

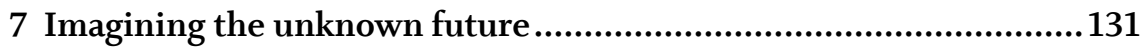

The limits to knowledge of the future .................................................132

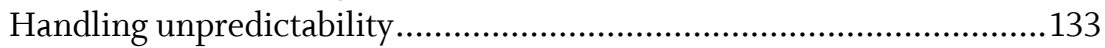

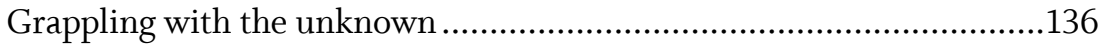

Imagining a doomed future: Consequences for education ......................142

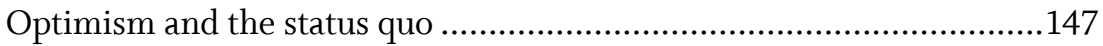

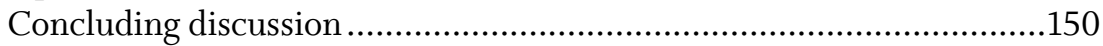

8 Conclusions: The politics of imagining environmental change in

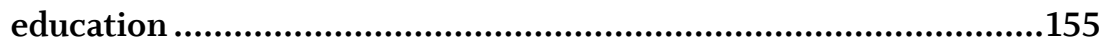

Tracing the sustainability imaginary in education .................................156

Re-politicizing sustainability ............................................................158

What now? The politics of imagining environmental change in

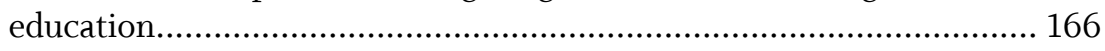

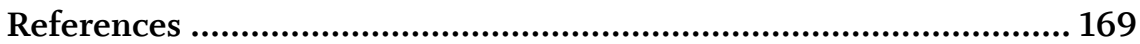

Appendix A: Links to images used as stimulus material in the focus

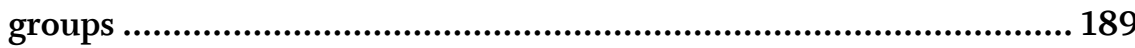




\section{Acknowledgements}

Writing a dissertation has been a confusing, challenging, difficult, exciting, fun, rewarding, and incredible experience. I am glad I had the chance to work through questions, theories, thoughts, and a rich empirical material within the framework of a dissertation. Thank you to those who gave me the chance, and to all who made it possible.

Thanks to the Swedish Energy Agency (Energimyndigheten) for funding my project. I also want to thank the focus group participants who made this study possible. Thank you so much for contributing with your time, experiences, and thoughts on sustainability in education.

Thank you to my two academic supervisors, Pelle and Cissi, you have supported me in different yet invaluable ways. My main supervisor, Per Gyberg, thank you for your presence and endless encouragements throughout these years. You have given me the space I needed to develop my own research, and I have appreciated your critical and encouraging readings of countless of drafts, as well as our shared interest in not only animals in education, but also in good falafel lunches. Thank you to my co-supervisor, Cecilia Åsberg, for generously sharing your worlds of feminist and cultural studies with me. Thank you for always encouraging me to do things I didn't know I would be able to do, and for showing me the possibility of new intellectual paths.

I want to thank the two different seminar groups I participated in during my $\mathrm{PhD}$ studies at TEMA. Thank you Green Critical Forum/Environmental Humanities Forum, and Technology, Practice, and Identity for providing me with the best education a $\mathrm{PhD}$ student could ask for.

Thank you Eva Reimers, Francis Lee, and Victoria Wibeck for your patient and insightful comments at my 60\%-seminar. Helena Pedersen did a thorough and much appreciated reading as the opponent of my $90 \%$-manuscript which helped me enormously. Thank you also to the $90 \%$-committee: Roger 
Klinth, Anne-Li Lindgren, and Harald Rohracher for asking all sorts of difficult questions that helped me to improve the text in the end. Jonas Anshelm gave additional insightful comments on the whole text during a walk after the seminar at Campus Valla in June 2014. Thank you Jonas for engaging in my project. I also want to thank Johan Hedrén who gave important feedback on the introduction chapter towards the end my writing. I also want to thank Martin Hultman and Karin Skill who have engaged in my project in different ways that I have appreciated deeply.

I have benefited enormously from being part of a $\mathrm{PhD}$ student collective, together with whom I've made most of this journey. Thank you Réka Andersson, Maria Eidenskog, Linnea Erikssson, Mattias Hellgren, Linus Johansson Krafve, Lisa Lindén, Maria Nilsson, Josefin Thoresson, and Anna Wallsten for great lunch company, coffee breaks, and invaluable moral support.

In spring 2011, I had to share an office with Simon Haikola. At first, we glared at each other from opposite desks, but soon enough our friendship took off. Thank you Simon for being the best roommate a new and anxious PhD student could have had, and for sharing my interest in coffee breaks, TV-series, spin classes, ice cream, soul music at the office, and much more. I met Lisa Lindén in August 2011, when she joined TEMA. Thank you Lisa for our many discussions on feminist theory, politics of everyday life, and for all the veggie burgers and smoked tofu dishes I've had the pleasure of sharing with you. Anna Wallsten, thank you for your inspiring attitude and your kindness, and for bringing that exquisite cherry pie at crucial moment in life. Emmy Dahl and Malin Henriksson have been invaluable as friends and colleagues at TEMA, thank you so much for showing the way to feminist environmental studies, and for always being there for me in many different ways. Furthermore, Veronica Brodén Gyberg, Anna Kaijser, Anna Morvall, and Julia Schwabecker have provided me with enormous support and inspiration. And to all new friends I have made among the PhD students at the TEMA department, thank you for making TEMA a great place to work in. Thank you also Robert Aman, for being a wonderful weekly lunch companion when we both lived in Linköping, and for always encouraging me, and generously sharing your knowledge of academic life.

Thank you feminism! I had the great pleasure of being involved in a "liberation army" of feminist PhD students at the Norrköping Campus during my first years in Linköping. Thank you Sara Ahlstedt, Linnea Bodén, Veronica 
Ekström, Karin Krifors, Jennie K Larsson, and Sofia Lindström for all the fun and important discussions about academic life and feminism that we've had. Furthermore, I've had the great luxury of joining a feminist discussion group of friends in 2011 who made all the difference on so many occasions. Thank you Anna F, Anna M, Anna W, Elin, Emmy, Lina, Malin A, Malin H, Monireh, Silje, and Sarah.

I also want to thank some of my friends outside academia: Thank you Emma Mårtensson, words cannot describe what you mean to me and how much I apprentice that you are always just a Skype-call away. Dear Helena Engberg, my source of creative inspiration ever since first grade, thank you for the best long-distance friendship ever. Thank you Livia Johannesson, for sharing the various experiences of the $\mathrm{PhD}$ student life and of life in general. It has always been a pleasure. Thank you Jenny Jonstoij for always encouraging me do otherwise. Thank you Sofie Hultman-Collin for your surprising, curious, and fun text messages that always arrive when I least expect them to. Thank you Fredrik Åslund, for teaching me to pay attention to the details of not only cocktails but also vegan ice cream. Thank you Elsa Engstöm, for your friendship, for being my steady companion at demonstrations, and for all our conversations about politics of this and that.

I also want to thank some of my friends in London, especially Pinar Kayacan Aksu, Susanna Lohri, and Nadia Frost for invaluable support, and for making me feel at home in South East London.

I have had several exciting opportunities of being a visiting scholar during my PhD studies. Thank you to the researchers of the HumAnimal Group at the Centre for Gender Research, Uppsala University, Sweden, who welcomed me as a visiting researcher in May 2013. I learned a lot from you. Thanks to all of you who welcomed me to the English Department of University of Texas at Arlington, USA, in Spring 2013. I could not have asked for a better place to read, write, and develop my research. I have also had the pleasure of writing up my dissertation as a visitor at the Centre for Cultural Studies at Goldsmiths, University of London, UK. Thank you Matthew Fuller, and others at the centre, for generously inviting me to Goldsmiths, a unique intellectual and creative environment. No wonder the last month of the $\mathrm{PhD}$ has been so enjoyable and inspiring. 
At Goldsmiths, I have benefited from joining a weekly writing group at the Sociology department. Thank you Goldwig, for your moral support when writing some of the more challenging sections of the dissertation. Furthermore, thank you to all the enthusiastic participants in our reading group on posthuman subjectivities and ethics at Goldsmiths. I also want to thank Ville Takala for coffee and lunch breaks with discussions about research, politics, nationalism, globalization, sports, and much more.

A big thank you to family and relatives, especially to my mum - mamma Solveig Olausson, who helped us out with child care in unbelievably generous ways. I also want to thank my mother-in-law, Iclal Cakici, for your time and effort in helping us out with child care in the UK. A special thank you also to my cousin Ida Andersson for kindly helping us out.

My little family decided to take a leap into the unknown and move to London in early 2015. It's been a challenging but also an incredibly rewarding move. I'm glad we have given London a chance. To my partner, Baki Cakici, thank you for supporting me in all kinds of ways and also for encouraging me to apply for a $\mathrm{PhD}$ in the first place. Sharing the challenges and the fun of academic life with you has been invaluable, and I am so glad we keep making this journey together. Thank you also to my son, Devrim, our little revolution, born in 2014, life with you is always full of curious encounters and exciting adventures. Thank you for being the best company I could ever ask for when exploring our new neighborhood Greenwich in 2015. I look forward to all the different adventures we will continue to have together. How about we go out together to look for that black cat in our backyard?

Greenwich, London

April 11, 2016

Hanna Sjögren 


\section{Chapter 1}

\section{Introduction: Sustainability for whom?}

DAVID: The issue of sustainable development is rather complex, which makes it hard to teach, like Dan [a colleague] maybe mentioned; [after all] what is sustainable development?

The quandary over what sustainable development in education means is a curious one. The question quoted above is posed by teacher instructor David, one of the focus group participants in this study. It is a question he poses with a wry laugh towards the end of a long conversation about sustainable development in education. How is it that he does not seem to know what sustainable development is? And why is he laughing? At first glance the question he poses may seem rather absurd - and indeed something to laugh about - given that sustainability through education has been highlighted globally by organizations such as the United Nations and the European Union during the last two decades. These global initiatives can be seen in the light of how environmental issues have increasingly become part of political agendas and of our collective imagination. As part of this global trend, education for more sustainable futures has become an important matter of concern, not least in Sweden, which serves as the case for this study. Clearly, sustainability is now a general goal for the educational system - but how is this concept imagined and formed in practice? What does it make possible, and whom does it involve? Who is educable in the drive for sustainability? Or, to put it in a more critical way: What is it that sustainability education seeks to sustain, and for whom (see e.g., Alaimo 2012)? All of these questions are entangled with epistemological and political quandaries in relation to environmental change. As shown in the quote from David above, the answers to these questions are far 
from self-evident, but they nevertheless need to be addressed in order to make sustainability teachable in an educational setting. The fact that David is laughing when he asks what sustainable development is will here be seriously considered as a curious thing in itself. How sustainability is addressed, imagined, and made teachable is of interest in this study, which explores the formation of sustainability in education. Below, I further explain why this topic needs to be investigated.

\section{Sustainability and education}

The notion of sustainable development was established globally in 1987 by the release of the report Our Common Future written by the World Commission on Environment and Development (WCED), also known as the Brundtland Commission. Here, sustainable development is famously defined as "development which meets the needs of the present, without compromising the ability of future generations to meet their own needs" (WCED 1987, 43). Evidently, this is a definition that is open to interpretation, depending on, for example, how the present and future are understood, as well as what one includes in the notion of generations and in the notion of needs. The problem of defining sustainable development in practice has been discussed both in critical environmental research in general (see e.g., Bradley 2009; Alaimo 2012; Henriksson 2014) and in critical educational research in particular (see e.g., Bonnett 2002; Ideland and Malmberg 2014; Ideland and Malmberg 2015; Hasslöf 2015). Evidently, educational practice, with its raison d'être and historical trajectories, accentuates certain things as important while leaving others behind (see e.g., Gyberg 2003, 17-18). Arguably, how education as a societal institution handles sustainability is significant to investigate not least because education is an institution to which most humans are subjected during some part of their life (UNESCO 2015). According to educational researcher Michael Bonnett (2002), two main strands can be traced to understand sustainability in education. The first he calls the environmentalist approach, which focuses on teaching those who do not know. This approach relies on expert knowledge and an instrumental rationality with a certain outcome. Here education is seen as a means for changing behaviors and attitudes. The second approach he calls the democratic approach, which he also claims rests on a rational assumption leading to critical thinking and practical action competence. The role of education here is to foster rational critical attitudes for 
change. These two strands largely correspond to education's generally double role of both teaching specific knowledge areas and forming the future citizen (Gyberg 2003, 18). However, both of these approaches take sustainability as a given good and leave little room for critically examining underlying assumptions about education. The critical questions of what education for sustainability makes possible and who it involves are not often asked in educational research on sustainability. However, these critical questions are of importance for unraveling structures of power and for providing new possibilities through environmental change.

The educational field has come to play a politically important role in the drive to create new paths and make the future more sustainable (see e.g., Skolverket 2002; J. Öhman 2006; Björneloo 2008). Historically, education has been a major societal institution responsible for forming generations of future citizens in the modern society (see e.g., Foucault 2004; Åberg 2008). Becoming educated is a process that both transforms and disciplines the subject. Education is an institution that shapes us as humans, and education continues to be considered important even in times when visible nonhuman subjectivity is acknowledged in co-shaping our world. Education is therefore an arena that is considered politically important for dealing with matters associated with sustainability and the environment (Gough and Scott 2008; Kahn 2003). One example out of many is from the Baltic regional context, and Baltic 21 Education, a declaration initiated by the ministers of education in the region, emphasizing the role of education in creating sustainable development (Utbildningsdepartementet 2002). Another one is UNESCO's (United Nations Educational, Scientific and Cultural Organization) 2005-2014 Decade of Education for Sustainable Development, in which the goal has been for all education and all teaching to lead to knowledge "that motivate[s] and empower[s] learners to change their behavior and take action for sustainable development" (UNESCO 2013). This Decade has now been evaluated by UNESCO with the conclusion that, as a result of the work completed during those 10 years "the process of reorienting education policies, curricula and plans towards sustainable development is well underway" (UNESCO 2014, 6). However, the organization also claims that there is further work to be done in institutionalizing education for sustainable development and in ensuring strong political support to implement education for sustainable development on a systemic level. Furthermore, they conclude that more research needs to be done to 
prove the effectiveness of sustainability education in practice. In this way, education for more sustainable futures has become an important matter of concern.

It is often claimed that a single teacher can potentially influence thousands of students during her/his professional working life (see e.g., Gough and Scott 2008 , 41). Teachers are often recognized as a key factor in the success of introducing sustainability in schools (Campbell and Robottom 2008, 202-203). I focus my empirical investigation on teacher education in Sweden, and more precisely on those responsible for carrying out the teaching of future generations of teachers - the teacher instructors. By "teacher instructors" I refer to those involved in teaching tomorrow's generations of teachers at universities and colleges (faculty staff such as teaching assistants, lecturers, senior lecturers, $\mathrm{PhD}$ candidates, and assistant and full professors). Clearly, teacher instructors are given central responsibility for educating future generations of teachers. The empirical study consists of focus group interviews with teacher instructors conducted in order to capture the ways in which sustainability issues might impinge on the education of future teachers, and to create methodological prerequisites for the practitioners to define and grapple with how to handle this concept and make it teachable. The position as a teacher instructor can be seen as crucial for investigating the formation of sustainability and its subject positions precisely due to the location of the teacher instructor at the intersection of various educational and knowledge practices.

\section{The politics of environmental change}

How sustainability education is made possible - in teacher education and elsewhere - relates to how we imagine ourselves, and which stories we tell about ourselves and others in the world: Who are we, where are we coming from, and where are we going? The answers to these questions themselves carry different realities and different possibilities of becoming (see e.g., Yusoff and Gabrys 2011). Essential to this study is that these questions can be seen as political concerns, if we broaden the definition of politics to include questions of epistemology and ontology (see e.g., Haraway 1988; Haraway 1992; Haraway 2008a; Mol 1999). I will use a rather broad definition of politics loosely inspired by science and technology studies researcher Annemarie Mol's (1999) essay on ontological politics. For this study, politics is primarily about how phenomena are enacted or made, rather than a state-level process 
of visible (human) deliberations about issues (see e.g., Bennett 2010). This allows me to show that such seemingly mundane questions as how the teacher instructors understand their profession, envision their students, bring nonhuman animals into the discussions, and connect knowledge with the future are epistemologically and ontologically loaded, cutting across various axes of power with ethical - and political - consequences. Politics, here, is about how possibilities unfold, and "how political possibilities unfold within and through practices" (Gabrys and Yusoff 2012, 4). In the same vein as the Australian feminist philosopher Val Plumwood (1993), I consider how we relate to nature as a political rather than descriptive process, because of how our relation to nature is formed through multiple exclusions throughout Western history. I agree with Erik Swyngedouw's $(2003,6)$ definition of a political act as "one that re-orders socio-ecological co-ordinates and patterns, reconfigures uneven socio-ecological relations, often with unforeseen or unforeseeable consequences." Political theorist Jane Bennett's (2010) work on rethinking the concepts of political participation and democracy to include nonhuman forces has inspired how I understand the contemporary meaning of politics in the context of environmental change. Bennett holds that worms and other nonhumans should be regarded as members of a demos that is assembled to handle environmental change. Furthermore, my conception of politics in this study comes from an understanding that contemporary environmental issues are conceptualized as post-political (Swyngedouw 2003; Žižek 2008; Bradley 2009).

Erik Swyngedouw $(2010,215)$ defines the post-political frame that affects climate change as "structured around the perceived inevitability of capitalism and a market economy as the basic organizational structure of the social and economic order, for which there is no alternative. The corresponding mode of governmentality is structured around dialogical forms of consensus formation, technocratic management and problem-focused governance, sustained by populist discursive regimes." The problem of framing climate change and other environmental issues as post-political, with only one way to move forward, is that these issues get seemingly emptied of their connection to power relations and visible political conflicts (see e.g., Mouffe 2005; Macgregor 2013; Swyngedouw 2014; Neimanis, Åsberg, and Hedrén 2015). Political theorist Chantal Mouffe (2005) holds that the post-political frame avoids a critical analysis of modern capitalism, which makes it difficult to challenge the neoliberal hegemony in much of today's world. Mouffe $(2005,8)$ makes 
an important distinction between "politics" and "the political," where the first has to do with everyday practices of politics while the second has to do with theoretical conversations about the very meaning of what constitutes the political. Furthermore, Mouffe advocates conflicts and formations of collective identities as the very nature of the political, which also shows why different forms of dominating liberalism (based on the idea of the individual) fail to recognize and acknowledge seemingly depoliticized matters as political. Although Mouffe's view on the political is primarily a contribution to political science and political theory, I use her argument to study how practices of forming sustainability relate to theoretical questions regarding the very way the society is instituted. I see the issue of how things are brought into being as an ontological question which relates to processes of exclusion, and the post-political condition makes these exclusions invisible and ordinary. According to Sherilyn MacGregor $(2013,5)$, the post-political imaginary of climate change is closely linked to apocalyptic fantasies to which fear is central. This fear contributes to ideas of nature as the enemy, and as an Other to humans, and justifies unquestionable policies in the name of saving and controlling the world. This post-political condition, and its dangerous consequences, is one essential point of departure in this study in which I seek to contribute to re-politicizing sustainability in education with feminist tools. I do so by critically asking what today's sustainability education seeks to sustain, and for whom.

\section{A feminist posthumanities imperative}

We live in an era where humans of the modern Western world keep forcing our existence upon nonhuman beings, things and phenomena such as animals, bacteria, plants, and weather-related forces. The visible entanglement of humans with nonhumans might have the potential to challenge the dominant way of viewing our existence (ontology) and our ways of knowing the world (epistemology). An important assumption for this study is that we live in a more than human time (Whatmore 2002,146), which requires theoretical and analytical tools that take into account that our realities are shaped by both human and nonhuman practices and existences (see e.g., Åsberg 2012; Åsberg 2013; Oppermann 2013; Neimanis 2013; Neimanis, Åsberg, and Hedrén 2015). While environmental issues tend to be framed as affecting us all, many 
feminist scholars have pointed out the importance of questioning this assumption by asking what is at stake for whom (Haraway 1992; Plumwood 1993; Alaimo 2012; Macgregor 2013). As a way of re-politicizing sustainability education, this study directs attention to the question of which relations are considered important, and to the ways in which subject positions are formed by sustainability education.

It can be argued that rapid environmental change makes it apparent that humans are part of the natural environment; what is "out there," partly or completely unknowable, is affected by us as much as it affects us. Geological scientists, and others, talk about the Anthropocene, an ongoing geological period since the industrial revolution, shaped by the activities of the human species (Bird Rose et al. 2012, 3). The current ecological crisis requires an approach that can elucidate the fact that humans and nonhumans are in various ways intertwined with processes in nature and in the environment (for a discussion on this topic, see e.g., Alaimo 2010). This interdisciplinary study uses theories and concepts from cultural studies, feminist science studies, political theory, and philosophy of education to critically study what an educational field that concerns itself with that which cannot be fully known to humans, such as the nonhuman world, makes possible. Because of nature's position as the Other in almost any history of domination (racism, sexism, class domination, etc.) it is important that feminist scholars, among whom I count myself, scrutinize how the boundaries between nature and culture are done and undone in specific contexts (see e.g., Plumwood 1993; Plumwood 2002).

I will now explain in more detail first, why Sweden has been chosen as the national case, and, second, why I focus specifically on teacher education.

\section{Sustainable development in Swedish education}

Environmental education has been part of the Swedish school system since the 1960s (Hasslöf 2015, 21). However, the concept of sustainable development was established globally during the 1980s by the World Commission on Environment and Development, where it came to include ecological, social, and economic aspects of sustainability. In subsequent global conferences on sustainable development, education has been emphasized as an important means for achieving sustainability. In the proceedings of the United Nations Confer- 
ence on Environment and Development (UNCED) in 1992, education was afforded its own chapter (UNCED 1993 Agenda 21, Chapter 36) emphasizing, among other things, the teaching profession as crucial. During the following decades, education for sustainable development has been emphasized at other international summits and initiatives, including the United Nations World Summit on Sustainable Development (WSSD) in 2002 and UNESCO's 20052014 Decade of Education for Sustainable Development. However, it is important to note that education has played a major role in global initiatives for the environment at least since the 1970s, when the first international conferences were held on environmental issues (in Stockholm in 1972) and on environmental education (in Tbilisi in 1977) (see e.g., Björneloo 2008, 17).

Sweden has a long tradition of being perceived, both domestically and internationally, as ambitious when it comes to environmental initiatives and policies (Jänicke 2008; Anshelm 2012, 38; Lidskog and Elander 2012, 336). This self-image manifests itself, for example, in the former Social Democratic prime minister Göran Persson's public speech at the United Nations World Summit on Sustainable Development (WSSD) in 2002, where he announced that education for sustainable development was a prioritized area for the Swedish government (SOU 2004:104, 9). In 2003, the Swedish government appointed a committee on education for sustainable development. The committee released the report of their inquiry, Learning for Sustainable Development [“Att lära för hållbar utveckling”], in 2004 (SOU 2004:104), which, among other things, emphasized the role of teacher education in integrating sustainable development into the Swedish educational system (SOU 2004:104, 152). One of the changes that followed the committee's report was the addition of a paragraph in the Higher Education Act (SFS 1992:1434) stating that universities in Sweden shall "support a sustainable development that ensures that present and future generations are guaranteed a healthy and good environment, economic and social welfare, and equity" (SFS 1992:1434 my translation from the Swedish). As of today, each teacher degree category needs to, by the time of graduation, "show the ability to make pedagogical assessments based on relevant scientific, societal, and ethical aspects with special emphasis on human rights, particularly the rights of children according to the Convention on the Rights of the Child, and a sustainable development" (SFS 1993:100 my translation from the Swedish). In the most recent Swedish curriculum, a central document for all those working as teachers in Swedish schools, four broad perspectives are emphasized: a historical perspective, an 
environmental perspective, an international perspective, and an ethical perspective (Lgr11, 11-12). The environmental perspective states that "[ $t]$ eaching should illuminate how the functions of society and our ways of living and working can best be adapted to create sustainable development" (Lgr11, 12). Since sustainable development is put forward in the curriculum as well as in the demands on future teachers, there are several reasons as to why future generations of teachers need to become familiar with this notion during their teacher training, and need to handle it in their future teaching.

However, and this is a crucial point for the present study, how sustainable development comes to be teachable still seems to be an open question. Educational researcher Johan Öhman (2011, 5 italics added) holds that "[t]he interesting thing is therefore to reflect on what kind of changes these interpretations and negotiations bring about in educational practice." For that reason, I have chosen to carry out an explorative approach to what sustainable development comes to mean in education. I do not predefine the concept, but have chosen to study how the teacher instructors in focus groups define and handle this notion.

To date, education has come to be one of the most debated policy areas in formal contemporary Swedish politics. The present study focuses on the case of teacher education in Sweden because of Sweden's long history of perceiving itself as environmentally conscious. For these reasons I argue that Sweden in general, and Swedish teacher education in particular, offers an interesting case for studying how sustainability is formed and made teachable. Given that sustainability is a general goal for the Swedish educational system (SFS 1992:1434, §5) and has been introduced not as a subject area but as a general perspective, there is no single discipline or subject area that is ascribed responsibility for sustainability, which is why this study is not limited to a particular branch of teacher education.

\section{An introduction to Swedish teacher education}

In Sweden, as well as in many other Western countries, teacher education represents a highly contested institution (Ball 2008; Lilja 2010). The questions of who the future teachers should be, what they should know, and how they should teach are explicitly and implicitly political issues intertwined with questions such as what a good society is and which views on knowledge 
should guide the educational system (Åberg 2008; Sjöberg 2009; Sjöberg 2011). An often publicly voiced opinion is that teachers represent the most important parameter for the level of success of a nation's educational system (see e.g., Sjöberg 2011; Bursjöö 2014). As indicated above, the educational system has become a major ideological concern in Sweden, where it is assumed that knowledge and education are the means to solving a number of problems in society.

According to educational researcher Lena Sjöberg (2011), in her study of the discursive construction in policy documents of teachers and students in Sweden, the Swedish educational system is still undergoing a major restructuring process that started in the 1970s. That process, among other trends, has transformed Sweden from having one of the most regulated to one of the least regulated school systems in the world. The current trend follows the rationale of market competition in which the purpose of education becomes for the individual to perform well in a global competition (Sjöberg 2011, 64). As part of this global trend, the former liberal-conservative coalition government reformed the Swedish educational system extensively while they were in power between 2006 and 2014 (after a period of Social Democratic dominance). One of the major reforms during 2006-2014 was to initiate a new teacher education program. This reform still stands with the current Green-Social Democratic government (according to email correspondence with the Swedish Ministry of Education on December 15, 2015, the current Green-Social Democratic government plans no major changes to teacher education). The latest reforms started in 2007, when the former government appointed a committee to inquire about teacher education. The committee was appointed only six years after the last extensive reformation of Swedish teacher education (implemented in 2001). In December 2008, the report of the committee's inquiry, A sustainable teacher education ["En hållbar lärarutbildning"], was released (SOU 2008:109). In this case, the notion of sustainability referred to the hope that the forthcoming reform would imply "that teacher education will not need to be subjected to a radical makeover every ten years," and that it would provide teachers with "a solid knowledge base", "effective tools (...) to exercise their profession" (SOU 2008:109, 31) more effectively than previous reforms. In other words, it had nothing to do with sustainability in relation to current environmental change. Sustainability was mentioned only briefly as an area that could be taught. 
In February 2010, the new proposition Top of the class: New teacher education program ["Bäst i klassen - en ny lärarutbildning"] was presented (Government Proposition 2009/10:89). The proposition resulted in a number of new changes. For example, the previous degrees of Bachelor/Master of Education became four professional degrees: degree in preschool education, degree in primary school education, degree in subject education, and degree in vocational education (with different specializations for each degree). Another important difference from the previous reform was that each university and college that wished to conduct teacher education needed to apply to the Swedish National Agency for Higher Education for the right to award degrees for the different categories mentioned above. Students would no longer be able to select the courses they wanted to take; instead, a fixed set of courses was required for each degree. Lastly, the structure of the educational core (a set of courses considered to be the core of the teaching profession) was shortened, changed, and specialized for each degree.

It is worth noting that the reform hardly mentions sustainability except as one of several possible areas that the educational core could handle. But as shown above, after graduating, each teacher needs to demonstrate the ability to make pedagogical assessments based on sustainable development, among other things (SFS 1993:100). The latest Swedish school curriculum emphasizes sustainable development in many places, both in terms of general objectives and in the course-specific objectives (Lgr11). Subsequent to this somewhat contradictory governance, I want to capture ongoing discussions about how sustainability issues enter into the education of future teachers. In this regard, I find the position as a teacher instructor to be crucial precisely due to the location of the teacher instructor at the intersection of various educational and knowledge practices.

\section{Research aim and questions}

This study focuses on teacher education, and more specifically on teacher instructors in Sweden, in order to examine how sustainability is formed in education. The aim of this study is to investigate how sustainability is formed in education, and to explore how these formations relate to ideas of what education is, and whom it is for. By critically asking what today's sustainability education seeks to sustain and for whom, this study seeks to contribute to re-politicizing sustainability in education. 
The first research question I ask is: How is the role of education understood in relation to goals about sustainability? Of importance here is that the mundane and presumably ordinary can also be political, and what we understand as value-neutral statements or taken-for-granted assumptions - even what we are able to imagine - need to be critically examined. Thus, how sustainability is brought into everyday educational settings is a political and ethical issue with connections to epistemology and ontology, even though it may not commonly be seen as such. Imagining environmental change can be seen as "a political act that configures present actions, behaviors and decision making or future presents" (Yusoff and Gabrys 2011, 519 italics in original), which points to the powerful potential of what we can imagine.

The second research question I ask is: Which relations are brought up in the discussions of making sustainability teachable? How are notions of the Other handled in these discussions? The way education handles the unknown Other becomes a key ethical issue, and an issue grappled with using feminist insights into the powerful questions of what counts as nature and culture and as worth knowing in the formation of a phenomenon such as sustainability. Who these Others are and how they are brought into sustainability education is of essence to this study, as an intertwined issue of ontology, politics, and ethics (see e.g., Todd 2003; Biesta 2006a; Aman 2014).

The third research question I ask is: Which subject positions are made possible in the process of making sustainability teachable? Human or nonhuman, these positions are relationally constituted between nature and culture, and they carry social and political effects for the futures we can imagine.

\section{Survey of fields}

I situate this study in relation to three fields of research that I call Education for sustainability, Posthumanities education and Feminist environmental humanities. I have chosen these three research contexts because, together, they provide a position for my interdisciplinary study at the intersection of several fields. 


\section{Research context I: Education for sustainability}

The first field of research I consider is educational research related to sustainable development and sustainability, including overlapping fields such as environmental education (EE), education for sustainability (EfS), and education for sustainable development (ESD), which have in common the "commitment to changing knowledge, values and attitudes and actions" (Shallcross and Robinson 2007, 139) in the light of the current ecological crisis. There are various definitions and discussions of these terms and they often exist side by side in international journals on education (such as Journal of Education for Sustainable Development, Environmental Education Research, Journal of Environmental Education, and Canadian Journal of Environmental Education, to name a few). The overall field is quite broad, which is why I concentrate my review to research that relates to my study. Lastly, I give examples of studies that have tackled methodological quandaries similar to those encountered in my study.

Many studies in my review of the field manifest a strong belief in education in general, and in future teachers in particular (see e.g., Mckeown 2012; Martin, Summers, and Sjerps-Jones 2007; Shallcross and Robinson 2007; Bursjöö 2014). Global initiatives are often perceived as crucial for working with sustainability-related issues in teacher education (see e.g., Mckeown 2012; Hopkins 2012). However, case studies from, for instance, Jamaica (CollinsFigueroa 2012) and Australia (Buchanan 2012) show the difficulty of working interdisciplinarily with sustainability within a discipline-bound curriculum. Other studies focus on discussing best practices of sustainability education (Gayford 2001).

Many of the internationally published studies I reviewed display a rather anthropocentric approach to sustainability issues. The nonhuman environment is often discussed as a resource for human use. Shallcross and Robinson $(2007,140)$ claim that sustainable development "is not an emergency call to save our planet; it is an SOS to act to save our species." While they seem to view the natural environmental as prioritized in education for sustainability in order for humans to survive, they also problematize an instrumentalist view on the environment. While some authors study learning about biodiversity as a way for teacher students to learn in education for sustainable development (Collins-Figueroa 2012), others discuss how biodiversity and learning about biodiversity risk reproducing human-centered values, which exclude 
those that are not of value to the human species (Kahn 2003; Kopnina 2013). Authors such as Helen Kopnina (2012) warn us that education for sustainable development might create "anthropocentrically biased education" (2012, 699) and that education for sustainable development "undermines ecological justice between humans and the rest of the natural world" $(2012,712)$. Michael Bonnett (2002) shows how sustainable development as a policy in education relates to ethical, epistemological, and metaphysical aspects of our understandings of what it means to be human, and tends to be imagined within existing and taken-for-granted norms of what a good society is. The Swedish researchers Malin Ideland and Claes Malmberg $(2014 ; 2015)$ have critically studied how ESD is discursively constructed in textbooks and other materials directed to Swedish schoolchildren. In one article, they criticize ESD's good intentions of saving our common world as creating categories of Us and Them, which creates exclusions although the intention is to be inclusive. They claim that the textbooks construct Swedish exceptionalism, which makes ESD potentially both a colonial and exclusionary project (Ideland and Malmberg 2014). In another article $(2015,175)$, they argue that the school materials construct the desirable child for sustainable development through pastoral power which "operates everywhere and through everyone," distancing ESD from governmental politics but making it well suited for the market economy's belief in the responsibilities and choices of the free subject. Their articles are examples of the how discourse analysis can make visible that which is taken for granted in sustainability education.

Another critical study has been conducted by Ruth Irwin $(2008,187)$, who claims that education for sustainability is bound to the neoliberal market economy and that " $[t]$ he consequences of subsuming environmental concerns under the rhetoric of sustainability, is the continuation of status quo." This critique is sometimes framed as a problem of neoliberalization (Fletcher 2015; McKenzie, Bieler, and McNeil 2015). Coral Campbell and Ian Robottom (2008) study how sustainability is defined in practice in the Australian educational system. They found that education for sustainable development can be reduced to a slogan that is open to interpretation and can serve a variety of interests, including those intent on carrying on with business as usual. The Swedish researcher Helen Hasslöf $(2015,81)$ argues that education for sustainable development "creates and accentuates educational tensions" intertwined with ethical and political issues. Her aim is to problematize education for sustainable development from a conflict perspective. Her focus is on 
teachers' discussions about ESD with regard to three tensions: students' qualifications in relation to ESD, education for social change, and the possibilities for students to develop as political subjects.

The Swedish research context furthermore provides a number of scholarly works, mostly related to education for sustainable development (see e.g., Björneloo 2007; Jonsson 2007; Lundegård 2007; Wickenberg 2004; J. Öhman 2006; J. Öhman 2008). As mentioned earlier in the introduction, "sustainable development" is the dominating term in Swedish educational policy texts, which differs from, for example, the Australian context where the most commonly used term is "education for sustainability" (Buchanan 2012). In a special issue of the Swedish journal Democracy \& Education [Utbildning \& Demokrati] on Swedish environmental and sustainability education research, Johan Öhman $(2011,6)$ describes the characteristics of the Swedish research fields as empirically driven. One of the articles in the special issue focuses on teacher education; Ingela Bursjöö (2011) explores the tension that teacher students experience between their role as professionals and as private persons when teaching for sustainable development, showing that the teacher students are very conscientious regarding their personal lifestyles. In her doctoral thesis, Ingela Bursjöö (2014) focuses on understanding how teachers handle the assignment to educate for sustainable development, given that it has not been satisfactorily implemented in the Swedish educational system. She finds four different strategies that the teachers use, including leaving the teaching profession. She also finds that students' competencies related to ESD have a considerable ethical dimension. Yet another Swedish researcher, Katarina Ottander $(2015,153)$, shows in her study of high school students meaning-making regarding sustainable development in science education how the students negotiate meaning from psychological and ideological factors rather than from scientific facts. Scientific reasoning is used to justify the students' own subject positions and creates both a sense of powerlessness and individual responsibility $(2015,186)$.

Related to the study of sustainability education is the methodological quandary of how to study general knowledge areas that are not reserved for specific school subjects. These are areas that are not usually scheduled as subject areas or courses in their own right but are supposed to be integrated into the general curriculum. Designing these studies can be seen as an attempt to over- 
come methodological challenges, a task in which the present study is also engaged. Examples of general areas of this kind in Swedish teacher education include gender and gender equality (Hedlin and Åberg 2011) and diversity (Wibaeus 2008; Åberg 2008).

Below, I review some methods used to capture sustainability in teacher education. In a study from Australia, Reece Mills and Louisa Tomas (2013) explore how teacher instructors integrate education for sustainability (EfS) in their teaching, and what they define as factors enabling or constraining the integration of sustainability into teacher education. The method used is semistructured interviews with four subject coordinators at a particular university, together with an analysis of subject outlines. The study concludes that sustainability is integrated differently through the curricula and that the teachers need more resources in order to develop their understanding of sustainability. In the Swedish context, a report titled Lärarutbildningen och utbildning för hållbar utveckling ["Teacher Education and Education for Sustainable Development"] published by the Swedish National Agency for Higher Education in 2008 explores how sustainable development was handled in previous teacher education programs, based on interviews with representatives from 11 different universities (Lundh and Ruling 2008). The result showed, for example, that there was a great deal of variety in how education for sustainable development was conducted and that the courses on sustainability in general were held by individual engaged teachers (Lundh and Ruling 2008, 3). Gunnar Jonsson's (2007) study focuses on how teacher students understand sustainable development and how sustainable development is materialized in a teaching situation by using questionnaires and interviews, and by observing the teacher students during their teacher training. I have also found another study which uses focus groups with teacher instructors in Australia to study the difference between sayings and doings in teaching. The study conducted three focus group interviews and resulted in the conclusion that the inclusion of sustainability education into different subject areas was done somewhat sporadically (Buchanan 2012).

\section{Research context II: Posthumanities education}

Educational research can be described as "wholeheartedly humanist" (Sørensen 2007, 15) in its focus on human practices. But as I argued in the introduc- 
tion to this chapter, the sustainability realm goes beyond the human/nonhuman divide. One multifaceted area to which I also relate my study is what I call Posthumanities education. This area explores the importance and influence of the more than human world in education by challenging anthropocentric ideas and methods in educational research. According to educational researcher Simon Ceder (2015), anthropocentrism and subject-centrism are two main problems of the contemporary field of philosophy of education that prevent us from seeing entanglements of humans and nonhumans that already take place around us. According to Helena Pedersen (2014, 83 my translation from the Swedish), who edited a special issue on the posthumanities perspective in 2014 on educational research in Sweden, posthumanities "forces us to think differently about some of the ontological and epistemological assumptions of our [educational] research. What is a subject, and how can we understand relations beyond the analytical frames of the humanities?" The special issue in question presents studies on methodological development of focus groups using concepts from Gilles Deleuze (Johansson 2014), a specific pedagogic relationship between human and horse (Hagström 2014), interventions into challenging the child as the taken-for-granted subject of early childhood research (Ottestad and Rossholt 2014), conflicting ontological assumptions in Swedish policy documents regarding early childhood education (Dahlbeck 2014), and the building of an onto-epistemological and methodological framework where materiality is central in the case of preschool music education (K. Holmberg and Zimmerman Nilsson 2014). I also contributed to the issue with an article on human-animal relations in teacher education on sustainability (Sjögren 2014a). To my understanding, posthumanities education is about dislocating, and questioning, the role of human subjectivity in education, together with its history of fostering the human.

Altogether, a common politically and ethically important focus for posthumanities is the questioning of humans at the center of knowledge production. This is a particularly interesting and challenging quest for educational research's conventional focus on the educable subject, built on Enlightenment ideals of what humanism is (Pedersen 2010a). Theoretically, these posthumanities studies are inspired by Gilles Deleuze and Felix Guattari (Pedersen 2013; Mazzei 2013; Bodén 2013; Johansson 2014) as well as Karen Barad (Rosiek 2013; Hultman and Lenz Taguchi 2010) and approaches from science and technology studies in general and actor-network theory in particular 
(Fenwick and Landri 2012; Ceulemans, Simons, and Struyf 2012). Methodologically, these studies use ethnographic fieldwork (Pedersen 2013; Bodén 2013) as well as interviews (Mazzei 2013; Hultman and Lenz Taguchi 2010). A common denominator is the emphasis on decentering the individual human subject and attending to the agency of the material and the nonhuman world. Relations are highlighted to understand what becomes possible in a specific situation (Fenwick and Landri 2012). A recurrent argument concerns the importance of the particular, rather than abstract categorizations (Fenwick and Landri 2012; Postma 2012; Ceulemans, Simons, and Struyf 2012).

As an example, Lisa A. Mazzei (2013) strives to think about the qualitative interview in new ways; as a simultaneous account for the material and discursive. She sees voices in interviews as "an assemblage, a complex network of human and nonhuman agents that exceeds the traditional notion of the individual" $(2013,734)$. She develops the notion of Voices without Organs (VwO) inspired by Deleuze and Guattari's alternative account for subjectivity and shows how attention must be drawn to how the researcher is becoming together with the interviewee and forces and desires beyond human control. Lotta Johansson (2014) does something similar in her work with focus groups. Johansson seeks ways to use the focus group in post-qualitative research where voices and what they do are in focus, rather than what the participants are saying.

Another example of posthumanities educational research comes from Helena Pedersen (2013, 727 italics in original), who uses critical posthumanities analysis to show how the act of slaughter and the act of education become inseparable in veterinary education, where emotion and abjection are "an integral and necessary part of educationalized violence." She argues that emotional expressions of care and compassion for the slaughter victims encountered by herself and the veterinary students fail to challenge the slaughter machinery. Her result shows an interesting duplicity in the mutual entanglements and separation of humans and nonhumans for maintaining this particular practice. Thus, there are many thoughts in the emerging posthumanities educational research area that are of relevance for my study. The most important contribution for my study is to show the importance and influence of the more than human world in education, and the theoretical and ethical ambition of decentralizing the human subject in educational research. 


\section{Research context III: Feminist environmental humanities}

The present study investigates the sociocultural aspects of the environmental change that are currently addressed in education as well as in official politics, scientific reports, news pieces, movies, books, art, etc. An essential point is that our understanding of a phenomenon such as sustainable development is formed by discourses as well as dreams and fantasies, that is, by that which lies beyond reason and the known. This study has, maybe first and foremost, been shaped in dialogue with what I would like to call Feminist environmental humanities, that is, studies that critically and/or affirmatively seek to deepen our understandings of the intersections of nature and culture and their effect on the question of what it means to be a situated human in a specific context. According to Cecilia Åsberg and Astrida Neimanis (2016), feminist scholarship has a particularly important role to play within the environmental humanities "drawing on long-standing contributions in feminist bioethics, situated knowledges, science studies, ecofeminisms, environmental justice, and contemporary new materialist scholarship, feminist work in the environmental humanities (...) reject epistemological mastery, and foreground approaches of care, curiosity, and (...) an ethical stance in relation to both different humans and non-human nature." Feminist scholars such as Maria Mies and Vandana Shiva (1993) and Val Plumwood (1993) have led the way for a rigorous critique of Western reason and its role in different relations of domination, including relations to nature. Furthermore, Stacy Alaimo's work $(2008 ; 2010 ; 2011 ; 2012)$ on deconstructing and rethinking gender and race as well as the very category of human to form ethically accountable positions which take the (unknown) nonhuman world into account has been a great inspiration. Astrida Neimanis' (2013) work on developing feminist subjectivity by thinking through bodies of water - which we cannot fully know - is also worth mentioning. Myra Hird (2012) has shown what feminist theory has to offer in order to develop an understanding of the epistemological and ethical implications of knowing waste. I also find great inspiration in feminist researchers' attempts to make feminism relevant for ecological concerns as well as making environmental-oriented scholarships aware of what feminist theory has to offer (MacGregor 2009; Macgregor 2013; Oppermann 2013; Åsberg 2013; Neimanis, Åsberg, and Hedrén 2015). Donna Haraway's (2003; 2008b; 2015) work on creating feminist figurations and concepts for taking 
into account both differentiated human and nonhuman dimensions of our existence is a good example of how these feminist environmental humanities ideas have come to matter in different contexts. I will now zoom in on a few recent examples: Urban feminist researcher Malin Henriksson (2014), in her study of how planners in the Swedish municipality of Helsingborg define sustainable mobility, uses a feminist intersectional framework to study how the planners constructed the good traveler through dominating discourses of class, gender, and ethnicity. Another example comes from feminist environmental researcher Anna Kaijser (2014), who uses feminist intersectionality and posthumanities concepts to show who gets included in constructing legitimate subjects of environmental change in Bolivia. Feminist environmental researcher Emmy Dahl's (2014) study on how individuals make sense of and negotiate the discourse of individual environmental responsibility in focus group discussions uses a feminist poststructualist framework. Dahl shows how responsibility for the environment becomes an individual moral obligation rather than a societal obligation. What this field offers most clearly are different ways of critically countering the modern Western subject of rationality and purity. Feminist environmental humanities show how differentiated subject positions truly are in environmental politics, education, and culture (see e.g., Braidotti 2013).

The aim of this section has been to situate this study in relation to three research contexts: education for sustainability, posthumanities education, and feminist environmental humanities. The intersection of these three research contexts provides a position for my study and its results. Lastly in this chapter, I present the structure of the dissertation.

\section{Structure of the dissertation}

This dissertation consists of eight chapters. In this introductory chapter, Introduction: Sustainability for whom?, I have presented the research problem, the context of the study, research aims and questions, and I have situated the study in relation to three different relevant areas of research.

In Chapter 2, Theoretical perspectives: The politics of imagining, I present perspectives in the form of four main theoretical assumptions in order to theoretically situate the study and contribute to academic conversations about the 
formations of what sustainability is and whom sustainability is for in education. The discussions and assumptions create a theoretical framework for understanding the politics of the mundane, and for re-politicizing that which we tend to see as natural and neutral.

In Chapter 3, Material and methods: How to study social imaginaries, I introduce methodological considerations and choices I have made when carrying out this study. I explain my use of focus groups with teacher instructors and how I view the material. I also discuss what kind of conclusions I can draw from using this particular method.

In Chapter 4, Who can become sustainability literate?, I set out to examine who teacher instructors imagine the teacher student to be, and I examine how these discussions create certain ways of envisioning who it is that can become knowledgeable through sustainability education. Examining these formations more closely is a way to study which subject positions are available to teacher education students, and I analyze them in order to map out various available ways of being in, and becoming through, education.

In Chapter 5, The balancing acts of teaching sustainability in a post-political time, I identify three balancing acts that appear to generate conflicting and uncomfortable subject positions, and also strategies that the teacher instructors can use in the domain of sustainability. These balancing acts are operating as the teacher instructors, as both role models and mediators of knowledge, are educating future generations of teachers. I discuss why the subject positions that were made available mostly seem to be considered problematic, and I relate this to politics.

In Chapter 6, The possibility of nonhuman animal encounters in sustainability education, I investigate four dimensions in which the teacher instructors relate to the question of how it is possible to encounter the nonhuman Other in sustainability education. I analyze how the naturalization of understanding the nonhuman world as a resource for human use is reinforced and challenged in the focus groups. I argue that the processes through which humananimal relations are challenged, negotiated, and legitimized are of considerable importance for understanding which versions of sustainability appear reasonable, and who can be included in sustainability education. 
In Chapter 7, Imagining the unknown future, I look into how the role of the future and the role of education are imagined together in the focus groups. I pose questions about what kind of futures are imagined and how these futures are handled in education.

In Chapter 8, Conclusions: The politics of imagining environmental change in education, I turn to the final conclusions of this study. I discuss the main contributions and suggest four ways in which sustainability education can be repoliticized. 


\title{
Chapter 2
}

\section{Theoretical perspectives: The politics of imagining}

\begin{abstract}
The imagination that allows for emancipation and border crossing is the same faculty that constructs and fixes the borders. In both instances, the imagination is 'creative'. The 'creative imagination' is Janus-faced like modern bourgeois society which, on the one hand, promises emancipation but, on the other hand, creates borders and boundaries. The imagination is the source of freedom, change and emancipation as much as a source of the borders and boundaries that emancipation wants to challenge. (Stoetzler and Yuval-Davis 2002, 324)
\end{abstract}

What teachers should teach is often a matter of public debate. This marks teacher education as well as sustainability as two areas of contention. The present study investigates sociocultural aspects of sustainability, aspects that are also currently addressed in official politics, scientific reports, news pieces, movies, books, art, etc. Our understanding of a phenomenon such as sustainable development is formed by discursive formations as well as social imagery, collective fantasies, public morality, and other nonsensical aspects of social life. It can be argued that we filter a lot of common ideas through social categories, conventions, and norms that may or may not be sensical and factual. The aim of this chapter is to present my starting point and the theoretical perspective that guides my analysis in order to theoretically situate this study and contribute to academic conversations about the formation of what sustainability is and whom it is for in education. The discussions below create a theoretical framework for understanding the politics of the mundane, and for 
re-politicizing that which we tend to see as natural and neutral. Research responding to environmental change must investigate aspects of both the known and the unimaginable in the making of our common future. Ben Dibley and Brett Neilson $(2010,144)$ point out that current discourses on climate change oscillate between two poles, "between immanent catastrophe and the prospect of the renewal; between unimaginable humanitarian disasters and the promise of a green-tech revolution." Scrutinizing taken-forgranted assumptions as well as what it means to grapple with the unknown is important in order to develop understandings that make room for that which lies outside preconceived structures and categories. The concepts and perspectives presented below have been chosen to shed light on the study object, sustainability in education, from different angles and to provide a framework for analyzing and discussing the results of this study.

\section{The politics of (un)knowing}

My first theoretical assumption is that knowing is possible only from specific, situated positions. This makes knowledge situated and bound to who it is that knows something. The concept of situated knowledge is often attributed to feminist theorist Donna Haraway (1988), who introduced the notion to show that the knowing subject always sees and knows from a specific point of view. Using the metaphor of vision, Haraway criticizes what she calls "seeing everything from everywhere" $(1988,581)$ in favor of a feminist account of objectivity that is about a "particular and specific embodiment" $(1988,582)$. In this way Haraway reformulates what objectivity is and proposes knowledge production that is accountable and responsible for the knowledge produced. An important aspect of Haraway's argument is to counter relativist claims of "being nowhere while claiming to be everywhere equally" (1988, 584). For my study, Haraway's argument is used to formulate an understanding of knowledge as political and embedded in the sense that what one sees from a specific viewpoint stipulates what comes to be possible and brought into being.

Important to note here is that even knowledge that makes use of the gaze from nowhere is situated, although the situatedness is made invisible and the knowing subject is not accountable for what comes to be known. In other words, the production of knowledge and the claim to know are always intertwined with the question of who it is that knows something. In that respect 
knowledge is always produced from specific positions, and that makes the knowing of this world situated and located. The fact that knowing is always a process of conscious and unconscious cuts (e.g. delimitations, selections, ignorances) makes it quite important to consider both the unknown aspects of the world and what we can know. What is it that we leave behind during the processes of getting to know something or someone? In making sense of who we are?

Feminist authors, including Donna Haraway (1988, 589), have argued for humble knowledge claims through which "partiality not universality" is acknowledged. Similar thoughts have been developed further in the writings of Stacy Alaimo (2010, 16-17), who introduces the concept of trans-corporeality to argue that "ethical considerations and practices must emerge from a more uncomfortable and perplexing place where the 'human' is always already part of an active, often unpredictable, material world." Alaimo's concept calls for a variety of epistemologies, among them, knowledge that is mediated through scientific findings. The concept of trans-corporeality has clear parallels to Haraway's situated knowledges but makes visible the agency of the nonhuman environment. As feminist science studies researcher Nina Lykke $(2009,38)$ holds, it is important "to recognize that the knower's embodiment is not only about her/his individual body in a bounded sense, but about the unbounded bodily embeddedness in the material, earthly 'environment'." Alaimo emphasizes the unknown and unpredictable when seeking knowledge that does not try, in an Enlightenment fashion, to master the nonhuman world.

I will continuously elaborate on the political aspects of the unknown in the coming chapters and how the "conditions of uncertainty" (Yusoff and Gabrys 2011,517 ) shape what comes to count as knowledge in education for sustainability. In the same vein as feminist philosophers Nancy Tuana and Shannon Sullivan (2006, vii, italics in original), I turn to the epistemology of ignorance "out of the realization that we cannot fully understand the complex practices of knowledge production and the variety of features that account for why something is known, without also understanding the practices that account for not knowing."

Knowing is, to my understanding, a process that is embedded and subjectively situated yet collective. Marcel Stoetzler and Nira Yuval-Davis (2002) draw on feminist standpoint theory and Haraway's situated knowledges, together with 
the concept of imagination, to formulate a notion of situated imagination. They emphasize knowing and imagining as complementary and equally important for "the construction of all kinds of knowledge" (2002, 321). Seeing imagination not only as a "faculty of the individual" but as "a social faculty" shows the importance of the interconnected corporeal body with the society at large. In other words, what we can imagine is situated not as an individual experience but as a collective force which "[occupies] a place side by side with rational/scientific knowledge" $(2002,325)$ and affects what we perceive as possible and impossible. Below, I will elaborate further on how the concept of the imaginary can be used for understanding the formation of sustainability in education.

\section{The politics of social imagination}

My second theoretical assumption is that imagination plays an important role in what we might consider possible and desirable to do, to know, to think, to feel, and to dream at a certain point in time in a specific society. In what follows I will argue for the importance of developing theoretical tools for understanding the role of imagination in research concerning the intersection of sustainability and education. I will do this through the concept of the imaginary, inspired by how its been developed in cultural studies research by, for instance, Graham Dawson (1994), Arjun Appadurai (1996), and Kathryn Yusoff and Jennifer Gabrys (2011). I turn to the concept of the imaginary because I have found, while conducting this study, that a sole focus on discourse (which is a closely related theoretical turn) needs to be complemented with something that can explain and take seriously some of the abject and fantastic aspects of forming sustainability. Popular culture, for instance, gives us language, images, and references with which to communicate and share apocalyptic narratives and other unforeseen mirrors of modernity. To deal with abject and fantastic aspects, I treat the focus groups with teacher instructors as sites of storytelling about sustainability, where I see the telling of stories as necessary means for forming sustainability in order to make it teachable. As Haraway $(2015,160)$ puts it: "It matters which stories tell stories." In short, storytelling is here seen as a means to both forming and making use of social imaginaries - systems of imagination (Dawson 1994, 48). I find the concept of the imaginary to be useful in this study because of my focus on the formation of sustainability in education as an area which so clearly concerns itself with 
both knowledge and the unknown. In this study, I use the notion of the imaginary as a way to study something where knowledge is not the only mode through which we come to understand a phenomenon such as sustainability. Imaginaries, in my sense of the word, have three components: discursive formations, the nonsensical, and subject positions. I will outline the definitions of these concepts below.

I define discursive formations as structures of meaning and knowing. For example, the discursive formation of consumption as a sustainable practice makes it possible for most of us to easily recognize and know that Eco-friendly labels and recycled goods are regarded as sustainable. It is also through structure of meaning and knowing that we can recognize a hamburger as food, for example. I define what I call the nonsensical as a fantasy landscape that is used when a phenomenon cannot be explained through discursive formations, that is, when discursive formations are inadequate to explain what we encounter. Here the nonsensical plays the role of helping us to render what we cannot know knowable, by activating our (nonsensical) fantasies. For example, I consider being confronted with a scenario of the future extinction of humanity a situation that can potentially evoke our fantasy in order to make that which we cannot know knowable. Thinking again about how we relate to the hamburger, the nonsensical can make it possible for us to dwell on the burger next to a pile of dead cows as an act of killing (animals). Furthermore, both the discursive formations and the nonsensical produce subject positions, which are positions through which someone or something is regarded as a subject, such as a consumer, meat-eater, animal, human, woman, etc. In other words, imaginaries contain all these different components and are produced collectively, while being situated and embedded in individuals. Furthermore, imaginaries are shaped relationally through scientific knowledge production, political decision making, art practices, and popular culture. Examples of what an imaginary could be include genes, climate change, big data, and epidemic outbreaks. Climate change, for instance, contains competing discourses (as shown by Anshelm 2012) as well as psychological dimensions of nonsensical fantasies that together "oscillate between purposive reason and avoidance of an encounter with the unthinkable and unimaginable" (Dibley and Neilson 2010, 147). These different components are part of forming who we are and what we can become in times of climate change. The climate change imaginary affects us from many different directions: international political acts, scientific reports with global reach, disaster movies, and the embodied feeling of warmer temperatures, to name 
a few. Because climate change is an issue that requires us to grasp both its known and unknown aspects, it can also be fruitfully analyzed as an imaginary (see e.g., Yusoff and Gabrys 2011).

Furthermore, my use of the notion of formations refers to a definition from Oxford Dictionaries: "the action of forming or process of being formed." This process is not causal and it comes from many different directions. In The Archeology of Knowledge and the Discourse on Language, the French philosopher Michel Foucault $(1972,38)$ uses the notion of discursive formation to describe regularity and order "between objects, types of statement, concepts, or thematic choices." He writes that the rules of formation comprise the condition of existence to which these different elements are subjected. Discursive formations in Foucault's writings "work to make speech possible, organize ideas and concepts, and produce 'objects of knowledge'" (Danaher, Schirato, and Webb 2000, 22). Discursive formations also make use of what lies outside them, which makes "silence itself" an integral part of a discourse (Foucault 1990, 27). As indicated above, I will continuously use the notion of discursive formations to refer to statements of regularity and order which produce ("sensical") objects of knowledge in the focus group conversations. The notion of formations, however, is used to describe a more open process since my understanding of the imaginary also requires something else. This else-thing comes up in the discursive twilight zone of grappling with sustainability in the focus group conversations. Here I have found that it is essential to consider how things come to matter (see e.g., Barad 2003; Sjögren, Gyberg, and Henriksson 2015). When an entity (such as an animal or a weather phenomenon) matters unexpectedly and outside the known, when a being (in a broad sense) intrudes and insists on mattering, it has the potential to change the discursive formation. The discursive formation might be changed, or the unexpected "outsiders" will pass unnoticed, or will be regarded as unexplained or unexplainable. In order to stay with the trouble in the discursive twilight zone and to take into account the unknown, uncategorized, and fantastic aspects of what was brought up in the conversations, I introduce the notion of the nonsensical. It is the mutual existence of discourse formations and something else - here called the nonsensical, that strongly motivates my focus on imaginaries as a concept that pays attention to how situated and embedded subject positions are formed in between the known and the unknown. Drawing on Arjun Appadurai (1996), I want to emphasize imagination as both a 
situated and collective property in global cultural processes of handling sustainability. Appadurai $(1996,31)$ sees imagination as a new and important field of social practice "between sites of agency (individuals) and globally defined fields of possibility" in the context of the last four decades of globalization. He ascribes imagination a new role in our contemporary societies, where the imagination is a "space of contestation in which individuals and groups seek to annex the global into their own practices" (1996, 4). Using one's imagination might be seen as necessary for making sustainability teachable. In this way, storytelling as an everyday practice makes use of imaginaries as an important part of forming what comes to be known. It is by using our imagination that we can form some kind of knowing of the unknown and uncontrolled "by rending it knowable in recognizable terms" (Dawson 1994, 50).

In line with Dawson $(1994,23)$ I see that the stories told in the focus groups "not only exist in the imagination of the storyteller, but resonate with the experience of others, as shared, collective identities and realities." The focus groups allow for imaginaries as study objects because I see the focus groups as collectives which shed light on "the subject that imagines, and on the way in which imaginaries are worked on and through by individuals and groups who invest affectively in them, and how they ultimately contribute to change and social reproduction" (Dawney 2011, 539). I see the formation of imaginaries as crucial for collective social practice situated in individuals. The focus group conversations can be seen as a setting in which sustainability in teacher education is formed dialogically and collectively. According to Marcel Stoetzler and Nira Yuval-Davis (2002, 316 italics in original), imagination is both "individual and collective, self- as well as other-directed, a necessary condition as well as the product of the dialogical process involved in the construction of knowledge." Dawson $(1994,48)$ describes imaginaries as systems that are independent "of any particular imaginer," which is also crucial for my study of the focus groups as sites of collective imaginings, with connections to the surrounding society. In a focus group conversation this means that imaginaries are crafted and used collectively through dialogue, and that the study becomes concerned with how the group form their understanding of sustainability collectively by making use of ideas, discursive formations, and the nonsensical that can also be found in society at large. I will make clear in the next chapter on material and methods that I make analytical connections between the collective storytelling in the focus group and the formation of sustainability in society at large. 
As I have already discussed, imaginaries provide possible subject positions as to how one can know oneself in relation to others (Åsberg 2005, 30). The self is always crafted in relation to others: "In the transindividual constitution of selfhood the imagination plays a vital part" (Rossiter 2002, 84). An important argument for using the concept of imaginaries concerns its potential for investigating which subject positions are formed and made available through the collective imagining of sustainability in education. For Kleinian psychoanalysis, which is an important point of departure for Dawson, psychic life is a continual struggle to form a whole out of various identifications (Dawson 1994, 34). For this reason, it can be said to emphasize the constant shaping and reshaping of subject positions though imaginaries which contain both discourses and, for me, the nonsensical. Dawson, for example, studies storytelling with clear parallels to conversations in focus groups. He writes:

In composing a story of the day's events, for example, a complex process of selection, ordering and highlighting gives prominence to some events over others and interprets their significance, thereby making sense of an objective world. At the same time, the telling also creates a perspective for the self within which it endeavors to make sense of the day, so that its troubling, disturbing aspects may be managed, worked through, contained, repressed. (Dawson 1994, 22 italics added)

This quote reflects how I would like to understand the focus groups when I map the imaginary formed through their conversations. The collective imaginary creates positions for the participants, their students, and others, from which they can form and negotiate sustainability education between knowledge and the unknown. It is a collective and somewhat political process through which "some stories can be told, at the expense of others" (Dawson 1994, 24). It is a process through which sustainability is made sense of, and it forms certain subject positions at the expense of others (Åsberg 2005, 31). Penny Rossiter $(2002,84)$ uses Morira Gatens and Genevieve Lloyd's reading of Spinoza to argue that the role of imagination in social life is to understand who we are: "To be an individual self is to be inserted into economies of affect and imagination which bind us to others in relations of joy and sadness, love and hate, co-operation and antagonism" (Gatens and Lloyd cited in Rossiter $2002,84)$. In other words, the forming of possible subject positions is done through collective imaginings that contain both science and popular culture, 
and imaginaries play an important role in who we are and what we can become.

Imaginaries have the potential both to reproduce structures and norms and to craft something new. My understanding of the imaginary is that it is a relational space under formation, in education and elsewhere, which recognizes the interplay between the perceptual and material world, the individual and society. Imaginaries may play an important role in reshaping societies and environments and in making room also for the unknown and that which lies beyond reason or beyond that which we find reasonable and rational (see e.g., Webb 2013). In that way, it suits the ambition of this study, which is to re-politicize the mundane and trivial, that which we usually do not see as contested or political. Yusoff and Gabrys (2011, 516 italics in original) define imagination "as a way of seeing, sensing, thinking, and dreaming the formation of knowledge, which creates the condition for material interventions in and political sensibilities of the world." In other words, imaginaries are crucial for both the possibility of becoming and acting in this world. In this respect they are also political. My understanding of the imaginary, then, is that an imaginary is central to the questions of who we are and what we can know. I find these questions to be essential in a time of environmental change, which might contain an opening to include nature and the nonhuman world into our common imaginary of society (see e.g., Lotz-Sisitka 2010, 137). My posthumanities imperative has prompted me to search for theoretical tools that can include the irrational, the unknown - aspects that are not conventionally associated with what it means to be human (see e.g., Neimanis, Åsberg, and Hedrén 2015).

A relevant question asked by Penny Rossiter $(2002,85)$ is whether we should talk about one imaginary or many; is it "the social imaginary" or "social imaginaries"? Cornelius Castoriadis, for instance, talks about the social imaginary as a central imaginary with peripheral imaginaries, specific to every single society (Stoetzler and Yuval-Davis 2002, 322). One important dimension with Graham Dawson's understanding, as presented above, is his focus on interlinked cultural imaginaries. The focus in this study, however, is on the sustainability imaginary in education. How this imaginary is formed is an empirical question in this study. 
Imaginaries as a concept is, according to some, "being thrown in casually, but usually left unexplained” (Stoetzler and Yuval-Davis 2002, 316). Indeed, imaginary is used in many different contexts but presumably with different understandings and with varieties such as cultural imaginaries (Dawson 1994), social imaginaries (Taylor 2002), technoscientific imaginaries (Marcus 1995), and sociotechnical imaginaries (Jasanoff and Kim 2009; Jasanoff and Kim 2013). To me, however, imaginaries are important for who and how one can become a subject of sustainability education, and imaginaries relate to politics in an ontological and epistemological sense. Now, I will illuminate how subject positions can be understood as crafted relationally, with political and ethical consequences, with the help of authors from, first, feminist science studies, and then, philosophy of education.

\section{Feminist interventions into what counts as nature}

The third theoretical assumption in this study is a feminist understanding that sustainability formations take place in between culture and nature/the environment as an ongoing process of differentiation with social and political consequences. The nature/culture divide represents one of the most powerful metaphors in the history of Western knowledge production. Feminist theorists, who have traditionally been involved in deconstructing the nature/culture divide in terms of gender and sex, have also come to include categories such as race, class, sexuality, functionality, and nonhuman animals and “earth-others" (Lykke 2009; Lykke 2010; Birke 2012). The critique and scrutinization of how the production of Otherness works also include the nonhuman world by looking into how boundaries between nature and culture are produced, maintained, or challenged in specific contexts. The conceptualization of what constitutes nature and environment has wide-ranging consequences for social and political relations. Donna Haraway (2008a, 158) holds that " $[\mathrm{w}] \mathrm{e}$ must find another relationship to nature besides reification, possession, appropriation, and nostalgia." She voices this argument against the background of how nature as the ultimate and absolute other has played a significant role in histories of colonialism, racism, sexism, and class domination (2008a, 157-158). Haraway argues that nature "is not the Other who offers origin, replenishment, and service. Neither mother, nurse, lover, nor slave, nature is not matrix, resource, mirror, or tool for reproduction of the 
odd, ethnocentric, phallogocentric, putatively universal being called Man" (2008a, 159). Against this background, it is not difficult to recognize that the history of Western knowledge production holds a problematic relation to nature as an object for human use and abuse. Thus, the idea of "pure nature" in opposition to "culture" should not be taken for granted but can be seen as an ongoing process of purifying nature and separating it from culture. The separation between nature and culture can be seen as a process where nature and culture are made into different categories with ethical and political consequences (T. Holmberg 2005, 40; Hedrén 2002, 300). One important theoretical inspiration for understanding this divide and its consequences comes from authors within feminist theory in general (see e.g., Plumwood 1993; MacGregor 2009; Macgregor 2013; Oppermann 2013), and authors from feminist science studies in particular (see e.g., Alaimo 2010; Haraway 2008a; Haraway 2008b; Åsberg 2013; Neimanis, Åsberg, and Hedrén 2015). I bring in the work of these authors because of feminist theory's genealogy of paying attention to how power and norms operate in ordering the world with consequences for those inhabiting it.

Feminist theorists have long noted that the separation of "human" (as culture) from "nature" (free from culture) has allowed for a whole range of problematic knowledge practices and otherings of all those who have not fit into the narrow category of culture (Oppermann 2013). Feminist environmentalists and feminist science studies researchers such as Stacy Alaimo (2010) have argued for the importance of understanding that nature is not "out there" but always already within ourselves. Animals, plants, genes, and bacteria (which exist within the human body) are also involved in reading and de/coding the world. This realization implies a focus on natureculture continuums with an opening for the inclusion of nonhuman dimensions such as the environment and other natural forces. Donna Haraway (2008a, 158), for example, argues that "all the partners in the potent conversations that constitute nature must find a new ground for making meanings together." Haraway (2008b, 138) has suggested a focus on natureculture; "of being in technoculture that join cells and people in a dance of becoming" instead of a binary separation of the concepts. Two of the analytical chapters in this study (Chapter 4 and Chapter 5) focus mostly on humans and human practices. However, these practices cannot be seen as completely separated from beings and forces of the nonhuman world. 
Understandings of nature are politically loaded but often post-politically naturalized and difficult to question. The longing for a pure and pristine nature has a long history in modern Western societies (Lidskog and Sundqvist 2011, 41). Including nonhuman agency (such as nonhuman animals, the environment, objects, technology) and new concepts of subjectivity in social theory can be seen as a continuation of the feminist critique and theorizing of how various Others (women, indigenous people, animals, etc.) are "othered" in relation to specific norms of what a human is - norms that often rely on a perfected healthy, white, educated man (Åsberg 2012). Feminist theorist Rosi Braidotti $(2013,26)$ writes that the idea of the human is based on a specific norm about what "human" means by "transposing a specific mode of being human into a generalized standard, which acquires transcendent values as the human: from male to masculine onto human as the universalized format of humanity" (Braidotti 2013, 26). Boundaries have been used and reproduced in order to both include and exclude certain bodies and beings as belonging to the nature and/or culture sphere (T. Holmberg 2005). However, the current environmental crisis reveals more clearly than ever that these clear distinctions are far from stable and certain. For example, by examining the making of certain relations in the focus groups which involve both humans and animals (in Chapter 6), I discuss how certain relations allow for ethical relations while others close off such possibilities. I ask under which conditions it is possible to include nonhuman subject positions in education aimed at creating more sustainable societies. In these discussions I draw on the challenges nonhuman animals pose to the liberal tradition's understanding of the subject as human, rational, and active (Wolfe 2008). By devoting one of the chapters to human-animal relations, I analyze specifically how the naturalization of understanding the nonhuman world as a resource for human use is reinforced and challenged in the focus groups. Indeed, one of the "most radical poten$\operatorname{tial}[\mathrm{s}]$ of the arts and humanities is the ability to constitute alternative possibilities to neoliberal approaches to the environment" (Yusoff and Gabrys 2011, 519). A careful and simultaneously generous and suspicious reading strategy, as suggested by Haraway $(1992,326)$, might make this possible.

Another analytical chapter (Chapter 7) focuses on the possibility of ethical encounters with the Other through understandings of the future as unpredictable or unknown. How natureculture relations are ordered has ethical and political consequences for various humans and nonhumans who are co-evolving and entangled in the making of environmental problems and practices of 
sustainability. This is why it is important to investigate and intervene into how these natureculture relations are imagined.

\section{The Other in education}

My fourth, and last, theoretical assumption is that education produces and relates to Otherness in different ways, and how these relations are made has ethical as well as political consequences. By focusing on the relation as the smallest unit of analysis in educational studies, I bring in a framework for critically investigating who gets to be included in the formation of sustainability in Swedish teacher education, that is, who gets to be a subject. I will now discuss education as an arena of relations which makes certain subject positions possible and others impossible.

Education crafts subjects, but the kind of subject positions education makes possible depends to a large extent on which views of education are dominant in society (see e.g., Todd 2003; Biesta 2006b; Popkewitz 2008; Aman 2014). Educational philosopher Gert Biesta (2006b) sees education as an arena that can enable us to become in relation to others we encounter in education. Biesta further criticizes humanism, since humanism, according to him, entails an entrenchment of who the educable subject is - prior to becoming in relation to others. According to Biesta, modern education is based on a close association between rationality, autonomy, and education, which together form the "Holy Trinity of the Enlightenment project" (Biesta 2006b, 15 my translation from the Swedish). The answer to the question of what it means to be human creates exclusions, which make any understanding of subject positions beyond the idea of the human difficult. Such exclusions can be regarded as potentially unsustainable in light of environmental change, since an anthropocentric perspective risks devastating consequences for both human and nonhuman life (Hinchliffe et al. 2005, 43). Biesta's work is situated in an anthropocentric tradition, but his critique of humanism can be used to develop a non-anthropocentric approach to education. Anthropocentric assumptions make human activity and survival the focus for sustainability issues (Alaimo 2012). As a result, sustainability risks evoking "an environmentalism without an environment, an ecology devoid of living creatures other than human beings" (Alaimo 2012, 562). However, Biesta (2006b, 19 my translation from the Swedish) holds that "the challenge to overcome humanism is also a 
crucial challenge for education." We are now in a time when we need to rethink the educable subject in non-anthropocentric terms (Pedersen 2010b; Ceder 2015). A wide focus on difference as a ground for ethical relations can be found in Biesta's writings, as he claims that education should promote "the commonality of those who do not have anything in common" (Biesta 2006b, 69 my translation from the Swedish). Finding new ways of relating to the Other is clearly essential. In 1948 Emmanuel Levinas was already writing about the Other as another individual, unknowable to the self, while Simon De Beauvoir introduced the notion of the Other in 1949 as a construction in opposition to the self (Brons 2015, 74). Educational philosopher Sharon Todd (2003) uses a Levinasian understanding of ethics as an account for the Other's absolute alterity. Todd $(2003,2)$ sees Otherness as an "absolute and unknowable difference" to which responding, rather than understanding, is essential in order to enter an ethical relation of education. Education can be violent, harmful, and totalizing, but instead of asking what education ought to be (as if there could be one model that fits all), Todd $(2003,29)$ asks us to pose the question of "what makes ethics possible in education in the first place"? Relations to Others in themselves constitute a condition for learning, and it could be argued that the purpose of education is to become (something/someone new) with others $(2003,18)$.

There is an interesting duplicity in Todd's view on the relation to the Other as both a relation of alterity (where borders between the self and the Other can be maintained) and as a condition for transforming the self (where at least the borders of the self have to be changed). Relating to the Other as absolutely unknowable may change us in ways we can never know beforehand. In particular, her point about the important ethical difference between learning about the Other and learning from the Other has parallels to previous discussions in this chapter of turning to how difference is made. This differentiation relates to who or what is becoming significant in the sustainability imaginary. Knowing about the Other represents a rather colonizing notion of embracing the Other by erasing difference. Knowing from the Other is instead a mode in which the borders between the self and the Other are maintained. As I read this, understanding the Other is not a favorable mode or approach but, rather, "encountering the unknowable mystery of the Other means to be for her" $(2003,52-53)$. Is the teacher instructors' relation to Otherness (whether the Other is a student, an animal or the unknown future) within the sustainability imaginary one that avoids "reducing the Other to me" $(2003,15)$, or is it a 
relation to Otherness that reduces and erases difference? These are questions I will discuss further in the following chapters. How subject positions are formed through educational relations in the formation of sustainability is thus very much an ethical question.

The discussions above form the theoretical framework of this study. Four main theoretical assumptions summarize my theoretical stance: My first theoretical assumption is that knowing is possible only from specific, situated positions. This makes knowledge situated and bound to who it is that knows something. My second theoretical assumption is that imagination plays an important role in what we might consider possible and desirable to do, to know, and to feel at a certain point in time, which connects knowledge and the nonsensical to that which we can imagine. The third theoretical assumption is a feminist understanding that sustainability formations take place in between culture and nature/the environment as an ongoing process of differentiation with social and political consequences. My fourth, and last, theoretical assumption is that education produces and relates to Otherness in different ways, and how these relations are made has ethical consequences. The assumptions that I present above provide a framework for analyzing and discussing the results of the empirical study.

The next chapter will outline the materials and methods I have chosen in order to study the sustainability imaginary in education. 



\title{
Chapter 3
}

\section{Material and methods: How to study social imaginaries}

\begin{abstract}
It matters which stories tell stories, which concepts think concepts. Mathematically, visually, and narratively, it matters which figures figure figures, which systems systematize systems.
\end{abstract}

(Haraway 2015, 160)

Imagination is a social and collective field situated in individuals. In this study, I conduct focus groups as a methodological strategy to study the collective formation of sustainability in education. A focus group is a small number of people who meet on one occasion to discuss a specific topic. The group is led by a moderator, who introduces the topic and facilitates the discussion. Focus groups generate data with a "collective quality" that goes beyond opinions expressed by a single individual (Wibeck 2002, 50). The group processes can be used in order to study ongoing negotiations and formations of a specific phenomenon. The focus group discussions can allow participants to pose questions to each other, and the group dynamic can take the discussion in unexpected directions (Kitzinger and Barbour 1999, 4; Wibeck 2010, 52). The approach chosen for this study is rooted in the notion that a phenomenon is never finished, but rather is constantly becoming. Thus, examining collective processes of formations can help us develop deeper understandings of specific issues, including sustainability in education. The advantage of conducting focus groups, as opposed to individual interviews, is that the group discussions can be said to constitute "thinking societies in miniature" (Jovchelovitch cited in Wibeck, Dahlgren, and Öberg 2007, 250). In other 
words, ideas voiced in focus groups can be seen as both using and forming imaginaries circulating in society at large. In this chapter I introduce methodological considerations and choices I have made while carrying out this study. I also discuss the types of conclusions I can draw by using this particular method.

\section{Focus groups as a methodological strategy}

A single question has guided me throughout this study: What is sustainability in education? In order to answer this question, which at first glance might look simple, I have had to consider methodological choices and analytical strategies on different levels. During this study I conducted a total of eight focus group interviews with teacher instructors in universities and colleges in Sweden. I was considering ethnographic fieldwork as a suitable research method at the beginning of my research project. After a pilot study I carried out during the spring of 2011, where I conducted individual interviews with key figures at four Swedish universities that offer comprehensive teacher education programs, I came to reconsider my choice of method. In the pilot study, I focused on how the notion of sustainable development was defined and negotiated by these key figures in their work with the latest teacher education reform, a reform that was implemented in 2011. It turned out that sustainable development was not a very prominent or highlighted area in the local implementation processes. As a consequence, I had to consider other methods than ethnography since sustainability appeared to be marginalized in the ongoing reform process, according to my pilot study. I suspected that an ethnography would be difficult if I could not locate sustainability in the new teacher education structure. In other words, I needed to develop a methodological strategy through which I could locate sustainability in education.

In-depth interviews in qualitative research can give the researcher access to information and processes that would otherwise be inaccessible. The advantage of focus groups compared to individual interviews, which is a more common method in the social sciences, is the possibility of opening up the group discussion for surprises and questions that the interviewer could not have anticipated beforehand. Furthermore, relating to a professional role and practice can be further highlighted when the participants are recruited and appealed to in their professional role. With this in mind, I recruited teacher instructors to reflect on how sustainability can be handled in the practices of 
teacher education. I wanted to create methodological prerequisites for the practitioners to define and grapple with how to handle this concept, since stipulating a definition of sustainability before carrying out the study would go against the aim and objectives I had in mind.

Communication researcher Victoria Wibeck (2010) argues for the usefulness of focus groups in qualitative research when researchers wish to study a topic that might be hard to grasp using other research methods. She further argues for focus groups as a suitable method when the researcher would like the participants to have an active role in posing questions throughout the interview (Wibeck 2010, 52). Jenny Kitzinger and Rosaline S. Barbour (1999, 4) underline that focus groups are different from other group interviews because of the researcher's use of interaction to produce and generate empirical data. An advantage of focus groups in this case is that the participants often tend to ask each other questions, which is beneficial when the interviewer is initially unsure of what questions to ask (Wibeck 2010, 52; Kvale and Brinkmann 2009, 166). Thus, the agenda is not entirely governed by the researcher, but provides the possibility of an open ending to what might come up during the discussions. This aspect suits my focus on imaginaries formed and re-formed by both discursive formations and the nonsensical. Kathryn Yusoff and Jennifer Gabrys $(2011,518)$ claim that the "process of imagining and enacting future worlds encompasses the metaphorical, ethical, material, and imaginative registers through which environmental understanding emerge." Finding a way to study the formation of these imaginative registers is the purpose of my methodological design.

Focus groups have been suggested as a method suitable for feminist-oriented research, since focus groups can destabilize the sometimes unequal power relation between the researching subject and her/his study object (Wilkinson 1999). Although the set-up of a focus group can allow the participants to question and criticize the researcher's research questions, interview questions, and choice of method (which indeed happened in some of the focus groups I conducted), the group processes produce a number of relations that have the potential to both reproduce and challenge unequal power relations.

The methodological choice to use focus groups makes it possible to remain relatively open to what the participants bring up throughout the discussions, considering the ongoing process of situating and handling sustainable development in teacher education. Remaining open to what the participants 
brought up during the discussions was important to me when I began working with this project. Wibeck, Dahlgren, and Öberg $(2007,250)$ argue that focus groups can be seen as learning spaces and "participant-centered activities" (251). As a moderator of the groups, I generally spoke as little as possible during the discussions. I did intervene, however, by introducing a poem and various images during the interviews, strategies that I will discuss further below. I often remained relatively silent during the focus group discussions, listening actively and taking notes. The last focus group I conducted, in May 2013, was slightly different. Here, I was more active than in previous groups, and more inclined to test conclusions from previous groups by asking questions and formulating ideas. The last group had fewer participants than the previous groups as one participant cancelled at the last minute, which also played into my level of activity.

\section{Interview guide and stimulus material}

The interview guide I used was based on the strategy of conducting unstructured focus groups, although within a specified, limited framework (see e.g., Wibeck 2010, 56-58). The interview guide was prepared based on the idea of using the focus groups as relatively open forums for discussing and elaborating on the handling of sustainable development in teacher education. However, the focus groups created a focused frame for the discussion, both in the way I formulated the invitation to the potential participants and how I introduced the method of using focus groups. The participants were all invited in their role as teacher instructors handling sustainability in some way, which was a role they continuously related to throughout the discussions.

The loose interview guide was structured around three main themes: Teacher education's relevance to sustainable development, Experiences of sustainable development in teacher education, and Knowledge and sustainable development. I had a short paragraph in the interview guide introducing each theme. Apart from the three themes, I also had an initial section in the guide introducing the research project and another part where the participants, myself included, introduced themselves to each other. In introducing themselves, the participants were asked to specify the area of teacher education (subjects(s), age group) they were involved in. At the end of the interviews, I also asked a question about what they had found most important during our discussion. During one interview I tried a different strategy and asked instead 
what they would take with them from the discussion. For each theme I had a number of questions to ask in case the discussion started to fade, but it turned out that such prompts were not needed for most parts of each focus group since the discussions were often lively. Furthermore, the participants often asked each other questions without my verbal intervention.

Two of the themes were introduced by stimulus material, including a poem and nine pages of 23 images representing different concepts and tensions related to sustainable development in education. These types of material are often used in focus groups (Kitzinger and Barbour 1999, 11-12; Wibeck 2010, 78-79). When introducing the theme Teacher education's relevance to sustainable development, I used a comical poem in Swedish. The poem that I handed out and read is called "More of everything"1 and it elaborates on the difficulties teachers have in handling requests to cover many areas and subjects in education.

I gave each participant a slide with the poem and I also read the poem out loud in all groups. I picked this particular poem as part of the stimulus material because it draws attention to many of the different responsibilities that education and teachers are assumed to take on regarding various topics that could or should be handled in education. The poem also touches upon the teachers' responsibility to prioritize between these areas and topics. Sustainable development is not mentioned explicitly in this poem, although several related areas are, such as environmental degradation, the risk of smoking, the harvesting of mushrooms, women's movements, religion, art, technology, and so on. By introducing the poem, I wanted to give the participants a frame for talking about the responsibilities of education as well as practices of prioritizing among several demands on educational content:

1 In Swedish: "Mera av allt", written by Olof Hammarlund and published in the Swedish Government Official Report Skola för bildning (SOU 1992:94). 


\section{Mera av allt}

I kö står önskemålen

vid skolans kunskapsdisk:

mera om alkoholen,

mera om rökningens risk,

mer om det aktuella,

mer om historiens gång,

mer om det sexuella,

mer om musik och sång,

mera teknikundervisning,

mera om konstens mission

och (mot andliga värdens förlisning)

mera religion,

mer om miljöförstöring,

mer om förvällning av svamp,

mer om mopedrengöring,

mera om kvinnokamp,

mera om konstgjord andning,

mera om allt häromkring,

ja, mer om allt i skön blandning

och mindre av

ingenting.

Man nödgas vara flexibel

I detta konglomerat

Och läsa sin läroplansbibel

Ibland som en viss potentat
More of everything

(literal translation)

The wishes are queued up

at the school counter:

more about alcohol, more about the risk of smoking, more about the breaking news, more about the paths of history, more about sexuality, more about music and songs, more about technology teaching, more about the mission of art, and (against moral collapse) more about religion, more about environmental degradation, more about how to harvest mushrooms, more about how to clean a scooter, more about the women's movement, more about artificial respiration, and everything around us yes, everything in a nice mix and less of nothing at all. You need to be flexible in this conglomerate. And read the curriculum bible sometimes as a master.

I introduced the last main theme, Knowledge and sustainable development, through different images. My work with this part of the stimulus material was inspired by sociologist Jukka Törrönen (2002), who argues for the usefulness of images (and other stimulus texts such as film, news, and historical sources) in qualitative interviews. Törrönen $(2002,359)$ argues that a stimulus text in an interview "creates a fruitful tension between externalized, objectified culture and subjective, situational meaning-giving." Törrönen's work is in dialogue with semiotic readings of images used in communication studies (see e.g., Fiske 1990) as well as the writings on signs by Charles S. Peirce (1955). 
Similar to the poem above, the images chosen are meant to illustrate and embody potential tensions when making sustainable development teachable in education. The images and photos represent interpretations - my interpretations - of different concepts and tensions related to sustainable development in education. In a strategy from the United Nations Economic Commission for Europe (UNECE), key themes from education for sustainable development are described as follows:

Key themes of SD [sustainable development, my comment] include among other things poverty alleviation, citizenship, peace, ethics, responsibility in local and global contexts, democracy and governance, justice, security, human rights, health, gender equity, cultural diversity, rural and urban development, economy, production and consumption patterns, corporate responsibility, environmental protection, natural resource management and biological and landscape diversity. Addressing such diverse themes in ESD [education for sustainable development, my comment] requires a holistic approach. (UNECE 2005, 4)

These broad, all-inclusive themes need to be interpreted and made teachable in practice. I have developed methodological strategies to tease out different tensions that occur through the process of making sustainability teachable. In order to do this, I selected the images after reading the document quoted above as well as other policy documents regarding education for sustainability. One such policy document is the latest Swedish curriculum, which has several passages elaborating on sustainable development, both for the general educational goals and for different subjects (Lgr11); these passages, in my reading, contain many of the tensions I have tried to show through the images.

An image can be used to illustrate a situation that can be interpreted by different discursive formations. Moreover, images also allow the interpreter to draw on aspects of the nonsensical in ways that questions such as "What is sustainable development?” cannot achieve. Images are useful as part of contemporary societies' significant visual cultures, where visual media are central to many aspects of our everyday life (Mirzoeff 2009). Studies of visual cultures seek to understand "the visual construction of the social field" (Mitchell 2005, 345), and analyzing visual culture is about being situated "in the midst of conflict" (Mirzoeff 2009, 2). As part of these cultures, visual images are central to contemporary life and are everywhere around us: on cereal boxes, 
on shower gels, in our smart-phones, in social media interactions, in ads we encounter on public transit, in news we read and watch, in entertainment we consume, etc. The visual cultural aspects of our lives are salient for understanding the resources we can access when we form our understandings of almost any phenomenon (see e.g., Bryld and Lykke 2000). Although this study is not a study of images, I consider visual aspects of contemporary life to be salient for understanding social imaginaries and I use images in order to ask open-ended questions. In other words, my ambition in selecting the images for this study was to offer different frames for discussing sustainability in education.

Törrönen (2002) discusses three different aims of using images and other stimulus material in an interview: as clues, as microcosms (icons), or as provokers. While developing the interview guide I was inspired to use the images as either microcosms or provokers. As mentioned above, Törrönen builds on the work of American philosopher Charles S. Peirce (1955, 104), who classified signs as either icons, indexes, or symbols. Although images always are iconic in the sense that they depict something real, I suggest that each of the semiotic readings of the images in this study may be seen as either icons or symbols, depending on the context and the interpreter (see e.g., Törrönen 2002, 345). In my interpretation, many images can be seen as microcosms (icons), which put some aspects of sustainable development in the foreground while hiding others. Using stimulus material as microcosms in a study means, according to Törrönen $(2002,359)$, that we "construct iconic representations of the studied object and encourage the interviewees to express their values, ideals and subject positions in relation to it." Törrönen argues that stimulus texts as microcosms can be selected from a different level of abstraction. Furthermore, I developed some series of images as provokers (as both icons and symbols that relate to cultural conventions) that "question the cultural conventions of the phenomenon under examination" (Törrönen 2002, 359). I tried to create some provoking expressions that show some "carnivalistic elements, marginal phenomena, transgressive activities or extreme experiences" $(2002,357)$ in the selected images to further tease out the tensions of sustainability education.

On the one hand, images are just pixels on paper, and on the other hand, we live in a visual culture that makes images a very important part of how we make sense of the world. In order to access and question what is taken for 
granted, I have chosen visual materials that can help to challenge established social norms and conventions regarding sustainable development in education. In communication studies, the concept of redundancy is used to describe high predictability in a message, whereas entropy is used to explain a message that is highly unpredictable (Fiske 1990, 10-12). These concepts have been helpful for me when selecting images. By contrasting images with a high level of redundancy to others with a high level of entropy, I have aimed at illustrating contrasts that can be used to stimulate discussions about sustainability. As Törrönen $(2002,357)$ writes: "By using substitute worlds in a provocative way in the interviews one can evoke forms of orders, boundaries and peripheral areas that are connected to the world view, values, identities and lines of action of the interviewees." As an example of this, I included one image showing a dead sow and piglets, which created strong reactions in most groups. The selection of the image clearly had an impact on steering the discussion to include nonhuman animals, which will be discussed further in Chapter 6. My selection of images has been in line with recommendations that stimulus material should preferably be provocative or evoke emotional involvement "by containing a certain opinion or some kind of contrast or tension" (Dahlgren and Öberg 2001, 278).

During one of the focus groups, one participant, Dan, said "we are supposed to work with sustainable development: but what is it actually?" Others expressed similar concerns. Nevertheless, all of the focus groups were taking part in forming sustainability, as will be evident in the following chapters, which leads me to believe that the images were useful in facilitating the discussion, posing visual questions about what aspects of sustainability the participants recognized or found inaccurate. In selecting images to represent different aspects of sustainability my ambition was to find images that were rich in meaning. By "rich in meaning" I mean images that I thought would evoke microcosms and/or something provoking in relation to sustainability, and images that depicted both redundant and entropic aspects of sustainability. This strategy is in line with my theoretical interest in imaginaries as systems of imagination that contain both discursive formations and the nonsensical. Establishing or negotiating the meaning of a specific image can be a conflictual process. Arguably, all images are meaningful in some way, and there can be many forms of meaning ascribed to one image. However, the selection and presentation of images helped to situate me (in Haraway's sense of the word) as a researcher, and made my readings of sustainability visible and available 
for the focus group participants to question. Indeed, visual images can be seen as "normative statements portraying a particular way of sensing the world" (O'Neill and Smith 2014, 83). In this study they can serve as means for repoliticizing sustainability. When presenting the images to the participants, I always asked if they found that there were missing aspects. In several groups, participants criticized the images as too anthropocentric, too dualistic, or too negative, but there were also comments to the contrary - stating that the images were well chosen and recognizable. Although the selection of images could certainly have been done differently, and with a different vision, I read these different reactions to be in line with the theoretical assumption about the entanglements of situated yet collective ways in which we can imagine sustainability. Our interpretations might be personal and contextual, but never disconnected from collective and social aspects of knowing and imagining. My interest in the sustainability imaginary motivated me to choose the method of using images, as "images have been crucial to the narrative of climate change in popular imagination" (Yusoff and Gabrys 2011, 521), which should also be the case for sustainability. Images rather than oral questions may also have the potential to evoke open associations and nonsensical interpretations as individuals attempt to grasp the relation between the known and the unknown. I view the images as facilitators of the discussions, similar to but more open than the use of interview questions in conventional social science research. I selected images from the various sources available on the Internet, where most of the photographers or creators are unknown, which unfortunately means that I lack the right to republish most of them in the study. Instead, hyperlinks are provided for images available online in Appendix A.

I began my search for images by studying the visual material of different publications on education for sustainable development, published on the home page of the Swedish National Agency for Education. Most of the images I found showed healthy white children playing in various school environments or in outdoor "nature" scenes (with a high level of redundancy). These images seemed to be icons of happiness, freedom, and well-being (see e.g., Lindgren 2013). I began to ask which sustainable development issues or versions were excluded from the agency's visual illustrations (with a high level of entropy). It was with the aim of finding potential tensions that I began my work selecting the images to be used as stimulus materials. 
In order to select images, the researcher must first make a translation or interpretation of the phenomenon being studied. The important point for me here is that this interpretation work is to be made explicit for the reader, considering that the choices of images and the idea behind them is a crucial part of the interpretation process. The images in this study were selected for the purpose of showing the contrasts and tensions embedded in the notion of sustainable development, drawn from my reading of previous research and studies. The 23 selected images cover the following tensions: North-South, Individual-Collective Responsibility, Nature-Culture, Global-Local, Policy-Practice, Rich-Poor, Doomsday-Future Optimism, Technological Optimism-Skepticism, Human-Machine-Animal. I suggest that these tensions are related to the multifaceted concept of sustainable development. There are of course other areas, issues, and complexities that could have been brought up, which would be the case for oral questions as well. Below, I present the semiotic readings I produced when I developed the image series to be used as stimulus material in the focus groups.

North-South (provoker): Two of the photos are from the Swedish National Agency for Education's website (headline: Sustainable Development) and show two white boys climbing trees, and three white children wearing reflective vests right next to a biodynamic package of flour or muesli. The lower images are from Wikipedia's portal for sustainable development and illustrate children in contrasting environments: dark-skinned children who reside on a garbage dump (or similar) and a group of young brown women who are sitting on a floor in a teaching/learning situation. The images are intended to illustrate various aspects of nature and learning environments, displaying and questioning the North-South dualism, which is one of the tensions I believed that the teacher instructors may have to work with. Here I wanted to illuminate the colonial heritage's role in shaping our current lives.

Individual-Collective Responsibility (microcosm): These images are meant to trigger ideas about how responsibility is understood and constructed in the sustainability imaginary. On the one hand we see an image of North Korean soldiers marching in lockstep, all wearing identical uniforms. They stare into the camera with serious faces. The soldiers as a group signal a collective act. The second image shows two young white girls putting a letter or a note into a miniature mailbox, which a white adult male figure 
holds out for them. This image signals the importance of the individual taking a stand and voicing her/his own opinion. Responsibility on the individual and collective level is something that is often taken up in previous research regarding sustainability issues, which is why it is illustrated here.

Nature-Culture (microcosm): One of the images shows a tsunami wave that floods a small town or village. This image could evoke feelings about nature's inexorable forces and a feeling of humanity's insignificance in relation to the forces of nature. However, the image has other layers as well. Deforestation of mangroves in Southeast Asia is said to have undermined the protection against tsunamis in the region, which is an example of how aspects of nature and culture interact. The image of a tsunami wave is also an important and emotionally marked icon in Sweden, since over 500 vacationing Swedes were killed by a huge tsunami that hit Southeast Asia during the Christmas of 2004, following an earthquake in the Indian Ocean. The second photo shows a wind farm, pictured in backlight. Wind power can be seen as one of many technologies where humans try to use the forces of nature in order to maintain and develop a lifestyle based on high electricity consumption. Together, the images could be said to symbolize the distinction that is often staged between nature and culture, both maintained and challenged through discursive formations of sustainability.

Global-Local (microcosm): The first image shows an act of hand shaking (probably between a female and a male, one hand is broad and has some hair on the back of it, while the other is narrow with long, manicured nails). A globe is visible in the background. It looks like two people are shaking hands over a decision related to the future of the planet. The image could symbolize the idea that decisions and agreements relating to the globe need to be made on an aggregated level (perhaps between adults?). This image represents a clear contrast to the second image, which shows children who are using the planet as a playground. This second image shows a number of children with blond and dark hair. They seem to be busy with washing and cleaning the planet. The image could be an illustration of how children in preschools learn about and become responsible for sustainable development, but also an illustration of the intertwined dimensions of global and local actions and knowledge. These two images were selected to show yet another possible tension within the sustainability imaginary. 
Policy-Practice (microcosm): The first image shows black demonstrators protesting at the UN Climate Summit in Johannesburg in 2002. One of them holds up a sign saying "Our world is not for sale! No WSSD!" The image could symbolize a public movement about global issues. The second image has been taken inside the walls of the same climate summit. A number of white men in suits and ties (and an occasional white woman) are seated in comfortable chairs around a number of tables with microphones on them; they appear to be inside a parliamentary building. In the background there is a large banner with the text "Johannesburg, South Africa, 26 August-4 September 2002." The third image shows a middle-aged white man leaning over a table stacked with bio-dynamically labeled foods. The idea of selecting this last image was that it shows an important part of the intertwined global-local aspects concerning consumer power and consumer responsibility. In contrast to the other images illustrating this tension, it raises yet another dimension about the overlap between public policy and practice. These three images are meant to provoke thoughts and reflections regarding the connection between global policies and local people's practices. This kind of tension is visible both in the national political story and in the literature on education for sustainable development.

Rich-Poor (provoker): The first image shows a black child with a swollen belly, who sits naked on a wooden bench. This image depicts racialized poverty and extreme starvation. The second image illustrates two overweight Asian-looking boys, who are seated at McDonald's with a tray of French fries in front of them. Each boy also has a cardboard cup with soda and a straw. The image depicts material abundance parallel with the cultural underclass in the West, as the object of an ongoing debate about obesity and health. The last image shows a number of white children (mostly boys) who are outdoors playing rugby. They appear to have fit, well-proportioned bodies and to be in good health, as they are seen running towards the camera. The image depicts prosperity and health, which are often associated with the middle/upper class in the West. These three images are meant to show provocative and/or unpleasant contrasts around the dichotomy of rich/poor since the issue of wealth and development is strongly manifested within the sustainability realm.

Doomsday-Future Optimism (microcosm): The first image depicts a shoe on a human foot, just about to crush a small globe under 
its sole. The image illustrates a possible dystopia in the way humans live and interact with various nonhumans on Earth. It also invokes the message of the Anthropocene, that is, that human activity has changed the geological conditions on Earth. The second image shows three young white girls jumping around with arms stretched to the sky. They are in a green field under a blue sky. The image signals the good, utopian life where children are happy and free, surrounded by beautiful nature. In dealing with sustainable development, the teacher instructors are likely to have to handle the abrupt shifts between dystopias and utopias. This tension is meant to evoke the balance between the feeling that something must be done before it is too late and the feeling that it is already too late to do anything.

Technological Optimism-Skepticism (microcosm, provoker): The first image depicts the founder of the computer company Apple, the late Steve Jobs. In his hands he holds an iPad, a current symbol of technological development and unlimited possibilities. The second image depicts the iconic "mushroom cloud" that followed the detonation of the nuclear bomb in the Japanese city of Hiroshima, marking the end of World War II. I picked these two images because I think they reflect, in different ways, the conflicting emotions that technological development causes in our current society. I also imagined that this is something that might be of relevance to the teacher instructors who are trying to deal with sustainable development.

Human-Machine-Animal (provoker): The first image shows a woman in sunglasses who appears to be playing music with the help of a DJ mixer. The image represents a flesh-and-blood woman interacting with a machine. The second image shows a human-like face, but instead of skin and hair, lots of cables and cords are coming out of the back of the head. It appears to be some sort of humanoid machine. The third image is of a bulldozer filled with dead pigs - a sow and a number of piglets. The image was first taken from a blog and then traced to the Animal Rights Alliance's [Djurrättsalliansen] campaign Life as a Pig ["Ett liv som gris"]. The image was obtained during a break-in at a pig farm in Sweden. The image can be seen as both provocative and nasty and as a contrast to the otherwise "modern" machines and machine parts that were included in this set of images. It also shows the entanglement between humans, machines, and animals, which appear both separately and together in these images. This entanglement is a theme that I developed in order to grasp 
how sustainability is a politically loaded imaginary of inclusions and exclusions.

\section{Recruiting focus group participants}

As argued in the introduction chapter, teacher instructors are given a central responsibility for the education of future generations of teachers. The multifaceted position as a teacher instructor is central to this study, as the teacher instructor is located at the intersection of school practices, university education, educational reforms and, often, their own research. The position offers opportunities for active reflection over the tensions involved in who the future teacher of sustainability should be, and what the future teacher should know. I gathered the teacher instructors in order to discuss with them how they make sustainability teachable. I avoided limiting the scope to a specific subject, area, or age category within teacher education. Instead of focusing on, for instance, the education of science teachers or preschool teachers, I made an effort to bring together teacher instructors from various fields, areas, and disciplines.

The interviews were carried out in the spring of 2012 and 2013 at four different universities and four different university colleges around Sweden with a total of 34 participants. The eight universities/colleges were selected based on contacts provided during the pilot study with key figures at for universities/colleges in Sweden, and additional contacts met at conferences and through an Internet search on teacher education programs around the country. I began by recruiting at least one participant per university/college. Each first-recruited participant then referred me to other potential participants, creating a so-called "snowball sample" (Bryman 2016, 415).

I have selected both large universities with comprehensive teacher education programs and small colleges with limited teacher education. At some of the large universities, several participants did not know each other beforehand and met for the first time at the focus group occasion. At the smaller colleges, the participants often knew each other and had worked together before. I picked these different settings so as not to let organizational structures and university/college size bias the outcome of the focus groups. As it turned out, I could not detect any major differences between the groups based on organizational structures or university/college size. After conducting eight focus groups I experienced what is called data saturation as I was able to recognize 
recurring themes and discussions. I then decided that I had enough material to work with in order to answer my research questions. While analyzing the data, I came to recognize geographical inequalities within Sweden, where the north region, Norrland, has been continuously neglected in terms of politics, knowledge, and economic resources (Tidholm 2012). During the years while I was conducting this study, these inequalities gained more attention in Sweden due to, for instance, reports on indigenous protests against contemporary mining politics (see e.g., M.-B. Öhman 2016, 63). However, I did not consider this geopolitical situation when I was selecting the venues for the focus groups, and I must admit that none of the eight groups was situated in the Norrland region. I am not sure whether this affects the outcome, but the question is definitely worth considering for anyone interested in challenging dominant patterns of power.

It is important for ethical reasons that people who contribute their time and effort to research do so voluntarily. Therefore, I have had to accept that a few people turned down my invitation to participate in the focus groups. Some said they did not have enough time, others felt they had too little to contribute, and some simply never picked up the phone or replied to my emails. Once I had gathered a reasonable number of participants (my rule of thumb was no fewer than four, based on recommendations from the focus group literature (Wibeck 2010, 62)) at a particular university/college, we booked a date when participants were available. Because of busy schedules, it was often difficult to find a date when everyone invited had the opportunity to participate. On one occasion the group consisted of three participants due to a last-minute cancellation. The interviews lasted between 80 and 105 minutes. In all cases, we met at the campus of the participants' university/college.

The focus groups can be seen as both homogeneous and heterogeneous, depending on which aspects are considered. Four groups were very mixed regarding academic disciplinary background; the participants had backgrounds in everything from preschool teaching to geography, social sciences, mathematics, and science education. Two groups consisted of three participants with natural science backgrounds and one participant with a background in social sciences, while in two groups, all participants had a background in the (broad) field of science. Most participants where either working as lecturers (without PhD degrees) or as senior lecturers (with PhD degrees). One participant was a professor. A few were currently working on their $\mathrm{PhD}$ degrees. 
No group consisted of only men or only women. Although I did not ask for the participants' ages (it did not seem relevant at the time of the interviews), I would estimate that the participants in all of the groups were between 30 and 60 years old. As far as I could tell, all participants had names that sounded traditionally Swedish or Nordic. The composition of the groups is summarized in Table 1.

I contacted all participants in advance by phone or email, introduced my $\mathrm{PhD}$ project briefly and asked them if they were interested in participating in a focus group to discuss sustainable development in teacher education together with other teacher instructors working at the same university or college as themselves. At the time of the focus group, I described my project further and introduced the idea of focus groups, pointing out that the participants' discussions and questions to each other were of great importance.

I introduced the stimulus material in all eight cases, but the number of questions I asked in the groups varied from one or two to several depending on the atmosphere in the groups and the extent to which groups introduced new themes themselves by asking each other questions. On a few occasions we had very little time left for discussing the images, but on those occasions I chose not to interrupt while relevant and interesting discussions were in full bloom. I dealt with the organization of the stimulus material in two different ways. During the first interview, I spread out all the images on the table in the room. My intention was that the participants would circulate the images and discuss them together. However, two problems appeared with this strategy: first, the recording got noisy since the participants were moving the images around, and second, the analysis stage got harder because the participants never mentioned which image they were talking about (something that complicated the transcription and my ability to relate their discussions to certain images). In the remaining seven interviews I changed strategy and let each participant have their own folder of images so that they could have a moment to go through the images alone before beginning to discuss them. A disadvantage with this strategy, however, was that the participants only mentioned some of the images and not others. 


\begin{tabular}{|c|c|c|c|c|}
\hline Group name & $\begin{array}{l}\text { Participants' } \\
\text { pseudonyms }\end{array}$ & Academic fields & $\begin{array}{l}\text { Number of } \\
\text { participants }\end{array}$ & Duration \\
\hline Group A & $\begin{array}{l}\text { André, Anna, } \\
\text { Anastasia }\end{array}$ & $\begin{array}{l}\text { Social science, } \\
\text { preschool, domes- } \\
\text { tic sciences }\end{array}$ & $\begin{array}{l}2 \text { women } \\
1 \text { man }\end{array}$ & 80 minutes \\
\hline Group D & $\begin{array}{l}\text { Dan, David } \\
\text { Didrik, Dagny }\end{array}$ & $\begin{array}{l}\text { Science and sci- } \\
\text { ence education }\end{array}$ & $\begin{array}{l}3 \text { men } \\
1 \text { woman }\end{array}$ & 105 minutes \\
\hline Group G & $\begin{array}{l}\text { Gert, Goran, } \\
\text { Gunnar, Gisela }\end{array}$ & $\begin{array}{l}\text { Social sciences, } \\
\text { biology, technol- } \\
\text { ogy education, ge- } \\
\text { ography }\end{array}$ & $\begin{array}{l}3 \text { men } \\
1 \text { woman }\end{array}$ & 105 minutes \\
\hline Group L & $\begin{array}{l}\text { Lisbeth, } \\
\text { Lennart, } \\
\text { Lillemor, Lisa }\end{array}$ & $\begin{array}{l}\text { Science educa- } \\
\text { tion, biology, so- } \\
\text { cial sciences, ge- } \\
\text { ography }\end{array}$ & $\begin{array}{l}3 \text { women } \\
1 \text { man }\end{array}$ & 90 minutes \\
\hline Group M & $\begin{array}{l}\text { Melker, Mats, } \\
\text { Merith, Maj, } \\
\text { Malcolm, } \\
\text { Minna }\end{array}$ & $\begin{array}{l}\text { Social sciences, } \\
\text { science education, } \\
\text { geography, pre- } \\
\text { school }\end{array}$ & $\begin{array}{l}3 \text { men } \\
3 \text { women }\end{array}$ & 100 minutes \\
\hline Group N & $\begin{array}{l}\text { Nils, Nora, } \\
\text { Nancy, Nelly }\end{array}$ & $\begin{array}{l}\text { Science and sci- } \\
\text { ence education }\end{array}$ & $\begin{array}{l}3 \text { women } \\
1 \text { man }\end{array}$ & 100 minutes \\
\hline Group O & $\begin{array}{l}\text { Oscar, Olga, } \\
\text { Olof, Ove, } \\
\text { Odin }\end{array}$ & $\begin{array}{l}\text { Pedagogy, science } \\
\text { education, the ed- } \\
\text { ucational core, } \\
\text { mathematics, } \\
\text { technology educa- } \\
\text { tion }\end{array}$ & $\begin{array}{l}1 \text { woman } \\
4 \text { men }\end{array}$ & 100 minutes \\
\hline Group S & $\begin{array}{l}\text { Sofia, Solveig, } \\
\text { Sebastian, } \\
\text { Sandra }\end{array}$ & $\begin{array}{l}\text { Social sciences, } \\
\text { the educational } \\
\text { core, biology, sci- } \\
\text { ence education, } \\
\text { preschool }\end{array}$ & $\begin{array}{l}3 \text { women } \\
1 \text { man }\end{array}$ & 90 minutes \\
\hline
\end{tabular}

Table 1. List of focus group participants 


\section{On transcriptions and language}

According to communication researcher Per Linell $(1994,4)$, a transcription always entails an interpretation of the interview situation. The level of detail chosen depends on the kind of analysis one wants to conduct. The transcriptions here were originally done word-for-word. In an effort to make the transcripts easily readable and accessible, I first chose to present them as "approximate literal" (Linell 1994, 12), which means that I removed some of the colloquial elements of the quotes. As a last step, I translated all the quotes from Swedish to English, and I found that some of the colloquial aspects would have been difficult to translate anyhow. The transcribed quotes in the analytical chapter have been presented on a level relevant for the interpretation and analysis. The translations have therefore focused on capturing the meaning of what was said (rather then how things were said) and I included laughter and other non-verbal communication only where it would be important for the analyses. Extra words due to repetitions have been removed since those do not play a role in the analysis. Where I was unable to hear something I marked it as "[inaudible]." Square brackets are also used when explaining something that the participants are referring to and that would not make sense to someone who was not present at the interview. Where sequences of words have been removed in the analysis, due to long pieces of transcripts, I mark this with "[...]" on a new line. Mutual talking is not highlighted as it does not matter for the analysis. Laughter and clearing of throats have been spelled out as "[LAUGHS]" and "[CLEARS THROAT]," especially when they might play a role in the analysis.

I have assigned pseudonyms to the participants in each group. For clarity, each group has been given names that start with the same randomly selected letter; for example, in Group A the participants are referred to as Anna, André, and Anastasia.

\section{Analytical strategies}

Research is a process involving ontological and epistemological cuts. This means that some things are studied at the expense of others. The researcher needs to make choices about which aspects are relevant and interesting to study. Doing this also means that there are things that will be excluded or ignored. Coding the focus group data and finding interesting themes for this 
project has been a gradual process (see e.g., Kvale and Brinkmann 2009, 212). When coding the focus groups I used a software called Nvivo, which is specially designed for qualitative data. An advantage of using software instead of, for example, scissors and pencils, is that it is easy to get an overview of the material, and also to code the same sequence under several themes or nodes. I have used Nvivo to create a descriptive overview and mapping of the approximately 700 pages of interview transcripts that were produced after the focus groups were conducted.

Throughout the transcription process I took notes when I found interesting things in the interviews that raised new or unexpected ideas. After transcribing the interviews, I read through each one several times. I have also listened through them again before revising the whole manuscript to capture more dimensions about each identified theme and to make more in-depth analyses of these findings. On the first reading, I underlined things that surprised me or made me curious, sometimes adding a note about the thought a particular sequence gave rise to. The initial coding of the data was done rather descriptively with labels such as "animals," "responsibility," "doomsday," "the teacher role," "consumption," "personal engagement," etc. These labels grew out of topics that were brought up in the groups. By using Nvivo, I was able to develop themes by grouping, re-grouping, and theorizing recurrent topics throughout the reading of the transcripts.

The empirical findings prompted me to read up on the field of educational philosophy in order to better understand the things that were brought up in the focus groups. My affiliation with an interdisciplinary research department, and participation in a seminar group with researchers within environmental humanities, has exposed me to a number of fields and ideas that have provoked my thoughts while analyzing the interviews. Through these encounters, themes have been grouped and re-grouped into chapter ideas. These chapter themes are based on identified elusive and uncomfortable topics in the focus group discussions, in line with my interest in a broad definition of politics. "Sensitive moments" (Kitzinger and Farquhar quoted in Wibeck, Dahlgren, and Öberg 2007, 259) have been of particular interest to me. This interest in the unforeseen led me to develop the theoretical concept of the nonsensical. The focus on elusive and uncomfortable aspects is motivated by my imperative to re-politicize sustainability and ask how sustainability is formed in education, and to explore how these formations relate to ideas of 
what education is, and whom it is for. During the focus groups, none of the participating teacher instructors gave a direct answer to the question of how they defined sustainability in their teaching. Vague references to the definitions in the Brundtland Report, repeated claims about the problem of defining sustainable development, and references to courses and course modules were the usual types of responses to the question of definition. To trace the definitions and delimitations of the concept when making it teachable, I have instead turned to tensions expressed as elusive and uncomfortable aspects of making sustainability teachable. Elusive and uncomfortable aspects were identified in the focus groups in six different ways:

1. By tracing unresolved dilemmas and problems, which is when one or several of the participants brought up troublesome quandaries that seem impossible to resolve.

2. By investigating the positioning of us against them, which is where one or several of the participants referred to problematic subject positions of Others such as students, politicians, or non-Swedes to construct their own identity.

3. By investigating irrelevant and/or surprising topics, which, for example, is when I as a moderator interrupted the participants because I thought that they were moving away from the topic, or when a participant introduced a topic as potentially irrelevant. This is an important aspect to investigate since the design of the study emphasizes that sustainability is not to be predefined.

4. By investigating provocation, resistance, and disagreement, which is when the participants seemed provoked, or tried to provoke each other, or when they resisted dominating formations of sustainability in the groups.

5. By defining a problem and then finding a solution to the problem, which is when one or several of the participants defined a difficult problem and then suggested a simple solution to it (for example, in terms of consumption of organic clothing).

6. By looking at laughter and clearing of throats as possible strategies to handle a problematic situation or to mark something as absurd, or as ways to handle something that seemed uncomfortable or elusive in the focus groups. 
According to Gery W. Ryan and H. Russell Bernard (2003, 87), "[y]ou know you have found a theme when you can answer the question, What is this expression an example of?" To arrive at the point where the researcher knows that an excerpt is an expression of something larger requires both listening to the recordings and repeatedly reading the transcripts. The empirical chapters in this study are organized as a mapping of themata (Marková et al. 2007, 135), or of collective cultural assumptions about sustainability in teacher education. Each of the selected themes represents an important piece for exploring sustainability in education. The chapters represent recurring elusive and uncomfortable topics in the groups. However, each focus group excerpt that I present and analyze below should not be seen as a quantitative representation of a topic; instead, each selected quote has been chosen to explore as many aspects of a specific theme as possible. I have striven to capture as many aspects of the identified themes as possible. I am more interested in how a phenomenon is collectively formed then in how different subjects present themselves in a group (cf. Dahl 2014; Johansson 2014). My study is in some ways oriented "to the actual content of the discourse" (Marková et al. 2007,134 ) and something else (here called the nonsensical) instead of how things are said in the focus groups. However, I sometimes analyze how things were said in order to perform more complex analyses of the transcripts.

The excerpts have not been analyzed with a view to judging statements made by particular individuals; rather, the intention was to develop an in-depth understanding of how discursive formations, the nonsensical, and subject formations operate as part of the sustainability imaginary in teacher education. Some interpretations may seem a bit harsh at times, but I have tried to apply the strategy of being "both generous and suspicious" (Haraway 1992, 326) in my analyses of the focus groups. Sometimes I have explored topics very critically, while at other times I have tried to be open to the possibilities that things can be interpreted and imagined otherwise.

\section{Situating the researcher by developing themes and chapters}

I consider this study to be a feminist one, especially as insights from feminist theory are used as a point of departure as well as in one of the four theoretical assumptions I presented in the previous chapter. As a feminist researcher, in the same vein as Donna Haraway, I think it is necessary that I situate myself 
as an embedded subject accountable for the knowledge presented in this dissertation, with a gaze from somewhere. There are many different aspects I could consider in situating my vision. What I have chosen to present below are the aspects I find most relevant for how the results of this study came to be. These aspects can help the reader to understand why this study focuses on certain things and not others. I chose to present this situatedness by accounting for the research journey I have made with regard to the analytical focus, in terms of chapters and themes, in this study. I have already discussed above why focus groups with teacher instructors in Sweden is a suitable methodological choice for this study. Below, I will consider other important aspects of the development of this study.

Throughout my years at university, from my first year as an undergraduate student to my last months as a $\mathrm{PhD}$ candidate, I have had an enduring interest in feminist studies and theory. However, I have encountered a number of other imperatives, fields, and questions during my work with this study. I conducted six of the focus groups during the spring of 2012, and presented some preliminary findings at a feminist conference on new materialisms in May 2012. Here, I was interested in negotiations of literacy in natureculture and in how teacher instructors grappled with the definitions of sustainability in education. I formulated my interest as concerned with how knowledge about sustainable development is delimited in teacher education and how these boundaries affect the images of what a future teacher is. Early on, I realized when reading the transcripts that sustainability seemed troublesome to the teacher instructors. Later on, it became more important for me to investigate in detail how this trouble was considered, and why it was considered so troubling. Because of my position as a PhD candidate in an interdisciplinary research department (Department of Thematic Studies, Linköping University, Sweden), I have been theoretically influenced by both environmental humanities in general and feminist posthumanities in particular. Concepts such as nonhumans and entanglements became important to me. Donna Haraway's writings, in particular, have had a strong influence on my way of thinking since my time as a master student of politics and gender at Stockholm University. Haraway's texts have always been irresistible to me, especially in terms of inspiring new and creative ways of thinking. Haraway's notion of significant otherness became important in the very first analysis of the focus groups. This was a concept I left behind later on when I had to accept that the focus groups focus on human meaning-making. In the early stages of analysis, 
I focused on things that surprised me, both during the interviews and when reading the transcripts. Places where I had interrupted the participants (because I thought that they were moving away from the topic) and places of discomfort (when unresolved dilemmas were presented, or when the participants disagreed) related to my interest in boundaries. I got particularly interested in the role of animals in this boundary work.

Halfway through my $\mathrm{PhD}$, when I was deeply entangled with posthumanities in ways that perhaps did not suit my focus group material, an invited opponent kindly said that it would be good for my further work if I could "fall out of love with the posthumanities." During the years that have passed since then, I think I have formed a more long-lasting relationship with the posthumanities, which allows for critique and questioning as well as a deeper understanding of key concepts. My focus on and interest in human-animal relations, which indeed was an important part of the focus group discussions, has been one way of finding a compass in the posthumanities theoretical landscape, where I have been able to deepen my understanding of certain concepts and ideas in the field.

Shortly after the halfway seminar, I travelled to the University of Texas at Arlington in the USA as a visitor, where I found a more solid philosophical ground for my work. More than anything, I realized that I needed to read up on educational philosophy to understand the focus groups better. The American context also made me realize that "the unknown" is not an innocent term; it can be misused by climate change deniers and other populist movements from the far right. Back home in Sweden, I took a graduate course at Stockholm University entitled Ethics and Educational Relations, taught by Sharon Todd. In-depth readings of thinkers such as Martin Buber, Lucy Irigaray, Emmanuel Levinas, and Nel Noddings made me more attentive to the embedded notion of the purpose of education in the focus group interviews. During this time I conducted two more focus groups and found the discussions to be quite similar to the previous ones. At that point I experienced data saturation. In May 2013, I visited the HumAnimal Group at Uppsala University for three weeks, an interdisciplinary research group with researchers from evolutionary biology, sociology, pedagogy, art history, and philosophy that work with different projects on the intersection of humans and animals. Here I really got the chance to work through and test my ideas about animals in education. 
Working with the dissertation has been a joyful and frustrating puzzle to solve. I have had a strong theoretical interest rooted in feminist theory throughout these years which has not always "matched" the themes of the focus groups. Finding the fields of educational philosophy halfway through was a breakthrough. My theoretical interest in the intersecting aspects of matter and discourse, together with the reality of the focus groups as collective sites of (human) meaning-making, has led me to the cultural studies concept of imaginaries, which came to be one of the key concepts in this study. Investigating the sustainability imaginary was a way to understand both discursive formations and what I have come to name the nonsensical. Developing the nonsensical was further a way to work through those surprising moments in the interviews and see them as part of the sustainability imaginary. During the last months of writing, I have been located as a visitor at the Centre for Cultural Studies at Goldsmiths, University of London, England. Here, turning to politics has been a way for me to both reconnect with and expand on my "roots" in political science, and to better frame and address the research problem in this study. While staying at Goldsmiths, I have also come to realize that, hopefully, this study may make an interdisciplinary contribution to several fields. Below, I will account for why the themes of the following four analytical chapters were chosen over other possibilities.

The first analytical chapter I started writing was on the balancing act of teaching sustainability (Chapter 5). Early on, this theme was analyzed in two different chapters. From the very beginning of the analysis, there was something elusive about how the conversations in every single focus group I conducted came back to the theme of how the participants as teacher instructors could balance between a sense of urgency and the ideal of the neutral teacher. I could clearly see how the teacher instructors were troubled by this problem and how it seemed to create unresolved dilemmas for them. Later on, I started asking when and why they expressed this discomfort. When I presented drafts of this chapter, my colleagues questioned whether neutrality really was an ideal for teachers, given what we know today about knowledge practices and knowledge production in the social sciences and the humanities. The question of why this idea seemed strong as an underlying ideal became something I started investigating.

The second analytical chapter I started writing was on animals (Chapter 6). The last image I added in the stimulus material before conducting the first 
focus groups was the image of the dead pigs. I added this image to show a tension, which worked as an anticipated provoker in most focus groups. I realized in the beginning of the analysis that the conversations on animals related to a lot of different issues regarding ontology, ethics, and politics. Finding out exactly how has been a gradual process. The focus on animals in education has been a way for me to really start grappling with the nonsensical, seemingly peripheral aspects of sustainability, aspects that I have found to be crucial for understanding what sustainability is in education. During my time as a $\mathrm{PhD}$ student I published two articles on the animals discussed in the focus groups (Sjögren 2014a; Sjögren, Gyberg, and Henriksson 2015), which has led me to develop this interest further.

The third analytical chapter I started writing was on what it means for education to acknowledge the end of the world (Chapter 7). This chapter has existed in different forms and is inspired by the ethics of the unknown, which I began to explore while I was in Texas, and got further interested in as I read up on the field of educational philosophy. Salient here is the rather discomforting question of what education can be if there is no future for humanity. This question has led me further into the field of educational philosophy and posthumanities.

The fourth chapter I wrote is on how the teacher instructors talked about the students (Chapter 4). There was something here that bothered me about how critical the teacher instructors seemed to be about their students. I was wondering why that was the case. I started relating this theme to the question of the purpose of education. I presented a draft of this chapter at an educational conference in Norway in March 2014 and received a comment about whether the negative understanding of the students might relate to the categories of class and gender. When presenting a full draft of my dissertation to an opponent and a committee during an internal defense (what is called the "final seminar" at my department), I was advised to tone down the critique and try to find further nuances in what was being said about the students. Since then, I have listened to all recordings one more time and tried to make more generous interpretations of what is said about the students to better understand how these conversations relate to broad questions about the purpose of education.

Over the years, other themes and ideas have been drafted as well. In some ways, the focus groups offer almost endless opportunities in terms of what to 
analyze. It is indeed rich material, which means that the researcher needs to make a number of significant cuts in order to choose what to focus on. It is my ambition with the text above to show that the themes of the analytical chapters are not randomly chosen, and that other themes and angles could have been possible, too.

\section{What can come out of working with focus groups}

I use focus groups as a method to map how the sustainability imaginary is formed in education. It is important to further situate a study that uses focus groups methodologically; what kind of conclusions can I draw from using this particular method? My aim is not to make quantitative generalizations of the results of this study to all teacher instructors in Sweden. Instead, I would like to stress the focus groups as parts of qualitative collective processes that are forming sustainability education. My analysis of the focus groups focuses on theoretical generalizability rather than empirical generalizability. In other words, the claims I make based on the focus group data concern collective ways of thinking; they are not quantitative claims about how common a certain way of thinking is. Ivana Marková et al. $(2007,133)$ show that focus groups can be carried out in order to study socially shared knowledge, including ideas that are "continuously, or at least potentially, negotiated, modified and transformed, as they circulate in dialogue." Socially shared knowledge is intended to focus not on ideas and opinions of individuals, but on norms and meanings that are shared collectively (Marková et al. 2007, 139). In other words, it is primarily the collective work in the focus groups that matters for the analysis, not the expressions or thoughts of single individuals. Even when a single participant is quoted and their words analyzed, it is methodologically seen as related to the collective work of grappling with sustainability. Instead of having a primary focus on the frequency of themes discussed, I see the focus on the elusive and uncomfortable aspects in the focus groups as a way of mapping as many collective aspects and angles of a specific theme as possible.

I use the group dynamics of teacher instructors who met and discussed their handling of this area as an analytical strategy to study how sustainability is formed and made teachable in education. Without using my result to generalize empirically about how all teacher instructors grapple with these issues, I argue that the selection of professional participants allows me to draw theoretical and more general conclusions that relate to the practices of teaching 
sustainability. Even though my primary study object is not practices, analyzing the elusive and uncomfortable aspects of the conversations about practices can be defined as an active part of teaching practices. The purpose is not to claim to know what happens in concrete teaching situations but rather to investigate a relevant practice (the focus groups conversations) that cannot be seen as separate or independent from the act of teaching. As will be evident below, the focus group participants relate to each other throughout the interviews in their role as professionals. Thus, using focus groups can be understood as a way to study a specific profession's handling of a specific phenomenon, and, based on that, to make more general claims about sustainability education as a phenomenon.

The group conversations can be seen as a form of storytelling (Dawson 1994, 23) that makes use of publicly available discursive formations and the nonsensical in processes that form subject positions. The focus group participants made use of and related to various texts, images, and practices that exist in society and culture at large (i.e., outside the groups), which shows that there are constant connections to collective processes that take place outside the groups also. I investigate at least one "outside" references for each chapter (a news article, a public policy text, the practice of meat eating, a textbook used in teaching, and a website with a strong message about the future) in the analyses to show that the conclusions also have relevance outside the walls of teaching and education.

\section{On sustainability and sustainable development}

Finally, in this chapter I will make some methodological remarks on how I use the two concepts sustainable development and sustainability interchangeably throughout this study. "Sustainable development" is the term most often used by global organizations such as UNESCO and in Swedish policy documents, whereas "sustainability" is a more common term in the international research I draw upon. I use both concepts for the sake of readability of the text. While many researchers have criticized the emphasis on development (see e.g., Bradley 2009, 9; Irwin 2008, 171), both concepts are open to interpretation and negotiation, as argued by environmental researchers Johan Hedrén and Björn-Ola Linnér (2009), feminist environmentalists such as Stacy Alaimo (2012, 562), and educational researchers such as Johan Öhman $(2011,5)$. Both concepts are widely used in educational research, together 
with the concept of environmental education (González-Haudiano and Peters 2008). To trace the definitions and delimitations of sustainable development when making it teachable, I have studied the collective formations of the concept through discussions in focus groups. Quotes from the focus group interviews are always sensitive to which specific concepts were used in those discussions.

Having presented my point of departure, my theoretical assumptions, and methodological considerations, I will now present the analyses of the focus groups. 



\title{
Chapter 4
}

\section{Who can become sustainability literate?}

\begin{abstract}
DAVID: [...] sometimes it's a bit like we as consumers have to make all the choices, but what is the responsibility of politicians and countries and all the others? And I think the students, that's what I notice sometimes, that they find it difficult when we, when I as a teacher am talking about something, "argh, how am I as an individual supposed to fix this?" and I can agree that there governance and politics come in as big [players], now how can you make the students more political?
\end{abstract}

The main objective of teacher education is to educate future generations of teachers. Teaching sustainability-related issues in teacher education means taking part in forming the future teachers and citizens. Who teacher instructors imagine the teacher student to be creates certain ways of envisioning who it is that can become knowledgeable through sustainability education. This imagination forms what the student is expected to know about sustainability before, during, and after graduating from studies at a teacher education program. By investigating the who of teacher education for sustainability, it is possible to trace some of the subject positions, some discursive formations, and some aspects of the nonsensical that the sustainability imaginary forms and is formed by. This chapter sets out to examine some relations to the student Other in the sustainability imaginary by focusing on elusive and uncomfortable discussions about the teacher students. These discussions came up in all focus groups. As seen in the quote from David above, the teacher student is both formed and problematized as a consumer, as someone who is supposed 
to make choices, and who knows how to fix difficult situations. Ultimately, the students are also supposed to be or become someone else, someone political. Examining these formations more closely is a way to study which subject positions are available to teacher education students, and they are analyzed here in order to map out various available ways of being, and becoming, through education. This discussion further relates to how notions of the sustainable citizen are crafted. I will repeatedly make connections between students and the notion of citizens. I use the concept of literacy here in order to investigate expectations about how the students should use their sustainability knowledge (see e.g., Barad 2000, 225; Lundqvist, Säljö, and Östman 2013, 11; Ottander 2015, 9).

\section{The student as an active and happy consumer}

The focus group conversations regarding the teacher students include a number of suggested activities and behaviors that the teacher instructors ascribe to both their desirable and undesirable students. In many cases, there is a significant difference between how the teacher students are perceived to be and how the teacher instructors think they ought to be. Sustainability literate students are expected to engage in a number of activities, events, and organizations; for instance, they are expected to participate in public debates and public demonstrations, to be involved in NGOs and in their university's student union, to hike, consume recycled or used clothing, travel abroad, listen to noncommercial radio stations, and so on. All of these suggested and/or required activities and behaviors contribute to certain understandings of the teacher student as someone who does certain things and who behaves in and feels certain ways. Civic engagement and an active lifestyle were particularly hailed, but also challenged, in the focus groups.

A domain of particular importance for the active student in the focus group discussions is the domestic sphere, where some of the teacher instructors expect the students to be both knowledgeable and behave in certain ways. In the following quote, an active lifestyle through consumption, and more specifically, the consumption of certain clothes, is brought up and related to the students:

SOLVEIG: but they are surprisingly ignorant, and I have tried to keep up with what is offered in terms of alternatively produced clothes and so on 


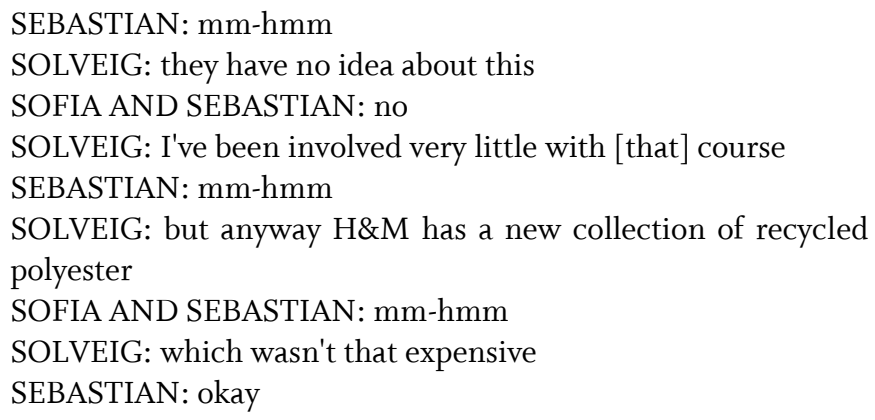

Here, Solveig's definition of what it means to be active in terms of sustainability becomes equivalent to knowing which clothes to consume; it involves consuming and behaving in certain ways. It should be noted that Solveig was particularly critical of the teacher students, and although her colleagues did not acknowledge her criticism explicitly, they did not challenge it either, which I read as a type of acknowledgment. What might be going on here is that the informed teacher instructors - such as Solveig - are held up as the norm to which the students are compared. An idea of sameness, that is, the idea that the teacher students should be like their teachers and behave as they do, is present here. This idea makes very little or no room for the Other (for a critical discussion on this see, e.g., Säfström 2011, 68). Furthermore, the act of consumption itself is left unproblematized. In this way, the sustainability literate student citizen becomes someone who knows what is out there to consume in terms of mass-produced organic clothing. A certain consuming student, a "citizen-consumer" (MacGregor 2013, 8), becomes a legitimate figure of sustainability.

However, Solveig, who explicitly criticized the students on many occasions during the focus group interview she participated in, also admits that it is hard to participate as a political citizen when it is difficult to grasp the far-reaching consequences of one's actions:

SOLVEIG: $[\ldots]$ that we are connected to each other in this net that is so difficult to control, so difficult to understand [...] there is new evidence every day about how hard it is to handle the role of being a consumer, to be a political citizen

Clearly, there are also ways of understanding the students' situation that counter the view of students as particularly ignorant. It is essential to understand the connection Solveig makes between being a consumer and a citizen 
in order to understand how students sometimes come to be imagined as particularly uncomfortable and problematic subjects in sustainability education. When the hegemonic discourse describes consumption as the legitimate way of acting sustainable and of being a citizen (MacGregor 2013, 8), students may indeed be seen as a problematic group. It is worth pointing out here that students as a group often have limited economic resources and may not be able to enter the subject position of the citizen consumer.

The consumption of clothes as a legitimate site of informed participation was also brought up, and problematized, in other focus groups. Below, one of the focus group participants, Gunnar, critically questions lifestyle choices as the solution to environmental problems:

GUNNAR: at the same time there is a rather frequent tendency to make this about personal lifestyle issues so to speak, so that we encumber our students, so that they in turn will encumber their students, with having to make the right choice, and in doing that we are in some way disavowing the whole system, what you talked about before, what actually makes it so difficult, there is almost nothing to choose from that is good

GORAN: no

GUNNAR: so there is a balance between the lifestyle issues and HANNA: I think I'll

GUNNAR: intervene here?

Here, Gunnar voices the difficulty of being faced with having to choose between bad alternatives. Unfortunately, he did not get a chance to expand on this discussion as I intervened to introduce the 23 images to the focus group participants (see Chapter 3). Maybe I expected this to be the end of the discussion, with the idea that it is hard to balance between lifestyle issues and critiquing the system. I did not leave room for the nonsensical to enter our discussion. Gunnar's doubts about requiring teacher students to take on a heavy responsibility shows that there was resistance to and doubt about the idea of domestic citizenship in the focus groups. But elaborating on other modes of being, and imagining otherwise, is not made possible in this interaction.

Drawing on the discussion about the right way to become involved, consumption choices appear to be dubiously considered as both desirable and undesirable by some of the focus group participants: 
OLGA: well, that's true; I have been engaged in Naturskyddsföreningen [the Swedish Society for Nature Conservation] here where we had a campaign about clothing and the impact the industry has and I probably thought, we had a day of exchanging used clothing [klädbytardag in Swedish] and a whole week devoted to this and I thought more young people, especially girls, those who consume a lot of clothes, would join, but it was more people like me [LAUGHS], of my age, who showed up

OVE: yes

OLGA: to this, it was popular, but not with that age, absolutely not

In this example, it could be argued that young female consumers become the sustainability illiterates in relation to the teacher instructors like Olga, who seems to conclude that it is actually only people like herself who are engaged in these issues of relevance for more sustainable futures. Again, the idea of sameness is used as a norm for what sustainability is and who it is that can live sustainably. In a study on inclusionary/exclusionary effects of official strategies for sustainable living, urban planning researcher Karin Bradley (2009) shows how the discourses of city planning use a middle-class norm in order to discipline and form the good citizen. The hegemonic idea of the middle-class lifestyle as particularly sustainable and as the measurement against which all others are compared was often apparent in the focus groups. This strong norm can perhaps be understood in relation to the fact that teacher education in Sweden has seen an extensive increase in female students from working-class environments (Bertilsson 2009). The students as a collective are not the same as they used to be, it seems. Above, it is the consuming female students who are blamed, but also made responsible, or disciplined, to change their consumption behavior towards becoming more sustainable. Gendered notions of over-consumption form the young female teacher student in this conversation as more problematic - and more responsible - than other groups of students. Female students are assumed to consume eco-unfriendly products, in contrast to the teacher instructors, who are already consuming according to the middle-class norm of eco-friendly organic food and recycled goods (see e.g., Bradley 2009, 261). There are two problems with this: First of all, the possibility of choosing to consume sustainably is very much a question of having the economic freedom to do so. Second, enforcing consumption as a lifestyle choice envisions the private sphere as the most important arena in which to achieve sustainability. Consuming and acting in line with 
middle-class norms may at first glance seem to be the best way to achieve sustainability, however, the taken-for-granted desirability of the middle-class lifestyle is in fact in many ways devastating for the environment (Bradley 2009). Odin, one of the focus group participants, expresses this problem as follows:

ODIN: I can sometimes, I might go beyond the point of this conversation, but sometimes I can get a little upset about what counts as doing something. Consequently, it is okay to carbonoffset the [holiday] trip to Thailand and to drink organic drinks on the plane

OVE: [LAUGHS]

ODIN: but to live in a rented flat and take the subway to work, that doesn't give any sustainable development points

OLGA: no

ODIN: do you see what I mean? Consequently, a green car is valued more than not being able to afford a green car but taking the bus to work, consequently there is a

OVE: only the concept of a green car is really interesting

ODIN: consequently some things count as environmentally

friendly

OVE: yes [LAUGHS]

ODIN: and have this green-wash label

Odin's concern here follows a discussion in the focus group about consumption choices and private responsibilities. What he seems to be saying is that the inability to make consumption choices makes the non-choices of the less economically benefited groups in society seem less sustainable. Or that nonchoices are not hailed as acts of sustainability. His critique can be said to voice the problem of the active, participating, and choosing subject for sustainability, since this subject has the economic capacity to consume in ways that are unsustainable. As can be seen, the other participants do not seem to disagree with Odin, although they are not exactly engaging in his critique either. One way of understanding the interaction above is to see that it is hard for us to imagine modes of subjectivity outside being active as consumer citizens of sustainability.

The importance of students' mental health, well-being, and feelings was also brought up as significant in relation to the possibility of becoming sustainability literate. In what follows, it is suggested that these areas can be addressed through individual consumption: 
NELLY: because this has to do with the social dimension of sustainable development, about how we feel. If we feel bad we can't care for each other, we can't care for resources and nature, it won't happen, and also it should be fun. I usually bring up as an example when I was 25 and I thought the world was coming to an end. You count the environmental problems - overpopulation, acidification, and mercury - and just "argh" and you just stand there with your terrible habits, and then I bought these unbleached filters for coffee that came out during the 80s NILS: [LAUGHS]

NELLY: and I felt "How fun, Nelly, now you have unbleached coffee filters" and I fell asleep with a smile on my face, so it actually started with the small things and that's a positive thing because when you feel good you do the next [good] thing [LAUGHS] it sounds a bit simplistic but it is crucial

Consuming the right thing could, according to Nelly, be one way to feel both good and hopeful about the future. Having fun and falling asleep happily are examples of how consumption activities and emotions are entangled in the conversation. Avoiding unnecessary worry and staying positive are examples of modes the participants bring up in the context of teaching sustainability issues. All of these ideas form the imagined sustainability literate student citizen in relation to certain behaviors, activities, and emotions connected to consumption. The emphasis on happiness and staying positive might be a reflection of a need to stay upbeat in order to deny the reality of Earth as doomed (see e.g., Žižek 2008). Indeed, it seems important to feel good and to have faith in the future when imagining sustainability in education. This was a recurring theme in the focus groups, although it was also regarded as problematic by some participants. Here I would like to turn to cultural studies researcher Sara Ahmed (2010) in order to understand why happiness and positive thinking might be regarded as problematic. Ahmed argues that happiness is a forceful and problematic imperative in the contemporary Western society. For Ahmed, the drive for happiness can be seen as a technology of creating the good and proper subject, and those subjects that remain unhappy are seen as deviating from the norm. She writes about a happiness duty and the societal expectation that we will be made happy by being part of what is deemed good. One interesting point in Ahmed's work is that she argues for unhappiness as a sign of political will and freedom and for the possibility of imagining otherwise. In that respect happiness in the domain of sustainability 
education can be regarded as a post-political feeling, because it hides its proximity to the status quo.

Indeed, staying positive in order to keep on acting for sustainability seemed important to Nelly and other focus group participants. However, as mentioned above, there were occasions in other focus groups (Group O and Group M) where some of the participants said that sustainability teaching should create more rather than less worry in the students. However, these statements did not resonate with the other participants as much as those about keeping up good spirits. The happiness talk in the focus group seemed to be capturing something elusive and uncomfortable. I read the wish, and arguably desperation, to hold on to positive thinking as a way to justify the futile act of consuming the right product when that is our only available option for creating the good society. This investment in the future that was made in the focus groups, I read, in the same vein as Ahmed, as our collective inability to imagine otherwise. What is there other than positive thinking? Donna Haraway $(2015,160)$ writes about the importance of mourning the many losses of ecosystems and species that have happened and will continue to happen in order to live well as a mortal being of current times. I think that both Ahmed and Haraway are onto something here, as the terror of happiness and the lack of room for mourning in the current public space seem to prevent the possibility of imagining and of becoming otherwise.

To conclude this section, I think it is fair to say that the teacher instructors to some extent want students who consume and act differently from what they are assumed to do today. They compare the teacher students to themselves and find that the students of today are quite far away from the ideal of the sustainability literate student citizen. One way of understanding this discrepancy is to investigate the intersection of class and gender in relation to sustainability. Stacy Alaimo's concept of "domestic citizenship" $(2000,176)$ is useful here to problematize the ways in which citizens become insulated from external environmental problems and only able to confront them within the domestic sphere. Staying happy and acting in accordance with middle-class consumption norms within the domestic sphere are often hailed but also problematized. The imperative of making the right choices is particularly problematized, although few alternatives are addressed. The contestation of these norms shows the political dimensions of both doings and feelings within the sustainability imaginary of education. Here, what we do and how we feel 
is not a private matter but rather is connected to how we organize and wish to organize society. Fantasies about the ideal student citizen of sustainability education regulate seemingly apolitical spheres of social life, by stipulating, for example, what we are expected to do (particularly as consumers) and how we are supposed to feel.

\section{Students as irresponsible youth}

Notions of responsibility are formed in the groups by the use of discursive formations about youth as irresponsible and different from older generations. This commonly expressed view came up in one of the focus groups described below, where Mats points out, although not unchallenged, that he finds teacher students to be lazier than the rest of his students (see e.g., Åberg 2008; Sjöberg 2010; Lilja 2010):

MATS: because if I'm completely honest, and this is probably the wrong forum for saying this, but I used to say: in an anonymous group of students it's easiest to find out who the teacher students are from their question: "What is optional [to study] and what is not covered in the [written] exam?"

MINNA: is that so?

MATS: yes

MAJ: that's terrible!

It should be noted that Mats is criticized by the other participants for this statement. Here it is the relation between the teacher students and other students that makes it apparent that the sustainability literate student and citizen should, in Mats' eyes, rise above an instrumental desire for knowledge. According to Mats, teacher students view knowledge as something one only learns to pass the exam. In the sustainability imaginary, on the other hand, the good student does not simply aim to pass the exam and is not bound by society's beliefs about what knowledge is considered valuable. I argue that these ideas about the students can be seen as part of a larger discursive formation about the youth which carries a mistrust in - and high demands on younger generations (see e.g., Lindén 2013; Joelsson 2013). As one example of how this discursive formation was used and reproduced in the focus groups, in the quote below, the teacher instructor Olof refers to an article published by Swedish Daily News [Dagens Nyheter] about how the younger generations 
relate to education and the purpose of education. The article is entitled "When the Ego Graduates" ["När egot tar examen"] (Udovic 2012):

OLOF: [...] I read this article: "When the ego graduates." It's a wonderful article in DN [Swedish Daily News] which describes the development of a more or less narcissistic youth culture where I, others, you leave the responsibility to others, it's not my responsibility to blah, blah, blah. So sustainable development is something that is collectively loaded and I think there is a tension between that and this individualized I, I think

The notion of an egoistic youth, unfit to deal with sustainability is, as can be seen, a discursive formation used not only by the focus group participants but also in one of the biggest newspapers in Sweden. The article that Olof mentions refers extensively to research in psychology and ethnology, which shows the wide circulation of this discourse. Seeing this discursive formation as not only being about the teacher students, but also about younger generations in more general terms, makes it possible to grasp who the sustainability literate citizens could be in sustainability education: people who feel responsible to others, resist dominant structures and ideals, learn for non-instrumentalist purposes, and take care of themselves. The responsibility they are supposed to take is both for themselves as individuals and for the collective good. The dominance of individual responsibility can be said to remain in Olof's critique of today's youth as Olof finds that the young generation does not take their individual responsibility but instead blame others. According to the article, the typical young person graduating from high school today is a borderline narcissist. This young person is described by the article almost as evidence of a narcissistic epidemic outbreak. One of the interviewed scholars in the article characterizes the contemporary society with these words:

L'Oréal's 'Because I'm Worth it' can be seen as a slogan for our time. One is worth the best grades and getting into the best universities without having to work for it. (Udovic 2012 my translation from the Swedish)

If we invert the criticism expressed in the article, we could say that it is by letting go of focusing only on oneself, by caring for others, finding visions outside oneself and working hard that a more desirable young person and citizen can be formed. The article does not comment on the role of education in fostering this alternative youth. The researcher quoted, Mats Alvesson, on the other hand, has continued to publish debate articles and a book where he 
claims that the university students in Sweden today take an instrumental approach to their education (see e.g., Alvesson 2013). The altruist ideal of knowledge and education resembles, in my interpretation, the call for feminized notions of care for others. These feminized notions of care risk placing responsibility for sustainability onto stereotypical feminized subjects, who are assumed to put others first.

In the following example, becoming responsible as an important part of becoming sustainability literate is related to practices of hiking in nature:

OVE: I mean those who walk the [hiking] trail a few times and who get that experience, they care more about preserving that nature, compared to those who have never been in the forest $[\ldots]$

OLOF: that's not certain, is it? Or? It depends a bit OVE: no obviously on an individual level it's not certain, but on a group level it's absolutely certain, of that I'm sure; I have several examples proving that. My daughter was in an after-school center where they hiked, very often. Later, in ninth grade when they were going to go on a school trip - it was in primary school, they slept outdoors in the forest under canoes, they got to choose whether they wanted to go to [the amusement park] or the [hiking] trail, and the whole class chose to walk the [hiking] trail

The importance of having a relationship and first-hand experience with pristine nature was stressed by several participants in the focus groups, although there are also participants who questioned the very notion that nature can possibly be separated from human life. The relationship between the forest, in this case, and the young generations makes nature a resource through which people learn to become responsible and sustainability literate. It seems to be the younger generations, not the teacher instructors themselves, who need this relationship in order to become suitable teachers or citizens for sustainability. Here the desirable teacher students can be traced through Ove's daughter and her classmates; by spending time on the hiking trail and sleeping under canoes, sustainability literacy seems to follow. In this way, the sustainability literate subject seems to be someone who forms a bond with forests as something out there to be discovered and experienced, rather than something that is already a constant part of the students' lives. Another thing to be said about this association between the youth and practices of hiking in "that nature" is that it forms a desirable youth with access to hiking and canoes (possibly urban middle-class, able-bodied youth). Karin Bradley (2009, 237) 
shows in her dissertation that spending time in nature has a strong connection to environmental stewardship in Sweden, reflecting a middle-class perspective on becoming environmentally concerned.

The youth in general, and the students in particular, are in many cases judged against standards that are drawn from ideas about who the teacher instructors themselves were when they were young, and also from ideas about who other students and citizens are. The ideal sustainability literate teacher student seems to be someone who resembles the teacher instructors themselves.

\section{The knowing student and the purpose of sustainability education}

How teacher student subject positions are formed in relation to understandings of knowledge in the sustainability imaginary also relates directly to ideas about the purpose of education in light of environmental change. Below, I will discuss how the purpose of education is formed in the focus group conversations through the particular ways in which the participants talk about the students.

In several of the focus group discussions, it became apparent that the teacher students are expected to know certain things before beginning their education program. In the quote below, two participants in one of the groups, Nils and Nelly, express concerns about the ignorance of the teacher students:

NILS: I believe that all people born in this country know this [about photosynthesis] already, that's citizen knowledge

NELLY: I believe that everyone has read during the last 20-30 years about scampi, about palm oil and such, but those who don't provide themselves with

NILS: I know it

In Nils and Nelly's discussion, specific knowledge is expected to follow from being born into citizenship of a specific country (Sweden) at a specific point in time. It also seems as if knowledge is expected to follow from continuously reading up on contemporary topics and actively searching for scientific knowledge. The students are seen as problematic when they do not live up to expectations that they possess certain types of common knowledge prior to entering the teacher education program. Participants in several of the focus groups expressed that the students are "surprisingly ignorant" (for example, 
Group S) in relation to sustainability. Those few teacher students who are knowledgeable are described as unusual and more aware than the rest:

\begin{abstract}
ANASTASIA: [...] still, I think that there are a couple of students who are well aware of sustainable development, but otherwise there is a terrible lack of knowledge I think among the students, that they are so unfamiliar and then I think, I mean they have gone through ... I mean most of them are pretty young so they must have gone through primary school while sustainable development must have been brought up, that I can also

ANDRÉ: should have been brought up
\end{abstract}

Despite going through the whole mandatory educational system, most students seem to know far too little about sustainable development, according to Anastasia and André. Education does not seem to have made a difference in this respect. Those few students who were described as aware seemed to be so for extracurricular reasons; they had not gotten this knowledge as a result of their regular education. These few students were described as conscious. Another interpretation is that André might be pointing towards a systemic problem, in that these issues are not brought up at school. Despite the teacher instructors' best efforts, some students still remain unaware according to Nils, who participated in another focus group:

NILS: yes I got the impression that there weren't many students who were very informed or had very clear ideas about what sustainable development could be, and my impression is that's still the case for a great many

What Nils seems to be saying here is that the students' poorly formed ideas about sustainable development is problematic, and what the students are and how they understand things can become a problem for the teacher instructors. What Nils says, arguably, is that a great many students do not improve their knowledge about sustainability while studying in the teacher education program. It seems as if some of the teacher instructors in the focus groups would prefer some other types of students, students who already know the right things and have little need to even go through the education program. Students who would be more same than Other to the teacher instructors. The following conversation is also on the topic of inadequate students:

SEBASTIAN: or what is your impression Sandra, from the seminar about the lack of planets and so on. Do you have any reflections from there? 
SANDRA: no, but it's mostly about what you can do as an individual I guess

SEBASTIAN: yes

SANDRA: you have to fight to get past the sorting-waste stage SEBASTIAN: yes

SANDRA: many write in their reflection diaries "but I sort my waste at least, or I will at least get better at sorting waste"

SEBASTIAN: yes, that's right, yes

SANDRA: maybe [they] should have reached a bit higher, but it's good if we start there and then you can continue the work

In my interpretation, what both Sandra and her colleague seem to agree on above is a rather static idea of the relationship between the student subject and the definition of knowledge in education. Ideas about what the teacher students should learn are seldom talked about, but rather what they ought to know before they enter into the teacher education program. On the one hand, Sandra seems hopeful when she concludes that the students' individual focus is a start from which she can "continue the work." However, the understanding of who the teacher student is and can become seems to be almost unchangeable independent of the perceived impact of education:

SOLVEIG: and I don't think we have a very high level

SEBASTIAN: no

SOLVEIG: on the course, what we talk about is what in some ways is present in the public debate

SEBASTIAN: $\mathrm{mm}-\mathrm{hmm}$

SOLVEIG: but the teacher students don't participate in that, if you choose to listen to Riks Megapol [sic! A mixture of two commercial radio channels: Riks FM and Mix Megapol] instead of P1 [a Swedish Radio public broadcasting station]

SEBASTIAN: $\mathrm{mm}-\mathrm{hmm}$

SOLVEIG: if you consistently neglect all news related to current affairs programs on TV and watch Big Brother or Halvåtta hos mig [a cooking program broadcast on a commercial TV channel], which I understand is very popular with the students

SEBASTIAN: [LAUGHS]

SOFIA: really [LAUGHS]

SANDRA: at least they have organic food sometimes

EVERYONE: [LAUGHS]

According to these teacher instructors it seems as if the teacher students are what they are and they do what they do independently of education. Accord- 
ing to Solveig, there seem to be students who watch other types of TV programs (news-related current affairs programs), but those are not the students in the teacher education program. In some sense, the teacher students seem to be understood as particularly sustainability illiterate, compared with an undefined conception of others, in this example. Left only with the act of choosing, as media consumers, the teacher students seem to be choosing the wrong thing. Clearly, both Solveig and Sandra expect their students to know certain things before they begin their teacher education, preferably things they would learn by participating in public debates. They seem to have specific notions about public debate - about what a public debate is and where it takes place. Gendered notions of caring only for the limited domestic space are criticized in favor of the public domain, showing a slightly different problem from what I previously discussed (where I criticized the tendency to locate sustainability in the private sphere). Here it is the domestic sphere that is neglected as important for creating sustainability, with the risk of forming the private sphere as apolitical. In this way, politics seem to become disentangled from eating habits, which is a problem I will discuss further in Chapter 6. The teacher instructors' understanding of the public debate also shows that certain modes of knowledge are expected of the students before they enter the teacher education programs. In some ways it seems as if the students should already be middle-class consumers and active in the public sphere before beginning teacher education. However, there is also resistance to these static understandings of students:

MERITH: but I actually don't think you can say that these ones shouldn't study here, or that they should, because I'm thinking that it's some kind of learning process that you as a student are also part of, all of a sudden the penny drops

MINNA exactly

MERITH: when you've been working, after two years or

MELKER: yes that's right

MERITH: it may drop after the first semester at the university

MELKER: yes absolutely

What Merith says above gives considerable credit to education, compared to how education is talked about by many of the other participants. Merith voices this opinion in opposition to the other participants' talk of students as either good or bad. Indeed, through Merith's account, the participants in this situation seem to form an understanding of education as a field of transformation, of becoming. 
Despite some resistance, it could be argued that teacher education in the domain of sustainability mostly becomes a passage point which requires specific, static subjects; education becomes a site of confirming identity by being, not of transformation and becoming. The ways the teacher instructors view knowledge in relation to the available teacher student subject positions tend to reflect a rather static idea of the purpose of teacher education and the aim of becoming educated. Furthermore, the students are compared to the teacher instructors, who are regarded as already fully sustainability literate. Sameness rather than difference, and preservation rather than transformation, seem to be what education and the sustainable citizen come to be about, although there is also some room for different accounts of the sustainable student subject. All in all this creates a somewhat unsustainable purpose of knowledge and education which preserves rather than challenges the status quo.

\section{Concluding discussion}

Teacher education is supposed to be a platform where students can become teachers. Teacher education is furthermore a platform that takes part in forming future teachers and citizens in the domain of sustainability. This chapter has dealt with the question of who can become educated through sustainability education by focusing on elusive and uncomfortable discussions about the teacher students in the focus groups. I have focused on discussions in which the students were both formed and problematized as active consumers and were regarded as irresponsible youth, and on how notions of knowledge and education are related to forming the sustainability literate subject. Examining these formations is a way to study which subject positions are available to teacher education students and can contribute to answering the question posed at the beginning of this chapter: Who can become sustainability literate? This question has been addressed by mapping out various available ways of being, and becoming, through education.

The first answer to this chapter's main question is that the sustainability literate student and citizen is, for the most part, imagined as someone who consumes in certain ways, is responsible, as shown by, for example, a love for nature, knows certain things, and relates to education in specific ways before enrolling in the teacher education program. The relationship between the 
teacher students and their education seems to be perceived mostly as a relation of being rather than becoming. The students are generally described and judged for who they are imagined to be, rather than for who they might be able to become through education. In that respect, the sustainability literate is someone who does not need education.

The second answer to this chapter's main question is that the sustainability literate student is someone who is just like the teacher instructors. In some of the discussions above, the teacher instructors seem to discredit their students for not knowing enough and for consuming, focusing on, and engaging in the wrong things before and during their education. One interpretation of these criticisms is that the students are seen as failures because of their inability to become (or be) the teacher instructors themselves. An ideal of sameness through education is used at the expense of imagining education as a site of becoming differently. In some ways it seems as if the teacher instructors are failing to meet the teacher student respectfully as an Other (Todd 2003; Biesta 2006a; Säfström 2011).

The third answer to this chapter's main question is that the sustainability literate student is someone who has an active lifestyle, participates in public debates, and consumes eco-friendly goods, often - again - in line with the teacher instructors themselves. Similar to earlier studies on desirable subject positions in sustainability-related practices, the sustainability literate teacher student often seems to be formed in proximity to Swedish middle-class norms (see e.g., Bradley 2009; Henriksson 2014). As an example of how these norms operate in the dominant environmental discourse in Sweden, Karin Bradley $(2009,245)$ shows that "the more affluent groups tend to buy more organic food, recycle and use cloth bags when shopping (...) these lifestyles are reinforced, whilst lifestyles implying other ways of economising with resources are not acknowledged or supported." The discussions in the focus groups both use and challenge discursive formations of the Swedish middle class as particularly sustainable and environmentally friendly subjects. The problem of the consumer citizen as one of the most accessible subject positions for the middle-class is not only that it is a position that uses a lot of resources. It could also be argued that by proposing environmentally friendly shopping, cleaning, and recycling, feminized subjects (who continue to do most of the housework globally) become responsible for dealing with environmental problems while 
the capitalist system, which generates most of the problems, is left unchallenged. Entirely too much emphasis is placed on the notion that change happens through individual behavior, change in humans, rather than a systemic political change in the distribution of resources and knowledge production. The politics of sustainability gets hidden by locating it in the seemingly neutral sphere of the home, free from politics. However, as Stacy Alaimo (2000) and others point out, the domestic sphere is far from a neutral sphere but is rather a space in which gender inequality, and other inequalities too, can be reinforced and maintained within what tends to be seen as a strictly private place.

What do the conclusions of this chapter have to say about the formation of a sustainability imaginary in education? Turning first to subject positions, they are often formed in line with the current neoliberal dream of citizen-consumers: middle-class consumers of eco-friendly goods, hard-working, happy - and sometimes feminized, since these subject positions tend to be located in the domestic sphere, where women still tend to do most of the work. I think that it is also fair to claim that the available student subjects are, for most part, anthropocentrically formed, without much room for nonhuman aspects of sustainability. In some ways it may seem impossible to imagine subject positions for the student as more than human, which can be explained by education's raison d'être as a cultivation of the human subject (see e.g., Pedersen 2010b). Second, the discursive formations form knowledge as certain and non-transformative, education as having little impact on knowledge, and students as able to go beyond the current instrumental views on knowledge; it also presents desirable knowledge as non-instrumental. Finally, the nonsensical is only present in the background, held back most visibly by maintaining positive thinking and happiness as a necessity for the sustainability literate. I discussed happiness and positive thinking as a collective problem, present in the groups, in which many of us are so focused on investing in the future as a happy place that no room is left for the nonsensical potential of imagining otherwise.

The balancing act of educating future generations of citizens to become both role models and mediators of knowledge is implicated in the discussions above about who the sustainability literate teacher student and citizen is. This is yet another elusive and uncomfortable aspect of the sustainability imaginary, and it will be analyzed in the next chapter, which zooms in on the role of being a teacher instructor for sustainability. 


\title{
Chapter 5
}

\section{The balancing acts of teaching sustainability in a post-political time}

\author{
NILS: what does development mean? For me it means change, a \\ neutral expression. But that's not how it is used \\ NELLY: what does need mean? Can you talk about... \\ NILS: sure, I think that's good \\ NELLY: whose need?
}

The act of teaching students to balance between their future role as both public figures and private persons has been described as a dilemma for teacher education (see e.g., Bursjöö 2014; Hasslöf 2015). On the one hand, students' experiences are considered valuable as a resource, and on the other hand, education is an institution assigned to serve the contemporary societies' specific needs and norms (Åberg 2008, 61). This chapter investigates how three such balancing acts are played out in the domain of sustainability teaching by looking at different aspects of a recurring elusive and uncomfortable theme that emerged in all of the focus groups. The meaning of neutrality is salient here, as indicated in the quoted discussion above. I investigate which subject positions, discursive formations, and aspects of the nonsensical the sustainability imaginary creates through these balancing acts, and how these acts relate to the positions of the teaching self.

\section{In between politics and urgency}

This chapter focuses empirically on understanding the role and responsibility of teaching others (future teachers) to take a stance, while trying to maintain 
a neutral position as a teacher instructor. To illustrate this quandary, I will begin by contrasting how sustainable development is described in the latest Swedish Government Official Report about teacher education (SOU 2008:109) with how the teacher instructors in one of the focus groups discussed this description. To begin with, the inquiry that resulted in the Swedish Government Official Report A sustainable teacher education (SOU 2008:109) describes sustainable development as part of the current societal value system:

Years ago children learned to fear God and to honor the king nowadays they learn about sustainable development. The difference might seem significant, but the foundation is the same the school is expected to mediate society's values to future generations. (SOU 2008:109, 193 my translation from the Swedish)

As mentioned above, this specific government-sanctioned interpretation of sustainable development as a value that needs to be mediated through education was brought up in one of the focus groups. The participants expressed criticism regarding how sustainability is framed as just one of many beliefs that the educational system is expected to manage and mediate:

GORAN: conceptualizations such as "before, one believed in God, later, one believed in sustainable development, later, something different will follow" [LAUGHS]

GISELA: alright [sounding surprised]

GUNNAR: yes, that was really intolerable

GORAN: [LAUGHS] that was, I was surprised they could express

it that way

GISELA: it's rather that there is nothing else

MANY: [LAUGHS]

GISELA: if we don't

GORAN: right [LAUGHS]

GISELA: succeed in this

By laughing together at the "intolerable" expression in the inquiry report, the participants seem to establish a common ground with the idea that sustainable development needs to be taken seriously as an indisputable fact. In the participants' discussions, it is clear that sustainable development is something other than a belief (as "in God") that can be exchanged over time. Quite the contrary, sustainable development seems to be regarded as an inescapable matter of fact - "there is nothing else" - displaying both a widespread concern 
that sustainable development is an answer to real problems and a response to a threat to humanity as a whole. The inquiry cited above, on the other hand, seems to present a matter-of-fact understanding of sustainability as a politically loaded value. What is interesting here is the relation between official statements about sustainable development and the perception of sustainable development among those who are supposed to teach sustainability. The fact that the inquiry quite clearly states that "the school is expected to mediate society's values to future generations" (italics added) pinpoints that the authors of the inquiry view this as a political issue.

It seems to be during the processes of making these political matters teachable as indisputable facts that the teacher instructors react. Why could that be? I suggest that this highlights the balancing act of mediating politically loaded issues in legitimate ways within educational practices. This balancing act becomes visible as elusive and uncomfortable as the teacher instructors sit together in the focus groups and discuss sustainability teaching. As illustrated in the excerpt above, the role and responsibility of teacher education seems to be understood as making sustainability teachable in between educationalpolitical discursive formations about mediating values and the fearful discursive formations and nonsensical fantasies of the consequences of an unsustainable future. The tension between seeing sustainability as just another societal and temporary norm and the wish to succeed in creating a sustainable path as the only way forward highlights one of the balancing acts of teaching sustainability to future teachers. This tension becomes visible as the teacher instructors have to make sustainability teachable in a landscape of environmental change. Furthermore, this tension connects to how teaching relates to politics.

\section{A depoliticized profession?}

The future teacher can be considered a contested figure in the public debate (see e.g., Åberg 2008; Sjöberg 2011) and in the focus group discussions, as shown in the previous chapter. Despite wide recognition of the political importance of teachers and teacher education, the focus group conversations revealed that, ideally, the practice of teaching should be regarded as non-political. In that respect, educating the sustainability literate teacher entails negotiating the role and the responsibility of teaching teachers to teach. Below, I will show how the participants express anxiety and doubt about prescribing 
certain acts in education over others. As will be evident, the prescription of certain sustainability-related acts is considered particularly problematic:

ANDRÉ: [...] the tension lies between the fact that the school cannot be normative [...] and say, "This is how you should act and this is how you should live" and that within the sustainability sphere there is an outcry "now you have to change"

ANNA: yes exactly

What André accounts for here - with seeming discomfort - is a specific type of normativity in relation to sustainability issues; the tempting normativity of telling the students of education what to do and what not to do to create a sustainable society. For André, it seems to be the prescribed doing (saying what others should do and how they should live) that is considered problematic when teaching sustainability. The implicit demand for non-normative education ("the school cannot be normative") seems to stem from a notion of ideal neutrality and, more specifically, of the teacher role as ideally neutral and non-normative - perhaps even depoliticized. The idea that teachers should attempt to bring about change, while remaining somewhat nonjudgmental about the students' life choices, seems to cause André discomfort. The students' right to make their own choices clashed with the call for necessary changes in the sustainability domain. The belief in independent and individual lifestyle choices as both a right and a solution to environmental change is widespread in the contemporary Swedish society and in the focus groups, which was shown in Chapter 4. However, the ideal "citizen-consumer" (MacGregor 2013, 8) can create change through individual lifestyle changes, but is unable to bring about changes on a structural level. Above, André seems to be skeptical of the possibility of teaching sustainability in a non-normative way when any call for change relies on a specific way of viewing the world - with political consequences.

In discussions about the role of sustainability in education, some focus group participants further dwell on possibilities and problems of educating teacher students to make informed choices and decisions:

LISBETH: yes, but also that one should eat organic foods, one should eat, one should recycle one's garbage, I think it's much more interesting to bring up questions like: Are organic foods really so good? Is organic farming, are we agreeing completely that that's always a good idea? Consequently, I think, I can make my own decision about doing this or that, but I think education 
is about giving them the prerequisite to make their own decisions

Against the discursive formations of personal lifestyle choices as the given answer to environmental problems (which I discussed in Chapter 4), Lisbeth proclaims a critical stance of questioning taken-for-granted axioms - paradoxically, in order to foster in students the capacity to make their own decisions as individuals. Lisbeth seems to hold that education is about the process of becoming an informed subject. It is, however, about becoming informed in a very specific sense, a becoming that creates opportunities for the students to make their own decisions, presumably as individuals and in relation to the highly individualized discourse on sustainability (see e.g. Skill 2008, 276; Cakici 2013, 182; Henriksson 2014, 213). Lisbeth's claim that the purpose of education is to prepare individuals to make their own decisions could be seen as in line with the assumption that decisions are made by rational human beings. On the one hand, education seems to be about becoming differently, and on the other hand, about being precisely the ideal citizen-consumer individual of the post-political era.

Sustainability education seems to challenge the implicit and seemingly strong ideal of the teacher as a neutral and disembodied public figure. Is it wrong to drive a car to work if you can choose other means of transport? Most of the focus group participants would probably say yes. Is it okay to express this stance in the role as a teacher or a teacher instructor? This time the answer would probably not be as quick and easy. One of the participants in particular, André, finds such claims to be problematic in the teacher role. When he discusses this problem with his colleagues in the focus group, he remembers a situation that played out in his previous job as a middle school teacher:

ANDRÉ: [...] this is probably out of context but when I worked in middle school the amazing book about the cod in the Baltic Sea was published. I read it and I felt "there's no doubt about it, I have to talk about it in the classroom," about the book on cod extinction or whatever it's called, that it was endangered. And not long after, a parent came, smiling, but still, and asked: "André what are you doing?" [ANASTASIA LAUGHS] "we are no longer allowed to eat cod at home"

EVERYONE: [LAUGHS]

ANDRÉ: it felt instinctively problematic

ANNA: yes, right, right 
ANDRÉ: am I allowed to do this? What happens now regarding normativity? It didn't feel good in the teacher-body, but in the André-body it felt great

ANNA: yes exactly [LAUGHS]

HANNA: yes

ANDRÉ: [...] I thought these were the facts. Because I mean I didn't look for it but there might be a book [stating the opposite] [EVERYONE LAUGHS] because that book I'm not interested in reading. Well, we are also human, the three of us sitting here are humans with our own values and norms which we're suddenly supposed to drop when we enter as [teacher] instructors and that is not working fully

Even though this quote describes a scenario André recalls from working in a middle school, it also illustrates current dilemmas faced by the teacher instructors. This is clearly shown when André ends the quote by referring to himself and his two colleagues as humans and teacher instructors with their own values and norms which affect them as professionals. The problem for André here seems to be when his teaching leads to certain behavior changes of his students outside the classroom. More specifically, the problem seems to appear when his students change their behavior due to what has been taught in the classroom. When a student's parents point out that a certain lesson has led to a significant change at home - the family can no longer eat cod because of what was said in the classroom - André is forced to reflect on how his own epistemological-political ideals have become visible through his role as a teacher. The dilemma about whether one should or should not eat cod is at stake here, displaying larger issues about education: Is education supposed to change us, to make us become differently? Andre's regretful disinterest in books and research that show the opposite side of the "amazing book" he has read shows the strong ideal of never taking a stance, and of always remaining neutral. The focus group discussions show, however, that sustainability education seems to require a visible subject; a situated, embodied position from which some sort of assessment of more or less sustainable practices, futures, and acts can be done. However, the strong ideal of teachers and teacher instructors remaining somewhat neutral in their teaching demands quite the contrary: a disembodied teacher, free from social and political attachments. Much like the contemporary discussions on climate change, the reachable solutions seem to lie outside conflicts and unequal power relations. The neutral ideal assumes, just like the conventional answers to climate change, a homogeneous humanity and a disembodied subject. The consensus-oriented ideal 
of ignoring or hiding political conflicts, displayed through Chantal Mouffe's (2005) and Erik Swyngedouw's (2014) critiques of the contemporary postpolitical condition, which I discussed in the introduction, can be considered a problem for pinpointing what is at stake and for whom in sustainability education.

The overall possibility of affecting students' lives outside the educational sphere as a political and ideological imperative did not come across as an entirely positive outcome of sustainability education in other parts of the focus groups:

DAGNY: yes consequently when you see what they [the students] write at the beginning of the course and what they write at the end of the course, it is obvious that they take it seriously, it has affected their way of living, and affects their stance to teaching and they see things they haven't seen before, I think it's been rather... horrifying sometimes to see how much we've been affecting them

DAN: yes

DAGNY: how do you view this? I can sometimes feel ambivalent towards this: do we have the right to affect them this much? Because my answer is that we have affected them, of that I'm sure

The epistemological assumption above seems to be that knowledge should be separated from the knower, and from political stances and emotions. Whether the teacher instructors have the right to affect the students' way of living and thinking seems to be a critical question for Dagny. Her discomfort seems to appear both when educational outcomes stretch into the private sphere in unconventional ways and when the students are deeply affected by their education. Education that addresses and affects the activities of the private and domestic sphere challenges ideas about how far education should reach (see e.g. Hjälmeskog 2006). Education as an arena of transformational change is not a common understanding in the focus groups, as already shown in the previous chapter. On the one hand, the idea of a clear separation between the public and private spheres tends to ignore the activities and politics of the private sphere; on the other hand, the stress on individual responsibility and lifestyle choices makes the private sphere an important platform for handling environmental problems. On some occasions, participants in the focus groups expressed the hope that schoolchildren will teach their parents about 
recycling and similar activities. This hope relates to an idea of education as an arena for disciplining the citizens of the future.

Above, Dagny touches upon the question of how norms - what the right way to live and to think is - are mediated and negotiated in sustainability education, where some norms of the good life are established at the expense of others ("it has affected their way of living"). In another focus group Olga and her colleagues discuss how to handle this problem in practice:

OLGA: but don't you become normative or normalizing when you select what to present

OSCAR: yes you do, always, but you always have to make a selection, I think there is a great difference between entering [the classroom] with an opinion, or illuminating different views and entering [the classroom] with the idea of making everyone share a specific view, and that doesn't mean that I don't show what I believe as a teacher so to speak

As can be seen above, Olga and Oscar are trying to come to terms with how to strategically handle the burden and responsibility of teaching sustainability. For Oscar, the problem seems somewhat resolved by dividing the situated (political) position of the teacher with the selection of which content to teach. For him, it seems to be possible to separate the selection of content from one's position as a teacher. Although Oscar admits that the content selection is political in some sense, it does not seem as problematic as it would be to tell the students what they ought to do. The problematic part here seems again to be about telling someone what to do or not do, which makes certain versions of affecting others problematic while leaving other versions unproblematized. To clarify the point, teaching always has an effect, but some effects are here considered more problematic than others. Making the situated teacher invisible in favor of teaching content that displays many viewpoints, which seems to be what Oscar suggests, did not seem to be as easy for all focus group participants:

SANDRA: we usually discuss this, that does one have to live sustainably in order to teach about sustainable development, and that's a - that's pretty difficult

SEBASTIAN: yes

SANDRA: since we're living in the society that we're living in. And actually use a lot of resources. And live at the expense of others, strictly speaking, none of us would be able to do it 
SOFIA: no

SEBASTIAN: $\mathrm{mm}-\mathrm{hmm}$

SANDRA: teach about sustainable development. But many students believe that "well one has do it, one really has to do it," and that would disqualify all of us

$[\ldots]$

SOLVEIG: yes, I tell my students that you take this course now, then you can relax. I'm in it every semester [LAUGHS]

In the exchange above, the teacher instructors seem to be trying to figure out how this simultaneously necessary and difficult visibility demand as a private, situated subject could be met when teaching sustainable development issues. Here, the participants are grappling with how each individual's way of life is conditioned by larger processes in the society. The focus group above seems to be pointing out that all ways of living are in fact affected by larger societal systems in which it is impossible to carry out an activity, such as teaching, in isolation from the conditions surrounding the teacher both privately and professionally. Here, Sandra claims that she and her colleagues are living in a society in which they get to live at the expense of others, and it becomes clear that simply by being in this world, Sandra is already a political being. This recognition could lead to what Sandra points out above: "strictly speaking, none of us would be able to [...] teach about sustainable development." In this way, one's private actions and activities become important in order to even qualify as a legitimate teacher instructor of sustainability issues. The teaching seems inseparable from the teacher as an embodied and embedded being. Solveig acknowledges towards the end of the quote above that her visibility as a private person, required by sustainable development education, prevents her from "relaxing" and acting in ways that are unsustainable. One way of interpreting what it means to be a teacher instructor for Solveig is that teaching is entangled with how she embodies the subjectivity and responsibility that sustainability education seems to demand. This means that what one is doing as a private individual becomes necessarily visible, and the seemingly neutral position diminishes. Consequently, disembodiment hardly seems like an option one can choose or disclaim when making sustainability teachable.

I will now look more closely into the focus group conversations that were grappling with the ideal of the teacher instructor (and teacher) as neutral in the making of the future. In the focus group conversation between Gert, Goran, 
Gisela, and Gunnar, they all resist and challenge the ideal of being objective as a teacher instructor simply because they seem to agree that it is impossible:

GERT: I actually find it hard to believe that one can be objective GORAN: of course you can't

GERT: that is some kind of ideal picture, that one should try to be as objective as possible

GORAN: yes, but is it actually an ideal picture? Is it good to be objective?

GERT: no

GUNNAR: I can agree with you, but when I'm in the classroom here I still feel that I cannot stand there... because this is such ideological stuff so I can't make the class into some kind of

GORAN: political

GUNNAR: propaganda

GORAN: no [LAUGHS]

GUNNAR: propaganda class for my opinions

$[\ldots]$

GUNNAR: but I don't tell them what I think, they notice it anyway

GISELA: exactly [LAUGHS]

GORAN: [LAUGHS]

Despite the impossibility of the objective, neutral teacher position, in this example the opposite of objectivity seems to be connected to ideology and propaganda - things that are assumed not to belong in a classroom of any kind. However, education is of course inherently ideological and political because of its role as a central institution in any modern or postmodern society. The ideal of being non-ideological and neutral as a teacher still seems to remain implicit; it seems difficult to claim anything else from the teacher position. The problem here is that the neutral position seems impossible when teaching sustainability. This impossibility becomes visible as Gunnar ends this excerpt by pointing out that regardless of what he is saying in class, his students can still tell what he is thinking about specific issues. Judging by their laughter, Gisela and Gert also seem to recognize this situation. Although neutrality is recognized as an impossibility, it still remains an ideal for the teacher instructors.

The impossibility of neutrality is further discussed by other focus group participants as they explicitly elaborate on the future as a highly political and normative phenomenon: 


\begin{abstract}
LENNART: but also what one wonders, education for sustainable development, then you have to do something for the future and it becomes really normative, everybody wants a sustainable development but it's like there are some things that are good and one constructs certain good students or pupils or humans LILLEMOR: yes, what teaching should look like LENNART: yes, what teaching should look like and what kind of ideals are important and whose future we are talking about and so on

LISBETH: yes that's also interesting when we consider that we think that education for sustainable development is about something critical

LENNART: yes, yes

LISBETH: critical thinking is a crucial ingredient and at the same time it easily becomes prescriptive

LENNART: yes
\end{abstract}

As can be seen in this excerpt, "doing something for the future" seems highly problematic to Lennart, Lillemor, and Lisbeth, because talking about the future seems impossible without being normative in some way. Since sustainability issues are discursively tied together with ideas of the future, it seems impossible for the teacher instructors to manage sustainable development in education without being - contrary to the ideal of neutrality - subjective and normative. As I will discuss further in Chapter 7, how the future is imagined is important for which realities we can collectively make possible. It seems as if sustainable development requires a visible teaching subject - an embodied, historically, and locally situated teacher; someone who does something and takes a worlding stance in issues regarding the future. The notion of neutrality, as I discussed in Chapter 1, can be linked to the maintenance of the status quo and entails an often hidden political dimension of business as usual. The call for change in response to climate change, for instance, tends to rely on a natural science world view with its own implicit ideas of what a good society should look like (governed by experts etc.) - often without questioning the deep structures of our society in relation to unequal power relations.

Below, Lennart opposes the others in the focus group he participates in by pointing out conflicts that disturbed the consensus-oriented atmosphere:

LISA: [...] it's easy to fall into misery or to be problem oriented, but I think

LILLEMOR: yes, I think that happened in the 70s

LENNART: yes 
LILLEMOR: namely that it became so moralizing so that people didn't want to listen any more

LISBETH: it has to be easy for people, you shouldn't have to be so skillful

LENNART: it should be easy for the middle-class most of all, right?

LISBETH: yes, or...

Lennart's provoking point about the middle-class as the implicit target in the focus group's discussion about addressing sustainability problems in an easy and unproblematic way shows an uncomfortable visibility of underlying norms. In balancing between teaching that fosters free informed choices on the one hand and correct behaviors for a specific change on the other, the teacher instructors seem to be caught in an act where the role and responsibility of teaching others to teach must be negotiated between notions of normative and seemingly value-neutral claims. This dichotomy can be considered somewhat false against the background of post-politics (outlined above), where the status quo is seemingly emptied of conflicts and political struggles, as also suggested by Lennart in the quote above. I suggest that the negotiation between normative and seemingly value-neutral claims makes the teacher instructors uncomfortably visible as private and situated subjects. This is especially noticeable where actions and subject positions outside the classroom merge with those of teaching inside the classroom. The seemingly strong ideal of a necessary depoliticized profession in practice is made problematic in the focus group discussions as the teacher instructors try to balance between ideals of neutrality and the quest for change. In the following section, I will look more closely into how entanglements of facts and values in sustainability education create yet another balancing act for the teacher instructors.

\section{Troublesome knowledge in between facts and values}

Negotiating the legitimate teacher education position in between neutrality and specific embodiments draws on the discussion about what sustainability knowledge might be. Several of these discussions concerned the negotiations between facts and values. At first glance, in many of the focus groups, facts seemed to be equated with numbers, information, and things that could be plainly described, as something "concrete." Values, on the other hand, seemed to be about telling someone what to do, problematizing something, 
doing something in the name of the future; values were about ideals and certain practices such as eating organic food and recycling. However, the seemingly clear separation of facts from values seems quite tricky to maintain. Anastasia discusses this problem:

ANASTASIA: [...] you want to give them [the students] some information so that they can understand what it is about; sustainable development in relation to food, what is it? And then that needs to be problematized, when it comes to food and sustainable development, then I feel like it's easy to become normative, that there is a right answer. And I think that it might have to be a little like that, I must be able to be a little normative when I do a presentation on food and sustainable development $[\ldots]$

In this instance, it is clear that it is tricky for Anastasia to create the separation between facts and valuations of those facts when she teaches sustainable development in the domain of food. To give a presentation about food and sustainability within the teacher education program requires her to be, as she claims, at least "a little normative." Her desire to first give "information" to the students seems not to be enough. It seems that as soon as Anastasia starts problematizing what sustainable food is, she feels obliged to give answers to the students about what is right and wrong. The notion of value-free knowledge seems both present as an ideal and contested at the same time:

ANASTASIA: I also think about the thing about the cod, how to bring it up, now it isn't overfished any more, it's not as problematic since for a long time we avoided eating as much cod because it was nearly overfished, and if we want to preserve the cod, what do we tell the students? I think you have to be able to say this: The cod is almost overfished. If we went to preserve the cod we should stop eating it, or? What...?

ANDRÉ: well that's one way of presenting reality [LAUGHS]

ANASTASIA: yes [LAUGHS]

13 seconds of silence/

ANASTASIA: yes

HANNA: but is that what

ANASTASIA: show different alternatives of course

HANNA: sustainable development is about, or is it something different?

ANASTASIA: well to a certain extent it is, it isn't only about showing options but they should also be able to make informed choices, be critical [...] 
Anastasia's talk about the overfishing of cod and her wish to give advice in the classroom about whether to eat it or not seems, for her colleague André, to be just "one way of presenting reality." They both laugh about this as if André's response is somewhat absurd, or as if making normative claims in the classroom would be absurd. There seems to be a general insecurity about how to handle a situation like this in the classroom. Presenting seemingly hard facts about the cod population is seen as already bringing along tricky valuations, and of presenting reality in simplistic ways. In this way the notion of how things are is intertwined with how things ought to be. Instead of creating endless opportunities for dealing with sustainability issues, the teacher instructors seem pinioned by the impossibility of separating facts from values in sustainability education in general, and in the cod case in particular. How the teacher instructors should talk about the cod when teaching is unresolved in this conversation. The unresolved problem runs the risk in the long run of creating a nihilist approach in which everything is up for question. The problem with a nihilist point of departure is that "anything goes," as if choices about what to eat and how to farm can be made in isolation from necessary ethical considerations that involve and affect others' lives. Haraway's $(1988,584)$ critique of relativism as a way of "being nowhere while claiming to be everywhere equally" shows why nihilism is not an option.

Here I would like to make a parallel to the Swedish research field of Education for Sustainable Development (ESD), discussed in the introductory chapter, which was influential in the focus groups. ESD argues for a pluralist approach in which education should make room for different options to be negotiated and compared to each other in practice (see e.g., J. Öhman 2008, 22). Against the background of André and Anastasia's discussion, this approach seems to have certain limitations as a guiding principle for teaching sustainability issues. I would even go so far as to claim that pluralism, despite its ambitions, may seem to be a sort of post-political realization in which power relations might remain hidden. Erik Swyngedouw (2014, 24 italics added) writes similarly that "the past few decades have been characterized by a process of depoliticization whereby political matters have been reduced to the pluralist negotiation of a series of techno-organizational activities designed to manage consensually established issues and problems (...) but within a social and political-economic frame (...) that is itself beyond contestation." The question is whether the pluralist approach to education can provide a tool for change that the teacher instructors above seem to be searching for. Chantal Mouffe 
(2005) holds that the liberal democratic focus on dialogue and consensus, of which I identify the pluralist approach to be part, hides the conflictual dimensions and deeper unequal structures of the society - the hidden political reality of the status quo. The discussion in the focus group above shows that the pluralist approach has limitations. Oscar, from another focus group, seems to point to why this might be the case:

OSCAR: because obviously it [sustainable development] rests on [politics] [LAUGHS] consequently there is a questioning of economic growth and that's political, it is, and the neoliberal dominance within the whole political field makes it rather sensitive

For Oscar, here it seems to be the seemingly non-political, non-ideological aspects of sustainable development education that makes it difficult to teach. The consensus-oriented belief in economic growth, for instance, as a seemingly neutral fact, makes all other stances politically visible and therefore sensitive to bring up in education. In another focus group, Lennart and the other participants discuss how this scientific knowledge view is separated from "society":

LENNART: yes, when it comes to those of us who teach, 'cause most often it's biologists or those from biology or biology teachers or those working with biology in teacher education who work a lot with sustainable development and have taken the responsibility to do so, and you may ask why that is so because for me it's largely about, like, well the political and the idealistic parts that I bring in, from my youth, and my life, and that contains, although I'm a biologist by training the political and social science parts are actually from my private engagement in society, so in the biological parts there is some kind of professional role, but the other is much more biased towards some kind of will to change society or something like that, I don't know, it's a little, and then you have the soc... consequently there is a weakness in how the social science part is brought in as a professional part in everything [but] it's more like a volunteer part that you bring in LISBETH: it's not exactly a real area of knowledge

LENNART: no

LISBETH: it becomes more an approach or something and that's not...

One of the things Lennart does above is make a clear separation between biology knowledge and political views incorporating calls for change, which he 
locates in his lay interpretation of social science. This is probably a rather common-sense way of understanding science, as separated from the self's political and emotional desires. However, as I have discussed earlier, this view carries a few problems with my expanded notion of politics. In the example above, sustainable development becomes uncomfortable because it is teachable only when things outside disciplinary boundaries (of biology) are brought into the classroom. This seems to be why Lisbeth suggests that sustainable development is "not exactly a real area of knowledge." This problem pinpoints the specificity of education as a practice in which the world is divided into neat school subjects and disciplines. The problem Lennart addresses above may raise the question: Is there an educated way to teach sustainability issues? Somehow, due to the insecurity of not knowing, of being a vulnerable subject in a web of intersecting power relations, and of desiring a better world, the teacher as a figure of knowledge does not seem to fully work. Something else seems to be required. What was perhaps once perceived as the inside (biology) and outside (society) of the educational sphere is interestingly blurred in Lennart's problematization of his own role. Or, to put it differently, the attempts to make sustainability teachable show that it is impossible to maintain a separation between an inside and an outside.

Walking the line between facts and values, and negotiating this tension in a precise way by seeming neutral, is discussed in another focus group in terms of not wanting to cause conflict with parents, colleagues, and educational boards:

GERT: [...] than we are at the interesting question: and that it is what do they [the students] actually get to know through the teacher education? And then what they actually can mediate to their students, because there is some kind of objectivity requirement and what does the objectivity consist of? [...]

HANNA: is that something that the rest of you have reflected upon as well?

GORAN: well, I actually believe that there is a bigger fear of bringing up issues [...] about taking a personal stance and acting on issues that teachers understand as crossing the border of what is moral, or what the policy documents and the legal aspects of the teaching role are, that's an obstacle and you cannot just say anything, many see it that way anyway [...] you don't want to cause conflicts, you don't want to annoy [anyone] and then you 
skip issues that can be controversial, with parents or with colleagues, or with the board and so on, you often hear those arguments

In Goran's view, the role and responsibility of being a teacher seems to be about walking the line and presenting oneself as objective in order to remain legitimate in one's professional role as a teacher. To transgress the boundary of objectivity means to speak one's mind and cause conflicts with others (parents, colleagues, and educational boards) of importance for maintaining the position as a good teacher. Maintaining a consensus-oriented status quo seems important to the students and teachers Goran refers to. However, the consensus-oriented status quo is based on the possibility of a seemingly neutral, depoliticized idea of uncontroversial environmental problems. Walking the line when teaching sustainability issues seems easier said than done, given that Gert's question of what teaching objectively really means seems to have no easy answer. One way of seeing this problem is to consider that sustainability issues bring about messy knowledge that challenges conventional definitions of what knowledge is: what facts are, what a valuation is, and what a knowing subject is (see e.g., Gyberg 2003, 89). The messiness seems to have implications for the teacher role. The entanglement of facts, values, and teacher bodies creates challenges for the role and responsibility of teaching sustainability issues where clear-cut boundaries seem difficult to establish and maintain. My point here is that every time the un/sustainable future is spoken of, a stance has already somewhat been taken, which is also what several of the teacher instructors seem to realize. To put it simply, ontology is political (see e.g., Mol 1999) and it makes it possible to imagine certain things and not others. This point can also be made in the context of the participants' discomfort when trying to separate facts from values. How, when, and where one talks about the future in relation to sustainability has worlding effects; it creates certain possibilities and makes others harder or impossible. Normativity, which in Lennart's account above is connected to "doing something for the future," gives a glimpse of the implicit ideal he and his colleagues hold in the conversation about neutral knowledge, which seems to be about mediating things to the students independently of the contextual relation between teacher and student and the world they inhabit. It almost seems as if sustainability is not supposed to affect and change the students and make them become differently. 


\section{Concluding discussion}

Why does it seem so difficult to teach sustainability? This chapter suggests that one answer might be because the teacher instructors have to undertake uncomfortable educational balancing acts in a post-political landscape of environmental change. These balancing acts appear to generate conflicting and uncomfortable subject positions but also strategies for the self as a teacher instructor in the domain of sustainability. Throughout the chapter, I have identified three elusive/uncomfortable, and somewhat impossible balancing acts that the teacher instructors seem to be engaged in when teaching sustainability.

The first balancing act is about the tension between seeing sustainability as just another societal and temporary norm and the wish to succeed in creating a sustainable path as the only way forward. The balance between official politics and a sense of urgency opens up a number of issues that concern how the focus group participants form their understanding of knowledge and the purpose of education within the sustainability imaginary. Here, sustainability issues visibly intertwine knowledge with subjectivity, which can be said to pose a challenge to the role and responsibility of teaching. The post-political characteristics of environmental problems as urgent and all-encompassing can be read as overlapping with the sustainability imaginary in teacher education, built on both urgent, apocalyptic ideas about the future and on discursive formations about what counts as knowledge and what it means to be a teacher. The teacher instructors' ambivalent stances show that the contemporary postpolitical framing of sustainability education is problematic when teaching sustainability, and it is challenged as the focus group participants are trying to understand what it might mean to teach for a sustainable future. Sustainability becomes somewhat re-politicized when the teacher instructors collectively try to make it teachable. The seemingly strong ideal of neutrality can further be explained through the lens of the post-political process of depoliticization in the domain of environmental change.

A second balancing act I identify is that between the teacher role as an ideally neutral and non-normative one while any call for change relies on a specific way of viewing the world. This balancing act has do with whether education has the right to change those who are subjected to it. If education is not affecting the students, what does that mean for understanding the purpose of 
education? The teacher instructors seem to agree that, despite the implicit ideal of neutrality, sustainability cannot be handled within the realm of knowledge as independent of the subject who knows, as if a teacher can step away from her/his role outside the classroom. This quandary can be understood further with the help of the philosophy of Emmanuel Levinas (Levinas and Nemo 1985), who claims that to be, and to live, is political in the sense that being is in itself not innocent. Being violently includes some and excludes others. For instance, existing in the contemporary society as a Western subject located in Europe means that everyday practices such as drinking coffee, doing laundry, and taking the bus to work are activities linked to the killing of Others by means of pesticides, chemicals, water use, and fuel produced and used under conditions that cause invisibilized damage and death to Others. This violent politics of being in itself demands that we ask ourselves, over and over again, about the consequences and ethical obstacles of our (my) own being. Furthermore, I would like to claim that education changes those who are subjected to it - otherwise it is not education.

Making visible the violent yet necessary transformative purpose of becoming educated might be necessary for becoming accountable for one's situatedness and gaze from somewhere. When teaching leads to changes outside the classroom the teacher becomes visible as a situated, embodied position from which some sort of assessment of what sustainability is, can and must be done. The seemingly neutral position presupposes detachment from a historically and locally specific context, which ignores subjectivity as a relational position/process situated in a specific context (Haraway 1988). Teacher education scholar Magnus Åberg $(2008,212)$ holds that the idea of the teacher as "a neutral and objective administrator of difference" hides the fact that education is situated in a world where norms are repeatedly constructed and reconstructed. He shows that only specific teacher student subjectivities are understood as valuable and valid as neutral $(2008,208)$. These subject positions, then, become falsely disembodied as if they would possess omniscience and a gaze from nowhere.

One way of understanding the balancing act of the responsibility of teaching sustainability lies in the implicit paradox of the fact that we cannot be individuals in relation to sustainability issues and yet we are individuals according to dominant neoliberal discourses in which the rational individual is able to choose with a view to creating a better future. Individuality can be considered 
a surprisingly successful myth in a world of environmental change in which we are all connected and dependent. Sherilyn Macgregor $(2013,7)$ holds that "we are witnessing the masculinization of environmentalism" as men have come to dominate all spheres of climate politics and socio-environmental movements. Her critique might also explain the fantasy of disembodied neutrality that seemed both strong and contested in the focus groups. The consequences of climate change and other environmental problems are, as rightly pointed out by feminists such as Stacy Alaimo (2010), Sherilyn Macgregor (2013), and Donna Haraway (2015), not a question of equally distributed effects among humanity as a whole. Such all-encompassing ideas rest on insensitive understandings of the many different ways in which different humans exist on this Earth. Quite the contrary, the consequences strike very differently depending on geopolitical location, race, gender, and class, circumstances that are easily forgotten though fantasies of threats to humanity as a whole (see e.g., Plumwood 2002).

The third balancing act I identify is the negotiation of the difference between a fact and a value. Here, the notion of value-free knowledge seems both present as an ideal and contested at the same time. The notion of how things are is intertwined with how things ought to be as the teacher instructors discuss sustainability teaching in the focus groups. When the participants talk about phenomena in the world in connection to sustainability, it is always interlinked with talking about how the world ought to be. One reason why this balancing act seems difficult is because it appears to be important to maintain the status quo as a way to remain a legitimate teacher instructor. Embedded in the tension of informed choices and correct behaviors, facts and values, and normative and neutral teaching ideals lies the mutually necessary and impossible visible subject positions that sustainability education seems to require.

What does all of this say about the formation of the sustainability imaginary in education? For the formation of subject positions, visible, politicized, situated, and troubled teacher subjects full of desires became uncomfortably apparent the focus group discussions. The available positions for the teaching self show how sustainability complicates conventional understandings of neutrality while trying to make sustainability teachable in practice. For discursive formations, both strong ideals of neutral teachers and understanding sustain- 
ability as inherently political were used throughout the discussions. The nonsensical aspects could, arguably, be about a dream of possible and disembodied neutrality. This can be regarded as nonsensical in the sense that neutrality as an ideal fails to recognize subjectivity as a necessary relational political process in, and outcome of, sustainability education. In other words, sustainability education requires an embodied teacher subject, a subject that does not seem to feel comfortable in its necessary visibility. This uncomfortable situation of negotiating between official political values and a sense of urgency, of one's professional role in between ideal neutrality and demands for change, and of what the difference between a fact and a value is, opens up the role and responsibility of the teaching subject, and of teacher education. The role of the teacher in relation to sustainability can be said to be somewhat "impossible," and this impossibility should be seen as part of the very condition of the teaching profession for sustainability which reaches and teaches for the future.

The next chapter investigates how animals are brought up in the focus group discussions, and I show how human-animal relations can be analyzed in detail in order to understand further important aspects of how the sustainability imaginary is formed in education. 



\title{
Chapter 6
}

\section{The possibility of nonhuman animal encounters in sustainability education ${ }^{2}$}

\author{
SOLVEIG: I have to admit that it is only "by accident" that I bring \\ it [human-animal relations] up.
}

It could be argued that animals, however enormous and empty that category is, represent an absolute Other in education as an institution of modernity. Animals ${ }^{3}$ displayed on educational posters and in textbooks have long been used in order to teach and learn about nature, about the world, and about "ourselves." How education relates to nonhuman Others, such as animals, can be regarded as an essential question in a time of dramatic and visible environmental change. The focus groups touched on a number of different human-animal relations, which entered the conversations in elusive and uncom-

2 Some parts of this chapter has been published as articles in Swedish (Sjögren 2014a) and in English (Sjögren, Gyberg, and Henriksson 2015).

3 Lynda Birke (2012) argues for the importance of combining feminist theory with human-animal studies. In an attempt to rethink the difference between "us" and "them," Birke points out that the very term "animal" is used as a counterpoint to human, although humans in a biological sense should be included in the animal category. The binary positions between humans and nonhumans has had wide consequences for the understanding of (other) animals as inferior to humans. For the readability of the text I will use the categories human and animal, although I recognize and acknowledge that a more accurate way of writing these broad categories would be human animals and nonhuman animals. 
fortable ways. I will present four dimensions below in which the teacher instructors relate to the question of how it is possible to encounter the nonhuman Other in sustainability education. Thus, human-animal relations discussed in the focus groups are analyzed in detail in order to understand important aspects of how the sustainability imaginary is formed in teacher education, even when it only is brought up "by accident" as Solveig indicates above.

\section{"Meating" animals: Reification of domesticated creatures}

Meat eating is considered one of the most environmentally damaging practices in industrialized societies (Naturvårdsverket 2013, 7). Despite this reality, relations to animals in general and meat eating in particular only entered six of the focus group conversations on sustainability through the provoking image of the dead pigs. However, consumption, which can include meat consumption, and its role in creating sustainability was discussed widely, as I showed in Chapter 4. The post-political reality of animal captivity and killing as the status quo motivates me to look specifically into how human-animal relations in the focus groups are formed in order to create subject positions for the self to justify the killing of domesticated animals. Domestication refers to "the situation in which people actively force change in the seasonal subsistence cycles of animals to make them coincide with particular human needs" (Haraway 2008a, 177). The following conversation shows how one of the participants, Gert, forms a subject position for himself through humananimal relations of eating and killing:

HANNA: these animal-human relations?

GERT: yes well

HANNA: is that something you talk about in your teaching?

GERT: there are different ways of engaging, partly how we view what we eat, for instance when we talk about hunting and such things and are condemning it, I eat meat at least and you - well there are these Buddhist countries in Southeast Asia where you can't kill an animal, consequently you hire a Muslim or a Christian to do the slaughtering, but you don't do it yourself because it'll give you bad karma [...] 
In this excerpt, Gert's subject position as a meat eater is shaped through the Othering of people in the global South and their prescribed unethical treatment of animals. It might also be interpreted as a strategy Gert uses to show how his eating can be defended in comparison to how Others kill and eat. My methodological choice to use the image of dead pigs together with my explicit question might have triggered this defensive approach. When Gert admits that he eats meat, he does so by immediately referring to the killing of animals in other cultures. Carnivore and animal treatment thus become equivalent to how Other humans treat animals badly. Gert does not challenge the using and eating of animals per se; instead, he blames bad practices of using and eating on humans that are Other to him. This conversation continues below:

GORAN: the other day there was an interesting item on the news, this thing about slaughter, Halal slaughter just to be on the safe side so to speak, to be able to

GERT: that is

GORAN: sell

GERT: that's an interesting debate

GORAN: $\mathrm{mm}-\mathrm{hmm}$

GERT: because there is, there are the strangest arguments voiced on this, I've heard those who, ordinary Swedes, who have seen how Halal slaughter works and say "well that's great"

Halal refers to actions that are allowed and suitable under Islamic law. Halal meat denotes meat from animals that have been killed according to practices determined by Islamic law. In the excerpt above, animal care is brought up and understood through a disdain for how Muslims treat animals. Other humans (other than "ordinary Swedes" that is) are understood through their treatment of animals. The slaughtered animals seem to become commodities that people can use in good or bad ways, which in turn makes people either good or bad. In this way the slaughtered animals can be understood through reification, a process through which something or someone becomes an object or a thing, separated from its context and history (Haraway 2008a, 175; Hedrén 2002, 321). Furthermore, Other people become entangled with animals in ways that make them seem irrational and immoral, that is, less "human." Again, it makes Gert seem like a more sound and ethical meat eater, while those people who prefer Halal become less sound and ethical. The fact that there are "ordinary Swedes" who support Halal slaughter despite having seen how it is done also contribute to Gert and Goran's position as ethically 
and morally sound subjects to which others are compared. Seeing is highlighted as a crucial sense for forming ethical relations to the animal Other, which leaves the non-seeing of millions of slaughtered animals unproblematized. I will discuss ethical possibilities of seeing later in this chapter.

A recurring relation in the focus groups was that of making animals into food and associating animals with meat eating for human purposes. The following excerpt exemplifies how animals are often understood as food:

HANNA: no, I thought questions regarding the human, human relations to animals, if that's something you use

SOFIA: [inaudible]

HANNA: in education?

SOLVEIG: in middle school I did that, but here [in teacher education] I haven't even given it a thought

SEBASTIAN: no, here it's much more human-nature

SOLVEIG: yes, it's humans [LAUGHS]

SEBASTIAN: I think, and it's in case of, if it comes up it's not, now I say what I experienced, it's not discussions about caring for animals, but rather about eating in more organically sustainable ways

SOLVEIG: vegetable-based

SEBASTIAN: vegetable-based so it's more organically sustainable, consequently they don't argue from the point of the animals, there is nothing, this about the freedom of animals

This is just one example of how domesticated animals seem to become reified as commodities in the focus group conversations. To a certain extent, animals do not even seem to be part of the "human-nature" relation but seem, in Sebastian's account, to be outside that relation. Domesticated animals that are eaten are not regarded as animals; rather, in writer and activist Carol J. Adams' $(2010,66)$ words, they "permit us to forget about the animal." Not eating animals is, as Sebastian holds, about eating "in organically sustainable ways" rather than caring for "the freedom of animals."

On a direct question from me, the teacher instructors reflect on the fact that animals seem rather absent from sustainability teaching. Solveig mentions that there is so much that needs to be covered during the course on sustainable development, a course that had been downsized after the new teacher education reform. She says about the new course: "it needs to be that, and then that, and then that." Clearly, animals are not or cannot be prioritized in this 
process of selecting relevant content for the course. Animals seem to become present only as "absent referents" (Adams 2010), that is, as meat connected to cooking and eating. The absent referent captures and explains how certain animals become edible and transformed into meat. Carol J. Adams (2010) argues that animals become absent as animals when meat production and consumption get linked to cooking and cuisine practices, rather than killing. Adams argues that the absent referent "permits us to forget about the animal as an independent entity; it also permits us to resist efforts to make animals present" $(2010,66)$. The absent referent works literally, linguistically, and metaphorically and maintains meat eating as a justified practice. Sebastian's reference to how their education is more about "human-nature" than the freedom of animals displays the possible operation of a "meat norm" (Gålmark 2005,83 ), that is, that eating meat is a taken-for-granted practice. It seems as if Sebastian might be critical of the assumption that the topic of animals in education is limited to discussions on food (e.g. eating more vegetable-based foods is regarded as more sustainable) instead of the freedom of animals.

It might be possible to understand animals as absent referents by considering the image of killed domesticated pigs in a machinery setting, which I introduced in the focus groups. On the other hand, the picture worked as a way of including and making animals visible when discussing sustainability. Below, the same focus group participants as above discuss the pig image for some time. Collectively, they seem to be trying to find out what the image is actually displaying:

SOFIA: but they are dead, or have they been poisoned or what? SANDRA: it's probably a large pig farm's normal shed while farrowing

SOFIA: what?

SANDRA: yes, it is

SEBASTIAN: pardon my ignorance

$[\ldots]$

SANDRA: while the sow farrows, consequently when you have a large production

SOLVEIG: they're giving birth

SEBASTIAN: alright, giving birth, yes, alright

SANDRA: yes, if you have a large production with perhaps 200 sows who are farrowing

SEBASTIAN: yes

SANDRA: at the same time, at least two of them will die and a fair amount of the piglets will die from being lain on and 
SOFIA: alright

In this quote, we can see how Sandra, a teacher of biology and science education, explains to the others that the image just shows normal death in a "large production" of pigs and farrowing. Again, animals are understood as reified commodities produced in large industries. Even though the other participants are raising some concerns regarding what is in this picture (Sofia asks whether the pigs are dead or poisoned, and Sebastian and Sofia in particular seem surprised by Sandra's explanation), they seem to accept Sandra's explanation of the normality of why piglets die during meat production. Understandings of dead animals as a normal consequence of meat production get naturalized in this discussion and so does the eating of pigs - not as animals but as meat. Sebastian excuses his initial interpretation of the picture by claiming that he is ignorant. By knowing what is displayed in the picture, he seems to accept the killing of pigs as a completely normal and unchallenged practice. The group's final interpretation of the pig picture makes animals into meat rather than beings to care for.

I will continue with an excerpt where some participants from a different focus group are negotiating how animals are viewed in our contemporary society:

DAGNY: I think mostly about the pig, well, I don't know the context of that picture, but I think more generally about our view on, you can feel consequently, isn't is something historical in this, how humans view children, it's changed in the last 100 years

DAN: yes

DAGNY: and now we are in, I hope, a time when the human view on animals is changing, towards, well, from eating them to associating with them, I was almost about to say, consequently DAN: and then eat them

DAGNY: no you have respect for animals in a different way and respect for different creatures with other conditions who see things differently

DAN: mm-hmm, let's hope so, I mean meat consumption, if you look at meat consumption in Sweden most people don't care where the meat comes from as long as it's cheap

DIDRIK: no, not me

DAN: yes, but

DIDRIK: I buy from [a local place] 
As can be seen in the quote above, Dagny connects the handling of piglets in the image to the historical treatment of human infants, much in line with the ecofeminist understanding that "how we treat nature and how we treat each other are inseparably linked" (Gaard cited in Oppermann 2013, 21). However, Dagny and Dan seem to disagree on whether we have reached a time of respect for animals. Dagny points out that one has "respect for different creatures with other conditions who see things differently" while Dan contests this by referring to Swedes' preference for cheap meat. Dagny's initial hopeful claim about a new and different time for human-animal relations is quickly dismissed by the other participants. Again, this quote reveals a meat norm in the focus group conversations about sustainability. As an example of this, Dan questions the choices of buying cheap meat, but he does not question meat eating as such. It reveals norms that make it difficult to question the fact that society, in which education is obviously part, is based on assumptions that normalize the ideas and practices that humans should eat other animals. The quote ends with Didrik's proud announcement that he is not one of those who buys cheap meat, instead, he buys from local producers. The assumption that it is normal for humans eat other animals remains unchallenged, as the topic ends with the announcement that Didrik is a different (and presumably better) human being as he buys and eats meat that is locally produced.

Above, I showed how domesticated animals that are killed for eating purposes play an important role in forming subject positions for the self in relation to Others, as well as for maintaining a norm of eating and killing certain animals. Indeed, reification seemed to be at work in the focus groups' discussions of human-animal relations. Consequently, animals as an absolute Other in education become a resource to use and abuse. Important to note here is that the domesticated animals are not seen as animals in Adams' sense, but as resources and possessions for human use, with complete lack of agency. However, the strong reactions to the picture of dead pigs shows an opening for encountering and imagining relations to nonhuman animals differently.

\section{A conditioned care for the individual animal}

In several focus group discussions, the number of nonhuman animals seemed to be important for including the nonhuman Other in sustainability education. The following discussion captures why it seems to be acceptable to kill collectives of certain animals: 
ANDRÉ: they [ants and spiders] are certainly okay to kill but then [someone] has written about [this] among other things, and it is also very fascinating, that certain animals we think are okay to kill so there we have no moral doubts

ANNA: no, there are so many ants that it... [SEVERAL LAUGHS] it's hilarious, with those Burgundy snails as well, when the first one or two show up early, then you can build a house for the snails and watch

ANDRÉ: yes

ANNA: but then it gets full and then you throw them away; in the preschool yard they are everywhere and they are disgusting; [we] throw them out and they break

HANNA: okay

ANNA: I have done that myself [LAUGHS] it is a nice development [LAUGHS] to start off by taking care of the little snail and then

The situation above provides an example of a relation where teacher instructors and various nonhuman animal collectives, such as ants, spiders, and snails are included. The contrast between the few snails ("one or two") that Anna first encountered at the preschool and the increasing numbers that later led to a feeling that they are "everywhere" shows the quick transition between caring and killing. As Anna points out, when there are snails "everywhere" on the school yard, they become "disgusting." In this example, it is the very number that becomes significant for whose life becomes important in sustainability education. It becomes clear that the number is significant to whether snails should live or die. Human geographer Jamie Lorimer $(2009,326)$ discusses ants and other insects that are encountered in multitudes by humans as distrusted because of "their radical alterity to humans in terms of size, ecology, physiology, esthetics, and modes of social organization that engenders popular feelings of antipathy and distrust." His account relates to the affective properties of insects and other organisms encountered in multitudes by humans. Furthermore, Lorimer accounts for the possibility of nonhuman agency through charisma. He argues that certain nonhuman places and organisms can be understood as charismatic by their ability to get noticed. He writes that "nonhuman charisma is both too lively and material to be a social construction and too variable to be naturally determined - it relates to both the agency of the nonhuman being witnessed and the social structure in which the witness in enmeshed" $(2009,324)$. Here I use the notion of nonhuman charisma to be able to read some of the human-animal relations I analyze as relations 
that nonhuman animals take part in forming. In this way, I see animals as potentially agentic in forming the educational human-animal relations accounted for in the focus groups. Furthermore, it is important to distinguish between relations that make it possible to care for or abhor (i.e. notice) animals, and relations that fail to recognize animals outside the realm of reification and possession.

In the quote above, it seems to be when the Burgundy snail is transformed from an individual to a collective that something happens with the relation: The snail is first met face-to-face and later confronted as a faceless collective (see e.g., Butler 2011, 15). It is precisely through Anna's initial relation to the specific, particular snail - that suddenly appeared in the preschool yard - that the pedagogical practice creates the possibility to deal with the snail as someone whom the preschool teachers can care about. When the factual quantity in the room is changed, the relationship is also changed. One interpretation of why this happens might be because it brings about a lack of control over the Other.

In the encounter between Anna and the Burgundy snails, it is when the snails form an unorganized collective that the ethically possible relationship suddenly disappears. When the snail population grows, from one or two to many, the relation is changed. This transition can be illuminated with the help of the metaphor of the zoo in the modern society. Susan Willis $(1999,672)$ compares the organization of the zoo to that of a garden. She writes that "[t]he brutal reality of the garden is beauty achieved on the basis of exclusion and death." The captivity of one animal is considered justified in order to feel and to understand that their kin should not be harmed. This logic justifies the idea that humans need to see and touch any one animal in order to develop an ethical relation and a sense of responsibility toward that species of animal.

I interpret the transition between the specific and general as occurring when the species of snail becomes unmanageable and beyond human control, so that care is rendered impossible. It seems as if it is only within the setting of manageable control that the animal Other can be cared for. The very relation between snails and preschool teachers that is addressed in the focus group can be placed in connection with the snail's factuality (presence, reproductive patterns, ecosystem) and cultural discursive formations concerning the snail in the preschool (with children's songs such as Little snail watch out [Lilla 
snigel akta dig] and the children's program The Bear's Magazine [Björnes magasin], whose main anthropomorphic bear character is always in the company of a snail). The relation between the Burgundy snails in the preschool yard and the teachers and children at the preschool creates double-edged effects, where the snails are understood as both individuals - with their cultures and houses - and as a collective - an infinite natural resource, which humans can use and control. As an infinite resource, the snails also become a threat to the educational practice by their uncontrollable growth. The boundary between individual and collective has, as can be seen above, possible consequences as to whose life is made significant in the pedagogical practice. It seems that as long as the snail is delimited into a manageable "zoo setting," care and responsibility appear possible (see e.g., Sjögren, Gyberg, and Henriksson 2015).

As I mentioned earlier, Lorimer (2009) argues that both certain nonhuman places and organisms can be understood as charismatic by their ability to get noticed. In the focus group discussions, animals were also interpreted and arranged based on, among other things, their iconic status:

SANDRA: I usually go around with two demonstration placards SOFIA: yes [LAUGHS]

SANDRA: and it's like "save the panda." Who wants to come along

SOFIA: yes

SANDRA: into town now? There are so many people out to save SOFIA: everyone agrees on that

SANDRA: the panda, since pandas are such cute symbols. Later, I usually show the other placard; "who wants to join me and who wants to save the tick?"

SOLVEIG: surely, they don't need saving? [LAUGHS]

In the contrast between the cute panda and, what Sandra does not think needs saving, the tick, we can see how the boundaries of the relations are drawn. The panda in the placard above becomes, thanks to its iconic status, an individual in the relation. The relation with the tick, which Sandra shows in the other placard, is formed in a different way. In the contrast between the two species, the panda appears to be an individual worthy of attention, while the tick becomes the opposite. Once again, individuality becomes relevant as an important condition as to who is worthy of living in this relation. The making of the relation has consequences for - and is connected with - practices where the tick is shown in commercials for the TBE vaccine and the panda 
adorns the World Wide Fund for Nature's (WWF) logo symbolizing a better world (see Lorimer 2007 for a discussion of the panda's status as a "flagship" in discussions and practices concerning biological diversity and conservation).

As the conversation between Sandra, Sofia, and Solveig continues, they arrive at the issue of whether all species are truly worth saving. Solveig answers by pointing out that one of the species is threatened with extinction (the panda), while the other continues to multiply (the tick). The pedagogical point that Sandra wants to make with the help of her placards helps illuminate how the relationships between humans and animals create different kinds of boundaries affecting who is considered worthy and who is not. The role of individuality raises further questions about the possibility of ethical relations with the more than human world through education. Lori Marino, Gay Bradshaw, and Randy Malamud (2009) draw attention to the brutal logic of the zoo: learning to care for certain species requires captivity and sacrifices of individual animals in order to save a species consisting of a collective of animals. A premise of the zoo is that "prolonged suffering of confined animals balances out the effort to save their counterparts in the wild" $(2009,27)$. The individual animal plays an important role in creating possibilities to care, although it is a very violent and exclusive way of caring for the animal as Other. Despite my strategy of reading the quotes with both generosity and suspicion, I could not find much hope for imagining otherwise while caring for individual, charismatic animals, with the exception of one quote, which I will discuss shortly.

\section{A moment of care for charismatic animals}

Individuality, as I described above, was criticized in certain focus groups as a double standard. Some of the participants pointed out that the teacher students were being hypocritical when they were inclined to care about a specific nonhuman individual rather than a collective of animals or animals in general. The discussion below follows the presentation of the images that I introduced to the participants in order to stimulate discussion:

OLGA: $[\ldots]$ there are few things that have upset our students as much as a visit to the [agricultural school] where a group in one instance was there when they found a small piglet that had died because the mother had lain upon it, and I can't tell you how long they talked about it 
OLOF: what are you saying?

OLGA: about how incredibly dreadful it was and the animal welfare they have there is still very

OVE: exemplary, sure

OLGA: yes, exactly. And then they all eat meat, but they don't really seem to make the connection; rather, it was just, it was more of a discussion on maternal instincts that followed. It was such a dreadful incident that... [said with sarcasm]

The participants in the excerpt above criticize the very transition between the killing of a collective and the care for an individual, similar to what I discussed in the previous section. In Olga's reference to the teacher students, her criticism comes from the fact that the students did not show concern for something with which they were not standing face-to-face. I am thinking here of the pork chop or slice of bacon on the plate, suggested by Olga's comment, which seem to be far away from the little piglet that the teacher students encountered during their field trip to the agricultural school. The fact that the students did not manage to make a connection between the meat on the plate and the piglet that was crushed to death can be seen as related to a sort of temporary charisma. When a concern arises within the relation because of the little piglet's material and discursive position, a limited responsibility is possible. That responsibility does not embrace all the pigs that are born, live, and die under industrial conditions. The "meat norms" (Gålmark 2005, 83), which make the eating of nonhuman bodies into a non-issue and which see nonhuman animals as naturally granted resources, are undeniably linked to the issue of who gets to live and die. Care, in the case of the study visit to the agricultural school, seems to be possible because of how the pigs suddenly resemble us. The discussion about maternal instincts that was prompted by the encounter of the piglet strengthens this interpretation. As Lorimer (2009, 326) argues, "there is a powerful axis of anthropomorphism at work that orientates people's ethical sensibilities. For many people, the organisms they feel the greatest affection toward are those that most closely approximate an anatomical or social behavioural norm." The piglet is not understood as an Other here, but instead as one of us (see e.g., Wolfe 2008). The pig appears as a present referent, as an animal worthy of living. I have modified the concept of the present referent based on Carol J. Adams' (2010) notion of the absent referent (described above). Several examples from the focus groups show that 
human-animal relations could sometimes go from an absent to a present referent. The norm of ignoring animals' lives could then be questioned, albeit just for a moment.

What the example above shows is that relations are flexible: They are not based on intrinsic essential qualities of the species, but rather on how they are arranged (materially and discursively) and what they create in specific contexts and situations. However, it also shows the particular being's significance for the possibility of an ethically responsible relationship to be formed. It is thereby in the specific, particular encounter where an encounter that "resists codification" (Todd 2008, 9) might be possible. The encounter that occurs beyond reification, codification, and appropriation happens beyond the compelling framework of knowledge. Thus, knowledge is not a requirement for enabling an ethical relationship to the Other. Rather, knowledge and the need to know, categorize, and organize pose an obstacle, sometimes an insurmountable one, to entering into an ethical relationship with something fundamentally different from oneself. The example with the pig cadavers in the photo - which become present by going from being products in a factory to being once more associated with living creatures that can suffer (see Wolfe 2008,120 ) - shows, however, that a lack of knowledge also runs the risk of causing devastating consequences for certain beings in this relation.

The next interview excerpt contains another discussion based on the pig image:

GERT: I usually talk about this sort of thing [points at the image of the pigs]

[...] yes when it's about how we use animals, like how we travel around in other cultures, for example, when you travel to China and you order a duck and then the duck is brought in and the head is still there, so you really get to see what this thing really was

GORAN: you can't cheat then and say that [LAUGHS]

GERT: no, but we have a completely different understanding. We don't want to see what it is; rather, it is a bit like there is some meat factory somewhere where meat grows; the fact that it involves animals is not at all part of [our mental picture]

The excerpt above contains at least two significant human-animal relations: the one between Gert and the pigs in the image, and the one between Gert and the duck on his plate. In both relations, Gert is compelled to respond to 
the Other's situation. Kathie Jenni $(2005,1)$ holds that "[w]e respond in dramatically different ways to suffering we see." The image of the pig, which many participants find disturbing, seems to make the pork on the plate present, that is, it goes from being something other than itself to once more becoming what it once was. In that respect, the ontology of the pig body is shifting. Thus the meat on the plate is given a "face" to which Gert must respond in some way. The duck's face on the plate, in a literal sense, makes it impossible for Gert to disregard the fact that what is about to be eaten has been someone. The sudden presence of animals in the relation made it possible for a response to emerge. Once more, I hold, with inspiration from Sharon Todd $(2003,9)$, that the aforementioned relation in which Gert is part can be regarded as one of the temporary "relational moments which resist codification." In other words, acknowledging the agency of the nonhuman world, that nonhuman nature can "talk back" (Alaimo 2008, 242), makes it possible to encounter the unknown. The pigs in the bulldozer and the duck on the plate create elements in the focus groups where Gert and his colleagues respond and thereby become someone else - someone who responds. One way of understanding these relations is to consider that the pigs and the duck assembled enough charisma to affect the focus group participants.

However, it is not unproblematic to be confronted with those elements that do not lend themselves to being discursively ordered within previous experiences and encounters. In the discussion below, some of the participants in one focus group talk about the image of the pigs as problematic:

HANNA: you brought up an image there

NANCY: I brought up an image here and this is what I thought: I could consider using all these images, but I don't think I would want to use this image with the pigs, especially not when introducing sustainable development because I think that it is so negative, it is so extremely negative and it would be such a bleak introduction to sustainable development. It is such a negative attitude so I don't think that I would use that image, at least not at first, it was just that

Nancy's reaction to the image with the pigs shows the dilemma of making room for the unexpected aspects of sustainable development as a teacher instructor. The dilemma here refers to the students' possible reaction to the death of the pigs. Nancy speaks of this as a "bleak introduction" to sustainable development. The present referent that emerges in the encounter with the 
image of the pigs challenges the teacher instructors by restructuring the relationships and creating something new and different - something nonsensical - the possibility of pigs as subjects that then challenge the seemingly naturalized order of human-animal relations. The "negative attitude" about which Nancy is concerned clearly has the potential to challenge the prevailing view of how pigs live and die, and of their well-being in our society. As Sara Ahmed (2010) has noted, the revolutionary subject is only possible through presumably negative feelings of unhappiness and discomfort that force us to question the status quo of our current situation. The dead pigs in the picture, in relation to the participating teachers, create both openings and closings for responding to the Other. The sudden presence of the duck on the plate challenges something that has been taken for granted, something the relationship with an absent, headless duck does not do. The present referent makes possible a moment of responsibility for the animal Other as an individual. At the same time it makes it difficult to craft responsibility for a collectives' health and well-being. This problem can be seen as connected to the problematic logic of the zoo, which entails caring for one or two animals in favor of the greater collective of an endangered species: One suffers for many, or many are ignored in favor of an individual. Certain charismatic animals, then, engender care for the nonhuman Other, although the collectives could not engender such care.

\section{The fear of losing control}

Control, or possession, is yet another way in which the focus groups handled human-animal relations in their discussions. Using two different examples I will show what control, and loss of control, enable in terms of human-animal relations. I will first turn to a focus group in which a frog is compared to a water lily. This discussion came up after I posed a question to the group about whether they speak about human-animal relations in their teaching:

GERT: I also talk about, a lot about having illustrative examples for how it works in reality

GISELA: [CLEARS THROAT]

GORAN: and that is, we can imagine the construction of a highway; first we have an anthropocentric viewpoint, we have two alternatives for its location: the first alternative means that the highway will cross a dam where a frog lives, the frog lives only in 
that place, the other alternative where the highway is supposed to cross is over a different dam, where there is a water lily GISELA: [CLEARS THROAT]

GORAN: that only exists in this particular place, and the question then is where do we place the highway? The anthropocentric has an easy choice, it is either the animal or the plant, depending on which one we value more, we either choose to cross over the frog or the water lily depending on which one we dislike most, but for the biocentric this choice does not exist because it's an impossible choice, it's impossible to choose between the two, they are of equal value

In this example, Goran seems to be trying to teach human-nonhuman relations in an educational context by offering the students a choice between two distinct alternatives; either they can choose an anthropocentric or a biocentric approach to deal with the life and death of nonhuman Others. The notion of choice creates understandings of human-centered control as if humans can control and master the nonhuman world. As can be noted, both the frog and the water lily are here understood as passive objects as they are described as if they "only exist" at this particular and controlled place - and it is thus up to humans to make the choice about whether they both should live or die. In the example, these nonhumans are not only made into easily manageable choices of either/or, they are also taken out of their context as a thought-provoking example of ethics - deterritorialized and stripped of their respective contexts. Gisela's repeated throat clearing might be read as a critique or resistance to Gert's simplistic reasoning. Control is rendered here through scientific distance, enabling a rational choice, and control of the lives of nonhuman animals and plants.

The focus group above continued their discussion by talking about a particular rare snail. The discussions about a rare snail species provides an example of loss of control in relation to nonhuman animals:

GORAN: but, that exists in reality here nearby, when you built the highway up to [a Swedish town] you departed from there, the area there, in [a biosphere area in Sweden] there was a land snail by the name [Threatened Snail Species] and you ran down, without discussion, built a highway straight over it, the only snail of that kind in the country

GERT: $\mathrm{mm}$-hmm 
GORAN: and that means that one population ends up east and one west of the highway, and how fun is that if you are a land snail that is so uncommon?

GERT: $\mathrm{mm}-\mathrm{hmm}$

GORAN: and has to cross the highway [LAUGHS] and that clearly doesn't work, that's interesting

GERT: mm-hmm

GORAN: how we

GUNNAR: are there two species now, or? Breeds?

GORAN: actually it's a different time frame, the highway won't exist until new species develop

GUNNAR: snail

GORAN: but they are two populations, what did you say?

GORAN: the snail is waiting, eventually it will come out

GORAN: yes [LAUGHS] after a few generations

GUNNAR: when the oil has run out

In this example the snail is far from passive and controllable. The snail in the nearby neighborhood is described by Goran as acting outside the realm of human control and with the development of both the highway and peak oil. Discussing the snail as a real and present being with agency challenges modern understandings of control over nature with its impossibility of clear-cut boundaries between the human and nonhuman world. The local snail's interconnectedness with the local-global developments of peak oil blurs and complicates the scale between local and global through which sustainability is imagined.

\section{Concluding discussion}

This chapter addresses the question of the possibility of nonhuman encounters in sustainability education. As a way of doing that, this chapter has focused specifically on elusive and uncomfortable educational relations involving humans and animals. I have focused on human-animal relations because animals, both as symbolic and embodied beings, have been shown to be crucial for understanding fundamental mechanisms in our society, including understanding ourselves in relation to other humans (Pedersen 2007, 16; Derrida 2008; Oakley 2011; Birke 2012). Educational scholars argue that the handling of animals in concrete classroom situations can illuminate how ideology operates (Pedersen 2007) as well as how scientific literacy is enacted (Solot and Arluke 1997). According to Jan Oakley (2011, 8), "many forms of human, 
animal, and environmental injustice are intertwined." I examined the handling of symbolic, discursive, material, and fantastic encounters with nonhuman Others in education and I argued that the processes through which the relations are challenged, negotiated, and legitimized are of considerable importance to understanding which versions of sustainability appear reasonable, and who it is that can be included in sustainability education. I further argued that what is included and excluded is significant for which beings become important in education for sustainable futures. In other words, it is significant in addressing the question: Sustainability for whom? I analyzed elusive and uncomfortable human-animal relations in the focus groups and I related these to the political, ontological, and ethical questions of possible becomings.

The first dimension I identified is that of seeing animals as meat. Here, animals are reified and made into resources for human use and abuse. Throughout this dimension, animals remain an absolute Other to the teacher instructors of sustainability. I provided examples of how human-animal relations form, reinforce, and challenge understandings of nature as part of the sustainability imaginary in education. Seeing animals as meat seems to make it rather difficult to form an ethical relationship to the Other.

The second dimension I identified is the conditional care for one or two animals, and I discussed why collectives of animals seem so difficult to care for. By relating care of the individual animal to the sustainability imaginary and the question of sustainability for whom, the inability to care for the multitude and that which is radically different from the humanity of the teacher instructors must be rendered problematic. Some of the empirical examples from the focus groups demonstrated moments when the educational relations and boundaries seemed negotiable and possible to change, while others displayed a reproduction of the norm of killing and/or eating certain animals. One important point of discussing these examples is to show that the boundaries of the relations are significant for the painful, and political, question of who gets to live and who dies through the imaginaries of sustainable futures.

The third dimension I identified is that moments of care seem possible when animals resemble us, or when we are forced to see animals as beings. In this way, only individual animals seemed worth caring for. I showed that it is important to zoom in on the details through which something or someone gets to be - to become a subject. The empirical examples that have been analyzed above show how the relations between the teacher instructors and nonhuman 
animals can be important for understanding the politics of imagining sustainability in education. As both Emmanuel Levinas (1985) and Donna Haraway (2008b) point out, being occupies a crucial political dimension, which recognizes ontology as political. Cultural studies scholar Cary Wolfe (2008) shows that the model of the subject dominating liberal democratic thought is based on the logic of sameness rather than difference. Those who are not granted agency in the liberal sense, such as disabled people and nonhuman animals, gain rights only based on the arguments that they are "diminished versions of $u s^{\prime \prime}(2008,118)$ instead of being recognized for having unique forms of subjectivity. Those that do not qualify as species worthy of being preserved (such as domesticated slaughter animals) are not even regarded as animals, but reified as commodities. The possibility of ignoring the everyday lives of pigs makes any opening for ethically responsible human-animal relations difficult. Derrida (in Wolfe 2008) teaches us that the visible can produce blindness by making the seeing subject unable to grasp the non-visible. Lorimer (2009) holds similarly that the human physical appearance and senses create limitations "that disproportionately endow certain organisms and places with ecological charisma." Thus, knowledge and what we can know can be seen as both a possibility and an obstacle for creating ethical relationships involving humans and animals. As Lorimer (2007) points out in his analysis of nonhuman charisma, there are many species that, for various reasons, will never reach the status of symbols/icons. This means that they will continue to be excluded from discourses of diversity and conservation.

The fourth dimension I identified is how control and loss of control lead to the formation of different human-animal relations. I have identified and provided examples of relations I claim are significant in crafting what and who becomes possible to imagine within sustainability education. The realm of these relations has consequences for the kind of knowledge, subject positions, and nonsensical aspects that are considered important in education for sustainability. Here is where it is important to highlight and study relations that create inclusions and exclusions, with consequences for who gets to live and who dies. Controlling the nonhuman world has been discussed as a modern condition of social organization (Calvo 2008, 33-34; Haraway 2008a, 158). It can also be seen as a highly problematic condition exemplified by, for example, the organization of the zoo (Samuelsson 2008, 223-225). Controlling nonhuman life is furthermore a significant part of the zoo setting with its colonial roots of categorizing and displaying of otherness (Marino, Bradshaw, 
and Malamud 2009, 25). Erika Calvo $(2008,34)$ writes that "[i]n societies structured around relations of human domination, the complex and highly diversified nonhuman animate lifeworld is homogenized as 'nature', as 'Other' to the human." In order to imagine otherwise - more inclusively and less violently - educational theory and practice need to continue rethinking what it means to be a subject outside the controlling realm of the human animal. In order to open up the possibility of imagining otherwise and further including the unknown, education for sustainability needs to move away from a relationship to nature as the Other, characterized by reification and possession and caring only for charismatic nonhuman animals.

Even if human-animal relations are only brought up "by accident," as Solveig indicates in the introduction to this chapter, why can focusing on these relations help me say something about the formation of sustainability in education? As I have shown above, these relations seemed both elusive and uncomfortable in the focus group discussions. For instance, the image of the dead pigs helped to denaturalize and re-politicize the nonhuman world as a distant resource for human use. My choice of stimulus material offered those participating in the focus group the means to visually encounter an everyday situation for pigs in our society, where the lives of many pigs are produced in industrial complexes. The elusive and uncomfortable conversations that I analyzed appeared, for instance, as the participants related this image to sustainability education. In the case of subject positions above, animals were often reified, that is, understood in terms of resources for humans to use and abuse. Swedes and Christians were, in some groups, understood as better meat eaters than people from other cultures. The conversations also reflected the view that animals can only become subjects when they resemble us, or when we are forced to see where meat comes from. Only individual animals are granted charisma and seem worth caring for. For discursive formations, there seemed to be a desire to control animals as nature and as something Other than ourselves, as a reified resource. But there were also openings to imagining otherwise with nonsensical fantasies about life after humanity. Here, the nonsensical evoked a future after peak oil and a life after humanity by the use of scenarios of nonhuman animals as both controllable and uncontrollable. Furthermore, animals can be regarded as subjects through the nonsensical sphere of losing control and of seeing suffering and of recognizing that humans, too, are animals. 
In the focus group discussions about sustainability, human-animal relations seemed for the most part to create an understanding of education as a project for an anthropocentric future. However, the ecological crisis requires responsibility that goes beyond the individual encounter and control of others (Haraway 2008a, 158). The current crisis entails, undoubtedly, the "faceless" Others whose lives and health affect us. As Donna Haraway (2015) has noted, the mourning of those ecosystems and species that we have lost needs to be an important part of how we deal with this crisis.

How the unknown Other relates to ideas of the future in the discussion will be analyzed further below, in the last analytical chapter, which focuses on how different notions of the future are handled in education. 



\section{Chapter 7}

\section{Imagining the unknown future}

NORA: $[\ldots]$ the strange thing about our teacher education, which we will never be able to solve is that we educate for a future that we have very few ideas about $[\ldots]$

Environmental change concerns the future. Similarly, education often entails both hopes and fears of the future, and to become educated is to be involved in that which is yet to come. The contemporary political debate in Sweden, for instance, tends to envision a future full of despair, unless the Swedish schools manage to improve students' results in international comparisons (such as the OECD's Programme for International Student Assessment, PISA). Clearly, education is seen as a key institution in the making and securing of the future. The images of the future that are produced and circulated in, and through, education have affects far outside the walls of educational institutions. More importantly, they affect who and what gets included in the making of the future (see e.g., O'Neill and Smith 2014). This chapter looks into how the role of the future in sustainability education is imagined in the focus groups as an elusive and uncomfortable topic. I pose questions about what kind of futures are imagined and how these futures are handled in education, in order to further understand what sustainability is and whom it is for in education. 


\section{The limits to knowledge of the future}

In recent years specific calls for "more" and "better" knowledge through education have become an important matter of concern, emphasized for instance by global and national initiatives in response to calls for strengthened "knowledge societies" (Hargreaves 2003). A recurring discussion in the focus groups concerned how teacher instructors can handle unpredictable, unknowable, and possibly unsustainable futures when knowledge is limited. When it comes to future-oriented concerns that are hard to fully know - such as concerns raised under the umbrella term of "sustainability" - I will suggest that the teacher instructors dealt with these either as unpredictable or unknown elements of the future. Furthermore, these elements lead to different strategies for making sustainability teachable. The mutual existence of unpredictability and the unknown in sustainability education can be illustrated by a warning example featured in a course reading used and discussed by participants in two of the focus groups (Group D and Group N):

The question we face is not what we need to do, because that seems rather clear to those who are analyzing the global situation. The challenge is how to do it in the time available. Unfortunately we don't know how much time remains. Nature is the timekeeper but we cannot see the clock. (Brown 2009, xiii-xiv)

These are the words of American environmental scientist Lester Brown, who has set out to formulate different versions of "Plan B" for humanity. Brown's plan takes as its point of departure what he calls the failed Plan A, explained in terms of business-as-usual. Plan B is about finding solutions and alternatives to the current unsustainable development. Brown's books contain familiar themes, such as the rapid increase of the human population, peak oil, energy use, food management, climate change, and collapsing fisheries, to name a few (see e.g., Brown 2008; Brown 2009). The quote above illustrates both unpredictability and the unknown, and their relation to each other. The unpredictability relates to the fact that we do not know how much time we have in order to make things right for the planet, while we still know that we need to do something. Unpredictability is handled by the conviction that we humans can make things right and take control of the future. The unknown, on the other hand, is indicated in the last part of the quote: "Nature is the timekeeper but we cannot see the clock." Here it is impossible to view and examine the breadth of the problem, and it is also impossible to know who can and 
should take responsibility for resolving it. Here, the agency of the nonhuman world, in terms of an unknowable nature, cannot be controlled and calculated while it also makes the role of the human species highly dubious. The quote above echoes the themes that are of interest in this chapter: how teacher instructors make aspects of unpredictability and the unknown teachable in sustainability education and what the different modes can tell us about the purpose of education.

\section{Handling unpredictability}

Here I will explore how unpredictability influences the kind of futures that can be imagined and how it is handled by the teacher instructors. The role of technology - here exemplified by nuclear energy - was brought up in one of the focus groups as contributing to an unpredictable future:

GERT: $[. .$.$] we know that what they say will happen won't hap-$ pen, and there are some really simple examples you can present to the students: for example why it's not going to happen, and that is the foundation of our economic system, how it works is pretty sick

$[\ldots]$

so I usually tell them, we know that the human economy will function for about 300 years, it's their lifespan, so when you tell people that nuclear power is unproblematic because we'll be able to take care of the waste by setting aside a certain amount of money, when we open the nuclear power station the money will grow, together with the waste, we'll be able to take care of the waste for eternity, we're talking about hundreds of thousands of years, and then we know after 300 years we've lost control over everything, what is sustainable with that you might wonder

GORAN: no it would be very unlikely that our economic system will last longer since no others have

GERT: no usually everything falls apart and then we find something new and we go again

GORAN: it's just when you're in the middle of the downfall you can't see it, I guess

GERT: no

By comparing the lifespan of an economic system with the management of nuclear waste, Gert seems to be imagining a society spinning out of control. A contributing factor to this seems to be a deterministic idea of how systems collapse after a certain period of time. The impossibility of planning for the 
future is visible here, not unlike the management of risks of later modernity as discussed by Ulrich Beck (1992), and further developed by Stacy Alaimo (2010). Technology as unpredictable, which is apparent in the discussion above, creates both doubts and reassuring images of one of the most important rationalities of the modern society (Gyberg 2009, 177-178). Technology, with its close connections to scientific knowledge, can be seen as part of a society characterized by risk (Beck 1992, 155). Storing nuclear waste in order to make nuclear energy safe and sustainable makes the uncertain future a threat. However, Gert seems to claim that we can know that our expectations and estimations will not come true, which is within the realm of the unpredictable. Despite losing control and living in collapsing systems, humanity is imagined to be in some kind of control because of our ability to, in Gert's words, "find something new and we go again." Understanding technology in this way can be said to be in line with contemporary understandings of the Janus face of technology. This means that technology is recognized as having unpredictable and possibly unknown consequences, and as developing momentum to which humans need to adjust (Gyberg 2009, 182). On the other hand, the trust in a renewed development seems to stay intact in Goran and Gert's discussion, as they seem convinced that we will be able to "find something new."

A problem with the unpredictable future is that it seems to cast doubt on the promise of scientific findings. Mats, from another focus group, discusses how scientific development creates both positive and negative effects:

MATS: [...] so I want to get back to this, that I think what we want with sustainable development in education and in education as a general metaphor is to avoid the obviously unsustainable [LAUGHS] given, so to speak, our social, technological frames; I mean the agriculture we had in the 1700s was unsustainable and then we discovered the mineral theory and got artificial fertilizer, suddenly we got a new sustainability in agriculture and we got other environmental problems [...]

By an almost deterministic notion of positive and negative aspects of new discoveries, Mats discusses the unpredictability that occurs when realizing that new discoveries bring problems with them. Despite the surprise element in these discoveries, Mats' discussion is still an answer to the question of where we are going. The unpredictability that can be identified in his discussion is handled by believing in recurring discoveries that seem to constantly create 
new problems and possibilities. Science and scientific development become means of handling unpredictability, and they contribute to maintaining faith in humanity's ability to continue on the path of discovering and conquering the nonhuman world. Analytically, I understand unpredictability as related to the question of in which direction we are going (as something that can be estimated by calculations and predictions), and unpredictability can be handled with the help of knowledge.

To continue, I found that the focus group participants used different strategies to make the unpredictabilities manageable and the education meaningful. For example, despite fearing the unpredictable future, it is assumed in one of the focus groups that education can claim legitimacy only if it holds on to the idea that education can affect and change the future:

GERT: you can't stand there like the guy with the placard "the world will end tomorrow" [LAUGHS]

GISELA: [LAUGHS] but otherwise there is no point in teaching it, if you don't want to bring about some change through education

In this exchange, keeping up good spirits seems to be considered part of teaching and of educational work. Gisela's comment shows the close connotations between education and the future, which makes it necessary to manage unpredictabilities by making environmental change manageable and teachable. Gert and Gisela laugh at the imagined placard guy, which might suggest the unlikelihood of embodying this figure while teaching sustainability: If the world is going to end tomorrow, why do we need education? Another aspect of not losing hope - and of making educational practices as well as education meaningful - is displayed in the next excerpt in which knowledge about vulnerable places is discussed. This discussion follows from the presentation of the images and in particular the Nature-Culture images depicting a tsunami wave:

MELKER: [...] the vulnerable places

MAJ: mm-hmm

MELKER: that in school one could work not only with the vulnerable but with adaptation capacity, consequently how do we prepare for the worst? And year four could go to the fire station and [look at] the municipality and the municipality's policies for how they handle vulnerability and risks, wherever we are, and then one could add a global perspective 


\begin{abstract}
MAJ: mm-hmm
MELKER: something like this: where are the most vulnerable places where threats and risks and, because that's also a way like I said, consequently knowledge prepares us

MERITH: mm-hmm

MELKER: knowledge gives insights into how we relate to our surroundings and here in this case, threats and risks, for every place in the whole world has some kind of threat and risk level, right, so it can give an insight into precisely this thing about vulnerability, and how one can be protected then
\end{abstract}

How do we prepare for the worst thing that can ever happen? One answer to that question is of course that we cannot ever prepare for the worst thing to come, precisely because that thing is unimaginable. For Melker, holding on to the idea that knowledge can save us seems to be one way. The answer to how we can prepare for the worst things to come seems to be through knowledge and insights in order to be "protected." In this way, the worst thing becomes something manageable that can be imagined, traced, resolved, and made teachable. Managing the unpredictabilities in this way makes education and teaching activities that seem meaningful and important for the future. It can be said to serve a psychological function which "allow[s] us to maintain ourselves psychologically while an apocalypse gallops toward us" (Alaimo 2012, 559).

In my analysis above, unpredictabilities represent an understanding of epistemology linked to the possibility of human control but also a potentially problematic separation of humans from the nonhuman world. The whole idea of managing and controlling processes in nature in order to sustain humanity risks making sustainability into "an environmentalism without an environment, an ecology devoid of living creatures other than human beings" (Alaimo 2012, 562). In other words, putting forward unpredictability means risking reinstating human-centered discursive formations and an epistemology in which it is possible to know which futures we are approaching, stances that might have contributed to getting us to this alarming stage in the first place.

\title{
Grappling with the unknown
}

The unknown in relation to the question of whether it is at all possible to know where we are going, is another way of imagining the future in the focus 
groups. Below, I explore what kind of futures the unknown makes possible and whether and how the unknown is made teachable in education by the teacher instructors. The discussion below follows the display of images and more precisely the Nature-Culture theme:

GISELA: [...] we mustn't forget that, it's both the humans and nature that will determine our future

GERT: yes, I think like this sometimes; I have said to the students a few times that we're actually omnipotent, we believe in ourselves way too much, we believe for example that we're able to extinguish all life on Earth, but I actually don't think that's possible, there are way too many strange life forms that don't work exactly the same way we do that always will have a chance to survive even if we kill everything living, such as sulfur fixing [organisms] and [LAUGHS] a number of strange [things]

Contrary to the belief that humanity can manage to extinguish all life on Earth, Gert talks about how he tells his students that this is an impossibility precisely because there are things living on this Earth that we - humans cannot know or control. Despite our best try, according to Gert, humans cannot extinguish life on Earth because of the existence of nonhuman organisms and agency that are impossible to control. Recognizing the agency of the nonhuman environment in co-creating the future shows a potential ethics of downplaying human impact when trying to change the path towards the future. However, anthropogenic agency is also recognized in Gisela's account for "both the humans and nature." The overlap of human and nonhuman bodies with the environment might require more humble understandings and aspirations for our common future in the Anthropocene. This insight can make the nonhuman environment into an unknown element - which cannot and should not be mastered - when making sustainability teachable in education. The unknown requires recognition of the future as more than human or only other than human, and seems to require epistemologies that take into account that the future is not in the hands of humanity alone.

Whether teacher education, and the educational system as a whole, is equipped for such inclusions is a question raised by how the role of the unknown is perceived in one of the focus groups.

OVE: consequently the total relativism of knowledge must also be contested somehow

OSCAR: sure 
OLGA: yes, but what

OVE: these models that we have about the atoms and electrons and so on, it is, they work pretty well today but tomorrow there might be something completely different, how do we motivate the students to learn our models and

The role of the unknown is here highlighted by Ove's claim that the models we have of the physical world can be completely different tomorrow. This short quote shows how there seems to be an assumption that scientific models should last over longer periods of time, but when they are discovered to be faulty or wrong they become hard to handle in education. The assumption here seems to be that education should provide the right answer and stable models, rather than an opening for the unknown. Knowledge is ideally assumed to be something stable. Yusoff and Gabrys $(2011,518)$ argue that contemporary climate science, with its focus on predicting the future "challenge $[\mathrm{s}]$ us to recognize the changed conditions of knowledge production." Knowledge production as speculations about the future indeed forces us to incorporate the unknown as a condition for knowledge. It seems as if the unknown becomes particularly problematic when the aim of education is about teaching specific models rather than viewing models as one way of understanding the world. Showing how different models contribute to different understandings of the nonhuman world seems to be out of the question. Ove seems to see the threat of relativism as a problem when models of the world might turn out to be totally different tomorrow. It becomes apparent that rather than seeing the unknown as a ground for nihilism, and seeing knowledge in terms of static models of the world, more complex epistemologies and ethics are required. Making room for the unknown seems to be a difficult task if knowledge is equated with facts akin to models that students should learn rather than understand in a specific context. The difficulty of making room for speculative predictions shows how the teacher instructors are struggling with incorporating elements of the unknown into the current educational discursive formation of stable knowledge.

The problem of teaching the truth in relation to an issue such as climate change raises an important question: if the knowledge practices that teacher education relies on in order to proclaim sustainability are largely changeable, how can a teacher convince students of the importance of this issue? David, one of the teacher instructors, talks about a dilemma that arose when his students asked him about the truth about climate change: 
DAVID: [...] many students ask, "But what is the truth, then?" Well, but there is no truth if I represent what climate change, it is what we, what our knowledge says today, I can guarantee that in three years, two years, when the next report is released, then nothing I said two years ago will be exactly the same number [...]

As can be seen above, David points to a challenge that he has encountered in his teaching, connected to the changing knowledge about climate change. David's comment about unreachable truths in the case of climate change points to the difficult question of what it means to actually know something. Admitting that the truth is changeable and not static seems to be causing a practical dilemma in David's teaching; how can one teach the urgency of sustainability and yet admit that the truth about an alarming issue such as climate change is constantly changeable? What becomes clear in this example is that knowledge about climate change is possible through a certain unknowability. The nonhuman world is not "out there" to be discovered but rather an active part of, and in, us (see e.g., Alaimo 2012, 563-564). It seems as if knowledge, in relation to climate change, lies closer to the unknown than the unpredictable. Whether the educational practices can deal with this, however, is a different question. What conceptions of knowledge in relation to sustainability lead to the - in many cases - practical discomfort in teaching issues that seem to be hard to fully know? One answer could be that the discomfort rests on a conception of knowledge that might be unfit for dealing with sustainability issues, a conception that seeks the known and that which can be calculated and estimated.

As can be seen above, the role of knowledge production as we know it is questioned and there are no known answers to the question of whether it is at all possible to know where we are going. In other words, the unknown challenges the role of contemporary knowledge in the making of the future. As will be evident below, recognizing and grappling with the unknown future can ascribe agency to nature and make the objectives of education into a non-anthropocentric query. One way in which the unknown could possibly be dealt with seems to be by enforcing worries and anxieties about the future. Several of the participants in the focus groups talked about the necessity of crafting productive fear in sustainability education. These discussions stand in contrast to the mutual wish for happy and positive students, which I explored in Chapter 4. Mats, to name one of them, suggests that "more worries" could be a productive path for change through education: 
MATS: but I'm not afraid of worries, maybe we should have more worries

SOMEONE: [LAUGHS]

MAJ: yes, but

MATS: yes, seriously!

MAJ: yes

MATS: $[. .$.$] you could say that unless there is a strong reason for$ getting involved and changing something it is actually pretty plain sailing

For Mats, the only way to get students seriously engaged in sustainability issues is to make them worried. The threat of the unknown can thus be used in education in order to regulate the feelings of the learning subjects, to shock the students into getting worried. Here worries are seen as productive. Contrary to Mats' belief in worries, his colleague Melker wants the students to be able to solve the problems of the future:

MELKER: [...] I think that in sustainable development as it is written here [in the poem "More of Everything", provided as stimulus material to the focus group participants], environmental degradation, maybe that's more imposing guilt upon

MAJ: mm-hmm

MELKER: and creating worry instead of creating the good student's ability to act in society with tools to, how we can solve the problems?

$[\ldots]$ to give the students the ability to act in society

MAJ: mm-hmm

MELKER: to solve the problems

It is obvious that Melker does not seem as certain as Mats above about whether worries can actually be considered productive in order to encourage people to strive for a more sustainable future. For Melker, it seems to be more important that the students will be able to solve problems in society. Melker and Mats seem to imagine different approaches to the future as they talk about the educational potential of worries. For Melker, the unpredictabilities of the future seem to be manageable, and sustainability-related problems are seen as solvable. His epistemological stance can be expressed with Alaimo's $(2012,561)$ contention that " $[\mathrm{h}]$ uman agency and master plans will get things under control." For Mats, on the other hand, the future did not seem calculable in the same way. In referring to worries, Mats did not seem to believe in a vision of the future as calculable. However, worries can potentially be problematic as they tend to fix positions in ways that do not include the possibility 
of imagining otherwise (Neimanis, Åsberg, and Hedrén 2015). Turning to Sara Ahmed (2010), we might think of the possibility of imagining otherwise as a rather unpleasant experience. Ahmed $(2010,169)$ writes, for instance, that "revolutionary consciousness might be possible only as a willingness to be stressed." I interpret revolutionary consciousness as the ability to imagine otherwise and that what she is pointing to are the possibilities that being uncomfortable, stressed, and unhappy hold for re-politicizing what was once seen as the status quo.

Teaching the students hope, then, becomes a way of having faith in the future. The importance of holding on to visions, despite what awaits us, is discussed:

GORAN: [...] but the only thing we can know is that none of those [different scenarios of the future] will be fulfilled, that we know for sure, it's not going to happen that way and then I think the important thing is to focus on the vision, that can lie within these scenarios of course, and if you work like this, what is it that we want to achieve, what is, how do we want to create the good life, and then I think it is important to start reflecting, what is it that we have to remove, what do we have to add in some way in order to proceed the way forward which is the only way, well there might be many ways, I think that's the important thing in this context

Despite the recognition of the unknown (we know that we cannot know), Goran proposes the importance of focusing on visions of imagining otherwise. Realizing that the sustainability area evokes the unknown, we dubiously focus on dreams and imagination "in order to proceed the way forward which is the only way," again reinforcing one possible scenario of the future which downplays the role of the imagination to take us somewhere else completely. One could even argue that Goran proposes that dreams are necessary in order to make the teaching meaningful. Also, dreams and imagination are powerful means of shaping realities and creating possibilities to become otherwise (Yusoff and Gabrys 2011, 522).

Both unpredictability and the unknown seem to be implicit in the futures formed in teacher education. It is important to clarify the difference between these modes in order to investigate the extent to which education can handle them and include and make room for subject positions and agency that lie outside the realm of the human world. The analytical categories of unpredictability and the unknown have been developed with inspiration from Stacy 
Alaimo's (2012) critical essay Sustainability This, Sustainability That: New Materialisms, Posthumanities, and Unknown Futures, where she asks whom the contemporary sustainability discourse in education and academia cares for. Alaimo holds that sustainability invokes a human-centered future and an epistemology that is linked to technological fixes and management plans, creating the ecological problems as "out there, distinct from one's self" (Alaimo 2012, 561). Her critique is similar to my definition of unpredictability above. She turns her hope to the unknown, which requires epistemologies and ethics that refuse to separate humans from the very stuff of the world.

In my analysis above, the unknown is less easily made teachable in the discussions, compared to unpredictability. The unknown seems to have the potential to open up for complex epistemologies outside the realm of human control and human-centered futures. Despite the presence of the unknown, the teacher instructors seem to have few strategies to deal with the unknown in practice in order to make it teachable. This might suggest that other more speculative modes of imagining the future have a role to play in sustainability education. By analyzing what worries and hope make possible in terms of imagining the future, I showed that worries can be considered one way of creating an opening for the unknown, although, as mentioned above, worries can potentially be problematic as they tend to fix positions in ways that do not include the possibility of imagining otherwise. However, both worries and hopes can be considered investments in the future as an essential component of education.

The next section will focus more specifically on the role of education in trying to handle the future as doomed, and it will explore further strategies for dealing with the unknown.

\section{Imagining a doomed future: Consequences for education}

The notion of an unpredictable, unknown, and doomed future is discussed in different ways in the focus group conversations. By imagining a doomed future, the teacher instructors seem to be dealing with the question of what the point of teaching for a future is if both the teaching and learning subjects, as well as the planet they live on, are doomed. Below, I look into how the idea of the doomsday is envisioned in the focus groups. 
Sometimes sustainability issues seem to open up for possible - even likely scenarios of the extinction of the human race. Some of the focus groups discussed how education should deal with this pressing scenario in a manageable way. This tension can be explained in terms of the urgency to do something and the worry that these actions will not be enough. This tension is interesting because on the one hand, unknowability is a crucial condition of educational relations (Britzman 2010), and on the other hand, becoming knowledgeable is a prerequisite for education. Dealing with a doomed future is considered both important and difficult:

OSCAR: there has been a lot of debate about how this shouldn't be atrocity propaganda, so now it's getting so incredibly cuddlesome especially in the schools

OVE: yes it's a little

OSCAR: sustainable development becomes like a quick fix

OVE: yes that's right

OSCAR: if we only do this and that and if we have wind power plants it will be alright

OLGA: it will be alright, yes

OSCAR: consequently

OVE: yes

OSCAR: it's actually an enormous threat to the survival of humanity that lies upon us

OVE: yes

OSCAR: and that's important, you can't get paralyzed by that threat, right, there are lots of positive things too, but it's important that we don't... so these issues shouldn't lose their serious side either, right

OVE: no

OSCAR: it's an intricate balance between these two

Oscar describes the balancing act between taking the sustainable development issues seriously - by emphasizing possible human extinction - and envisioning them as problems that can be fixed. Taking seriously the survival of the human species is here contrasted with quick fixes such as wind power and "cuddlesome" education in schools, in which the problems are considered highly likely to be managed and resolved. A way of managing a doomed future seems to be to negotiate teaching on a continuum between fear and the willingness to act. Turning to Graham Dawson $(1994,22)$, the formation of collective imaginaries creates a perspective for the self through which "trou- 
bling, disturbing aspects may be managed, worked through, contained, repressed." The unpredictable aspects can be managed and fixed, as I discussed above, whereas it is impossible to know the unknown future. In this example, the notion of a possible future becomes a possibility if it is handled as a serious and important matter of concern in education.

The doomsday is envisioned differently in different parts of the conversations in the focus groups, as well as differently in different groups. The future apocalypse could mean everything from peak oil (Group D) and the food crisis (Group M) to doomsday predictions of the Maya calendar (Group G) and humans trying to extinguish all life on Earth (Group G). Science fiction narratives and radio programs are brought up on these occasions. When the notion of the doomsday is brought up, it is not uncommon for the participants to start laughing:

MAJ: there I think the time perspective that you talk about, both to have a historical understanding and that it is changeable, but the question is how long the time perspective should be, because of this thing about creating anxiety or despair or resignation in the students when you work with it, that's dangerous, because that's something different, I listened to Filosofiska rummet ["The philosophical room," a Swedish radio show that discusses philosophical topics] yesterday evening, they were talking about the time perspective, and one person said "well in one billion years it won't matter what we do, right

MERITH: [LAUGHS]

MAJ: everything will disappear" so like don't do [LAUGHS] so there is everything $[\ldots]$

The laughter in this situation indicates how the notion of the final doomsday can be uncomfortable to deal with for the participants; it seems both hard to imagine and hard to grasp. The situation suggests that, in order to see their sustainability teaching activities as meaningful - or at least not meaningless - the teacher instructors could not allow themselves to accept the notion of the doomsday as real. The psychological function of denying what seems to be an unavoidable future of catastrophic dimensions has been analyzed by Slavoj Žižek (2010, 328 italics in original) as a paradox between knowledge and belief as he holds that "we know the (ecological) catastrophe is possible, probable even, yet we do not believe it will really happen." This psychological function can be understood as a continuous struggle for a subject to form a whole out of a fragmented reality (see e.g., Dawson 1994, 34) and to remain 
functional in a dysfunctional system. The laughter in the quote above can be read as Maj's and Merith's way of forming themselves as functional teacher subjects in relation to a devastating topic that makes human life (including teaching activities) seem pointless. Laughter, even humor, was used when talking about the end of the world in other focus groups as well:

GORAN: 2012, isn't it?

GERT: what?

GORAN: yes it is 2012, the last

GERT: yes that's right, but it

GORAN: the last year

GERT: that Maya counted like that, I recall it was because of, the series of numbers was completed then, that's why they stopped counting there

GORAN: you don't have to count any longer then?

GERT: no [LAUGHS]

GORAN: no, okay [LAUGHS]

GERT: it seems [LAUGHS]

GUNNAR: it will probably be alright

The focus group quoted above was conducted in early 2012, 10 months before the Maya's prediction of the end of the world. By referring to the Mesoamerican Maya calendar, a non-Western, pre-modern system of calendars, the participants are able to talk about the doomed planet in words that make the apocalypse an issue they can laugh about. By using references to previous civilizations, unlike our own, the teacher instructors create nonsensical images of how the doomed future might become. The doomsday becomes both possible to talk about, and a fictional and unlikely scenario. As Gunnar says "it will probably be alright," he creates a reassuring end to the topic, suggesting that the colleagues and their students have nothing to worry about. These examples from the focus group demonstrate how the notion of the unknown future is present in the conversations. It becomes present by the use of that which could only be imagined outside the realm of modern knowledge production, that is, the nonsensical. Other ways of envisioning disasters had to do with topics such as the destructive phase of our current economic system and lifestyles (Group G and Group D).

How is it possible to imagine otherwise? The next quote displays the use of science fiction as a strategy to estrange oneself from one's context: 
GERT: this image is interesting to me [pointing at the HumanMachine-Animal page of the image series]

HANNA: it's the Animal-Human

GERT: to solve everything, the one that's biomechanics, you can call it [pointing at the humanoid machine image] or is it only mechanics? Never mind, I usually say that the solution to all our problems lies in the science fiction series Star Trek, and especially Star Trek Voyager, on the ship where they create a replicator, you just charge it with elements and say: "a cup of tea, please" and it arrives [SEVERAL LAUGHS], everything just materializes, and if we invent it all our problems will be solved except for an initial garbage problem

HANNA: do you use science fiction in your teaching?

GERT: yes, science fiction is actually a way to free yourself from different emotional connections to things and try to see them in a sober light, to remove yourself from your context and see things in isolation

It is possible to argue that the sequence above is an example of bad interview technique on my side - at least I remember thinking exactly that when this interaction took place - because what could Star Trek possibly have to do with sustainability education? However, I think Gert's and my interaction above shows a moment of imagining otherwise which might have been possible because of what the images and the collective processes of the focus groups made possible. Yusoff and Gabrys $(2011,520)$ argue that " $[t]$ he utopian potential of SF [science fiction] is its ability to imagine an outside to scientific knowledge, while maintaining a dialectic relation to it, thus making us aware of our epistemic limitations." This exchange shows why imaginaries are so important to take into account. The irrational, the unknown - the nonsensical - which challenge established ways of understanding the world - need to exist in order to imagine a future in education.

Indeed, there were also moments of imagining the unknown. In a discussion previously analyzed for a different purpose in Chapter 6 (pp. 124-125), the focus group participants were fantasizing about a local site after humanity ceased to exist. In this discussion, they imagined the life of a local snail after the oil had run out. This imagined future that goes beyond the life of humans is far from Alaimo's critique of sustainability, where the illusion and belief in human master plans are assumed to get things under control. Instead, it shows the agency and life of local snails and their possible futures. It can still be argued that the participants account for the future of the snail in a way that 
maintains a separation of human and nonhuman life, as if the snails will continue to live independently of the ecological disasters. However, until the imagined oil peak - nonsensical to the capitalist system - the life and development of the snails are highly entangled with the life and activities of the humans who share the same geographical space with the snails.

In my analysis above, the teacher instructors' imagining of a doomed future seems to open up for some possibilities to include the unknown. Through laughter, fictional scenarios, and science fiction references - indeed the nonsensical - the teacher instructors were able to glimpse the unknown. This conclusion can be viewed as suggesting that in order to handle the doomed future, it is necessary to deal with the unknown. Imagining a doomed future seems to have consequences for the role of education as an activity - and institution - whose objective is to foster humans. However, turning to optimism as a way to maintain the status quo is another strategy that I identified in the focus groups. This strategy seems to lead to portraying the future as both predictable and knowable.

\section{Optimism and the status quo}

Optimism, as an investment and faith in the future to come, can be seen as both a necessity for the idea of education and a potential problem for imagining otherwise. Sara Ahmed (2010) argues in her work on happiness that both optimists and pessimists share a necessary investment in the future, of that which is yet to come. Along these lines, some focus group participants also recognize that dealing with sustainability as an issue of the future is more complicated than dividing it into a question of either optimism or pessimism, rather than seeing the dialectic relation between the two. Lisbeth is one of the participants who questioned this dualism by critiquing the images I had selected under the headline Doomsday-Future Optimism:

LISBETH: and then it is this thing about optimism against pessimism as well, it is something we have talked a little bit about that we have had periods of that here, when we were talking about the environment while teaching and just created future pessimism, talked about all the environmental problems and then it became so incredibly optimistic, and if it is too pessimistic you can't do anything about it because there is no point, and if it's too optimistic it's going to be alright anyway, and it's too, that polarization is not exactly constructive, it's not fruitful but rather it's 
about finding that consequently it's both, and in the same situation you can see different possible paths to take and you have something that you need to do in order to take one path or the other

LISA: active optimism

LENNART: that's right

LISA: [not audible] [LAUGHS]

LISBETH: yes, definitely, this thing about there being different paths to take, but there is also this need to make the world simpler when you describe it, I think that's what the guy from Gapminder means it is, in everything that is going on there is also a lot of positive

LISA: a lot of positive things but also

LISBETH: at the same time

LISA: it shows the power to change

Of importance here for knowledge in education is Lisbeth's recognition of the "need to make the world simpler when you describe it." In my interpretation this means making the world graspable, understandable, and knowable in order to act upon it and be part of it. One could argue that making the world simpler and more certain is a condition for knowledge production, but it could also be argued that the imperative of knowledge production should be to complicate the world and question what we take for granted. As indicated above, teaching sustainability could be described as a balancing act between optimism and pessimism. A too-strong belief in either one of them would not be fruitful for making sustainability teachable and, arguably, meaningful. Two of the focus groups, Lisbeth's group (L) and Group S, brought up the use of Gapminder as a strategy to counter the negative feelings of not being able to do anything. Here, I would like to explore what role Gapminder might be playing in forming the sustainability imaginary in education. Gapminder is a Swedish foundation initiated by a professor of public health, Hans Rosling. Gapminder's goal is "to fight devastating ignorance with a fact-based worldview that everyone can understand" (Gapminder 2015) by presenting visualizations on world health statistics to a wide range of audiences, including, for instance, YouTube and Twitter users. Teachers are one of Gapminder's target audiences, which might explain why this organization seems so appealing to some of the focus group participants. There is indeed a salient promise of knowledge at the heart of Gapminder's message. The world is neither unpredictable nor unknown. By browsing their colorful website of videos 
and visualized statistics presented with a hopeful message, it is clear that Gapminder has an anthropocentric, optimistic, development-focused world view with a promise to the audience that things are getting better for everyone. Of importance for this world view is that we trust and know (believe in) the world through statistical facts. For example, a so-called chimpanzee test is described where Professor Rosling uses chimpanzees as the reference group. Rosling uses bananas to represent different answers in order to get a random outcome to compare with his students' results, and to find out how much his students know about the reality of health improvements in Asia. The "surprising result" is that the students score lower than the chimpanzees and that Rosling's professor colleagues' scores are similar to the chimpanzees', proving the foundation's argument of widespread ignorance. One of Gapminder's most pronounced missions is to stop people from being "ignorant" about the world. Even though Gapminder helps us question stereotypical understandings of developing countries as inherently poor and underdeveloped, it also puts forward a large emphasis on knowing the world through statistical facts and on staying optimistic. As I show above, "facts" have a limited effect for making sustainability teachable and for ethically encountering the unknown Other. On the other hand, the use of facts may indeed serve as a strategy for making stories of the world appealing and optimistic and for making education meaningful. If we only know the facts correctly, things will be alright, it seems. What transformative affects might Gapminder offer?

SANDRA: so that you don't end up in the corner [thinking] that there is no point in doing anything $[\ldots]$ in these kinds of courses with complex issues, consequently that you don't get stuck in [thinking] that everything is miserable so that [not audible]

SOLVEIG: there, Hans Rosling is someone to hold hands with

Clearly, there is an appealing comfort in tuning in to the world of statistics and production of facts when dealing with "complex issues" that make things "miserable." But I will also argue, with the help of Sara Ahmed, that Gapminder is lacking as a companion to sustainability education in its inability to imagine otherwise. What Gapminder is offering is a belief in a bright, hopeful, and known future where things will get better for everyone. There are few words in their material about the effects of global capitalism, of capital accumulation, and of destructive mechanisms of reification of humans, nonhuman animals, and other parts of natureculture. These issues are silenced or ignored in favor of providing a message about a happy future to come. 
Visualizing, talking about, and teaching about the future surely require some kind of visual images, some invoked imagination, which obviously means that particular ways of conceptualizing the future are put forward at the expense of other images that are marginalized (see e.g., O'Neill and Smith 2014). André, in one of the focus groups, asks what an image of the future might look like:

\begin{abstract}
ANDRÉ: [...] and then it's the future, consequently what does an image of the future look like? It's difficult to take such a picture if you have something called future optimism [referring to the image Doomsday-Future Optimism] which I on the one hand think is central to education, which should also talk about teaching, about the future and its possibilities
\end{abstract}

How can you create an image of the future? What does it mean to do so? Evidently, André sees the future as a central part of education and of teaching. The problem of making the issues of the future teachable seems to lie in the inherently unpredictable and unknown aspects of what is yet to come. It could be argued that the future is an absent present in education: we need it in order to legitimize education and make it meaningful, but we also cannot talk about it because then it becomes apparent how political the future is. Even invoking a future with a so-called gaze from nowhere is evidently not a future for everyone. Because really, whose future are we talking about? If we are really to imagine something other than the status quo we need to take seriously the ethical question of who matters, the ontological question of who gets to be, and the political question of who gets to be included in the quest for sustainability. As my analysis above indicates, the current discursive formations are not equipped for these salient ethical, ontological, and political questions of, ultimately, who gets to live and who dies when creating sustainability by means of education.

\title{
Concluding discussion
}

This chapter began by exploring two modes of understanding the relation between the purpose of education and the future, unpredictability and the unknown. I have shown that the two different modes create rather different possibilities for including the nonhuman world in education and for the possibility of creating a "generative space of unknowing" (Yusoff and Gabrys 2011, 517). Unpredictability seems to be handled within dominant discourses of 
knowledge and education. Here, very few things are at stake. It seems possible to maintain that the future can be calculated, by holding on to epistemologies that separate humans from nonhumans. Grappling with the unknown, on the other hand, seems to take place outside the realm of current educational discursive formations on epistemology and knowledge with the help of fantasies and imagination. There are moments where space is given to the unknown, but with a great deal of laughter and the use of, for example, nonsensical jokes and fiction. The potential of the unknown seems to lie outside the realm of rational, calculable knowledge; that which cannot be searched for. It is through the passive encounter, which is not actively searched for, that one can enter into a direct, ethical relation (see Buber 1970). This passive encounter lies, in my reading, outside the realm of the known. Not knowing does not mean ignoring or neglecting relations to the Other; rather, it acknowledges the importance of ethical relationships to what we will never be able to fully know (see e.g., Todd 2003; Biesta 2006a; Säfström 2011). Acknowledging unknowing as an important part of different modes of knowledge might be crucial for developing respectful and humble relations to various Others, including nonhumans, in sustainability education. Therefore it is of importance to investigate which role the unknown can play in education and what the unknown might make possible.

This chapter displays implicit ideas about education's role in society. Living with the imaginaries of a future doomed humanity makes educational aims to foster humans for the future somewhat irrelevant. The teacher instructors seem to be dealing with this dilemma by trying to downplay the threat and limit fear or by decreasing the stress on the possibility of doing anything at all. The gap between being resigned to a doomed planet and installing wind power plants, for example, seems to lead to strategies such as reassuring ourselves that something can be done (by means of knowledge and learning) or by making fear productive (by creating unpleasant visions of the future). However, these strategies create little space for the transforming effects of the unknown.

It could be assumed that the focus group participants, grappling with the possibility of a doomed future, would find their work as teacher instructors to be rather pointless, as Nora might be indicating in the introductory quote of this chapter. However, the focus groups discuss these issues in different ways that seem to make their work meaningful. These strategies include reinstating the 
idea of knowledge as predictable and the future as predictable and calculable. But there were also examples of attempts to include the nonsensical unknown, under certain restrictions. Education as a social institution invokes promises and threats about the future. Nevertheless, the realm of education invokes a human future, and the question of whether education can include nonhumans can be considered as central to the question of whom education cares for (Pedersen 2010b; Pedersen 2010a). Clearly, it seems to be difficult today to include the unknown and to form ethical relations to the nonhuman Other.

Imaginaries of a doomed human species are, as shown above, present in the focus group conversations. However, the promising possibility of taking the sustainability issues seriously also indicates an understanding of humanity as universal ("threat to the survival of humanity"), and the threat to humans as universal. This assumption of sameness ignores the different economic and geopolitical conditions through which people are of this world (see e.g., Haraway 2015, 161). Assuming that we all are the same, and under the same threat, makes the future question into a question that we might not need to deal with today. Certain groups of humans - especially in the global South already live under conditions that make it hard to imagine the idea of a possible bright and sustainable future. The notion of a future threat to us all is thus far from inclusive of Others from both the diversified human and the unknown nonhuman world.

Above, I investigated references to the Gapminder Foundation, which was explicitly mentioned in two of the groups, and discussed the potentials and problems of education turning to optimism as an investment in the future. Holding on to the current status quo seems important here. This could suggest that it is easier to imagine the end of the world than an alternative future. Or, perhaps in the words of Mark Fisher $(2009,1)$ "it's easier to imagine the end of the world than the end of capitalism." Holding on to the status quo as a way to stay happy has also been analyzed by Sara Ahmed (2010) who describes the revolutionary subject as potentially uncomfortable and unhappy. Ahmed $(2010,165)$ helps us understand why: "The silly or ridiculous nature of alternatives teaches us not about the nature of those alternatives but about just how threatening it can be to imagine alternatives to a system that survives by grounding itself in inevitability." It is by investing in the future, in relation to the known now, that we risk reinstating a faith in seemingly depoliticized 
versions of the future and maintaining the status quo. After all, the unknown risks transforming us completely as subjects, for instance, by the extinction of our species. As pointed out by Freud (cited in Bernstein 2008), it is in times of war (taken as a metaphor in this context), when the future is highly unknown, that we are able to grasp what it means to not exist. Indeed, there is a psychological factor in our inability to believe in our own death, both as individuals and as a species. Here the contemporary reassurance and trust in happiness and that things are going to be alright contribute to our inability to imagine radically different futures. What would happen if we were to stop believing in happy endings; might that lead to the possibility of letting go of what we now know (capitalism, carnism, over-consumption, exploitation) in favor of something that we cannot know and imagine today? And, again, in doing so, what would the consequences be for education? Sara Ahmed (2010, 176) argues that "optimism has been confused with neutrality," which I find to be a useful claim to counter the emphasis on reassuring ourselves that things will be alright and to potentially open up for something else. The future might indeed be alright for some, "the millionaires don't go down with the ship" (Plumwood 2002, 2), but certainly not for all, and in this realization lies the political core of teaching sustainability.

Finally, what does all of this say about the sustainability imaginary in education? The subject positions formed above portray a universal humanity which is universally threatened, but also an insignificant humanity that grants agency to the nonhuman world and forces. In terms of discursive formation it is, in case of the unpredictable, human centered, and trust is given to knowledge as a solution and savior. Optimism, through the use of, for instance, statistical facts from the Gapminder Foundation, seems to be one way of maintaining knowledge as certain, predictable, and necessary. But the role of knowledge is also undermined. In the case of the unknown, more room is given to speculations and the fact that the future is not in the hands of humanity alone. Lastly, the nonsensical plays a great role for what I have analyzed above. The nonsensical is displayed through fantasies of a society and world spinning out of control, of a life after humanity, extinction of the human race by the use of per-modern beliefs, science-fiction-inspired scenarios, and fantasies of planetary extinction. Through these nonsensical fantasies it seems possible, at least for a moment, to imagine otherwise. As I have argued, if we really are to imagine something other than the status quo we need to take seriously the ethical question of who matters, the ontological question 
of who gets to be, and the political question of who gets to be included in the quest for sustainability.

Having said that, I will now turn to the final conclusions of this study. 


\title{
Chapter 8
}

\section{Conclusions: The politics of imagining environmental change in education}

\begin{abstract}
LISBETH: we can have extravagant policies but then it's up to the individual to interpret them, and there comes the problem of what you associate with the concept of education for sustainable development and how, is there any, not rule, but something about how broad you can be, or anything about limitations that we can agree upon $[\ldots]$
\end{abstract}

Teaching sustainability seems to be about handling the unknown. As indicated by the teacher instructor Lisbeth above, sustainable development is a widespread notion that both seems open to interpretation and at the same time is strictly situated and embedded within the contemporary society's limits on what may be considered rational and reasonable. That sustainable development cannot mean just anything is clear, even when "it's up to the individual to interpret [it]" in a setting of Swedish teacher education focus groups. Based on the theoretical assumptions of this study, I see these interpreting individuals as situated and embedded in a collective field of natureculture. A basic assumption in this study is also that education is supposed to change those who are subjected to it. This transformative process is necessarily violent: it transforms the subject and makes it become differently with an unknown outcome (Todd 2003). Furthermore, the feminist posthumanities imperative of this study makes it important to ask whether this transformation of the subject should be regarded as pertaining only to humans in education that addresses environmental change. And if the different entangled subject positions of sustainability education really become more than human, what 
does that do to education's raison d'etre as an institution that supposedly forms, disciplines, and educates humans? I have argued throughout this study that human entanglements with the environment pose a number of challenges to the question of what sustainability education seeks to sustain, and for whom. Therefore, the question that will guide this final chapter is as follows: Is education relevant for addressing environmental change?

The focus of this study has been on teacher education, and more specifically on teacher instructors in Sweden. The aim has been to investigate how sustainability is formed in education and to explore how these formations relate to ideas of what education is, and whom it is for. Furthermore, by critically asking what today's sustainability education seeks to sustain, and for whom, this study seeks to contribute to re-politicizing sustainability in education. In this concluding chapter I want to specifically discuss the overall problem of what it takes for education to make itself relevant and meaningful in the context of environmental change. Special attention will be given to how the unknown and the role of the Other in education were brought up throughout the analyses in previous chapters, and by returning to and expanding on some of the main identified challenges that sustainability seems to pose to education, I will also discuss what a re-politicization of sustainability might mean.

\section{Tracing the sustainability imaginary in education}

Whichever concept one prefers to use, sustainability or sustainable development, none of the participating teacher instructors in this study gave a direct answer to how they define sustainability in their teaching. Vague references to the definitions in the Brundtland Report, repeated claims about the problem of defining sustainable development, and references to courses and course modules were the usual ways of responding to the question of definition. Furthermore, it was not immediately possible to locate sustainable development within the recent reform process of Swedish teacher education. To trace the definitions and delimitations of the concept when making it teachable, I used stimulus material in the focus group interviews, such as a poem and images that were rich in meaning. Not all social categories, conventions, and norms included in imaginaries are necessarily sensical or factual, and using visual images has been a way to capture what falls outside of these descriptions. The images, with their excess of meaning, were helpful in opening up the discussions on the contradictory and conflictual aspects of 
contemporary human meaning-making about sustainability in education. I have argued that the formation of imaginaries is a collective and social process that is at the same time also contextualized and situated in specific individuals. I have studied the collective - yet situated - formations of sustainability in education through a gradual focus on the elusive and uncomfortable themes and discussions in focus groups with teacher instructors. This has been a way of finding an analytical focus while interpreting and working with the focus group material and its nearly 700 pages of rich and multifaceted transcripts. What in these transcripts could help me understand what sustainability is in education? By closely investigating those occasions where it became apparent in the discussions that knowledge is not the only mode through which we come to understand a phenomenon such as sustainability, I settled on looking more closely into the elusive and uncomfortable moments in the focus groups. By reading and selecting quotes based on the six criteria I presented in Chapter 3, I have worked with imaginaries as the guiding theoretical concept to take into account the unforeseen discussions in the focus groups. I have presented the notion of the nonsensical, which I see as a complement to subject positions and discursive formations - concepts that have all been helpful for understanding the formations of sustainability that took place in the focus groups. These three dimensions together form the sustainability imaginary I have been after in this study. As contradictory as it may sound at first, nonsensical aspects are crucial for making sense of sustainability in education. My notion of the nonsensical is not to be mistaken for something that does not make sense at all. The nonsensical in this context is rather about how we make use of things that are not only sensical and factual when we try to make sense of something. Really trying to take seriously the fact that more knowledge is not going to turn things around for most humans, and trying to theorize other modes of relating to the world through education, are contributions of this study that will be discussed further below.

The critical questions of what education for sustainability or sustainable development makes possible and who it involves are not often asked in educational research on sustainability. However, these critical questions are of importance for unraveling structures of power and for providing new possibilities through environmental change. I have chosen to study those who carry out Swedish teacher education as a way to study the sustainability imaginary. I made this choice because of Sweden's long tradition of being perceived, both 
domestically and internationally, as ambitious when it comes to environmental initiatives and policies. Sustainability is a general goal for the Swedish educational system. For these reasons I argued that Sweden in general, and Swedish teacher education in particular, offers an interesting case for studying how sustainability is imagined and made teachable. Furthermore, the position as a teacher instructor is seen as crucial for investigating the formation of sustainability and its subject positions precisely due to the location of the teacher instructor at the intersection of various educational and knowledge practices. The questions of who the future teachers should be, what they should know, and how they should teach are explicitly and implicitly political issues intertwined with questions such as what a good society is and which views on knowledge should guide the educational system.

The analytical chapters showed that sustainability and sustainable development in education point toward the future and what is yet to happen. However, sustainability also seemed to be handled by holding on to the now by, for instance, emphasizing the importance of accepting our current situation and staying happy with the futile choices that we have. Also, surprisingly strong norms of disembodied teaching showed how difficult (yet necessary) it is to claim visibility in the role as a teacher of sustainability. Furthermore, sustainability seemed to make it quite possible to continue to relate to nature as a commodity. However, it was in the focus group discussions that were specifically about the future where it became most apparent that sustainability in education seemed to require something else. It was then by going into the details of the politics of the mundane and the taken for granted that I have been able to show how various relations of power operate within the sustainability imaginary in education. Finding these often taken-for-granted political acts requires me to now attempt a re-politicization of sustainability in education.

\section{Re-politicizing sustainability}

Many of the published studies I have reviewed on educational research relating to sustainable development and sustainability display a rather anthropocentric approach to sustainability issues. The nonhuman environment is often discussed as a resource for human use. To counter this, the educational researcher Michael Bonnett (2002) shows how sustainable development as a 
policy in education relates to ethical, epistemological, and metaphysical aspects of our understandings of what it means to be human. Furthermore, sustainability tends to be imagined within existing and taken-for-granted norms of what a good society is. This study can be seen as a contribution to re-politicizing sustainability through my attempts to understand how sustainability is imagined within existing and taken-for-granted norms of what a good society is, as well as my attempts to show when those norms are challenged.

When outlining the theoretical framework of this study I have made clear that knowledge and imagining are far from neutral processes, and what we come to take as rational, known, and taken for granted at a certain point in time may indeed be seen as an effect of politics with ethical and ontological connotations. In the introduction I argued that sustainability may be seen as part of a contemporary post-political condition in which contested issues involving power relations come to be seen as devoid of politics (Swyngedouw 2003; Žižek 2008; Bradley 2009; Blühdorn 2013). Previous research shows that climate change is such an issue (see e.g., Swyngedouw 2003; Swyngedouw 2010; Anshelm 2012; MacGregor 2013). I argue that sustainability is yet another one. I have also argued for the necessity of a feminist posthumanities imperative in a study that critically concerns itself with the entanglements of human and nonhuman worlds. There is, however, a significant difference between stating that a phenomenon such as sustainability education is political and trying to (re)politicize it, that is, make it visibly conflictual. I have held that research responding to the environmental change of our time should investigate the relation between the known and the unknown in the making of futures. Now the time has come for me to re-politicize sustainability with the help of the analyses in the previous chapters. I will do this by discussing four areas of re-politicization which cut across the analytical chapters and correspond to the aim and research questions of this study. These four areas, outlined below, are posed as problems or questions that I suggest need to be addressed in order to re-politicize sustainability in education.

\section{The prospect of unhappiness and mourning}

Fear, as argued for instance by Sherilyn MacGregor (2013, 5), can contribute to paralyzation and abandonment of attempts to see an issue such as climate change as political. The analyses in this study have shown that most focus groups most of the time were strong advocates of optimism and of keeping up 
good spirits when teaching sustainability. I argue that there might be at least three reasons for this tendency. The first reason has to do with the purpose of education. Since the imperative of education must be said to invest in that which is yet to come by justifying the practices of the now, the status quo becomes the only available option. For instance, as shown in Chapter 4, consuming certain Eco-branded products was regarded both as problematic and as a solution to alleviate feelings of despair. In that way, no alternatives to the status quo (as in consuming in the name of sustainability) could be formulated. I have on several occasions turned to the work of Sara Ahmed (2010) to problematize and discuss what the fixation on happiness and feeling good might mean. For Ahmed, it is through feeling at odds with the world that we might create the possibility of imagining otherwise:

It is no accident that revolutionary consciousness means feeling at odds with the world, or feeling that the world is odd. You become estranged from the world as it has been given: the world of good habits and manners, which promises your comfort in return for obedience and good will. (Ahmed 2010, 168)

It should be clarified that not everyone will have the luxury of feeling good and well in the contemporary world. Those who are the Other to those with the potential to feel well, such as slaughter animals, people who inhabit flooded lands, and insects subjected to pesticides and chemicals (who are hardly regarded as in positions as subjects) already suffer the costs in terms of difficult life conditions and death, and of contemporary capitalism and other systems of domination and exploitation. Therefore, in the same vein as Ahmed, I want to suggest that the field of sustainability education might involve some unhappiness - or rather mourning - at least in the sense of letting ourselves feel the weight of our existence and the unknowability of our future.

The second reason for optimism has to do with an understanding that knowledge should be separated from the knower and, ultimately, preserve the status quo. In Chapter 5, I directed attention to the uncomfortable practices of teaching for a sustainable future. I teased out how the ideal of neutrality seemed to be in conflict with a situated, embodied teacher subject. Here, the expectation that they teach what was perceived as sustainable created a tension through the unspoken question of for whom a certain practice is regarded as right and sustainable. This tension shows that knowledge, no matter how deeply it has been wrapped into "the deadly image of the Same" (Haraway 
1992, 297), is always already situated from a specific point of view which requires accountability (Haraway 1988). This tension makes sustainability education a necessary political balancing act in an educational landscape, which continues to hold on to the ideal of the neutral teacher but at the same time makes teacher instructors uncomfortably visible as private individuals whose lives outside the university walls matter for teaching sustainability. This tension entails the potential to challenge the status quo of sustainability education by holding the unmarked position of the knower/teacher responsible for the knowledge taught in the teacher education classroom. Sustainability became, arguably, somewhat re-politicized when the teacher instructors collectively tried to make it teachable. Previous research on how teachers interpret and work with sustainability shows that they experience difficulties and obstacles on both a professional and personal level (see e.g., Bursjöö 2014; Hasslöf 2015). Furthermore, this visibility might expose the current lack of alternatives for imagining otherwise, but might also bring about the potential to let ourselves be unhappy and to mourn our precarious existence of pleasure and pain. Katarina Ottander (2015) argued in a recent study that high school students in Sweden use scientific reasoning to justify their own subject positions, which creates both a sense of powerlessness and individual responsibility. The students negotiate meaning from psychological and ideological factors, rather than scientific facts. Thus it is time to realize how emotional and nonsensical our meaning-making about sustainability really is.

A third reason for the tendency towards optimism might have to do with how education teaches us to relate to the Other. It is only by staying positive that we can maintain our ability to see the Other as a commodity not worthy of our care. Education's raison d'etre can be said to inspire hope and secure the future of a nation. But if this hope for the future is possible only within frames of reification and consumption, and by holding on to what we have now, it might be time for education to let the unhappy and mourning subject in. It should be clarified that I primarily locate my claim about unhappiness and mourning with the affluent groups of the global North and West, whose imagination I think might really need to change. I do not mean that it is necessary to understand contemporary environmental change in terms of "negative framing," as criticized by Neimanis, Åsberg, and Hedrén $(2015,78)$, but rather that there is potential in stopping for a moment to realize that, as Val Plumwood $(2002,2)$ observed, "the millionaires don't go down with the ship." As argued by Kathryn Yusoff and Jennifer Gabrys (2011), apocalyptic 
narratives may have some value in raising awareness. Realizing how inequalities are maintained by our holding on to what we have now might open up for a potential strategy of re-politicizing sustainability and questioning the status quo, which I consider to be one of the contributions of this study.

\section{The role of the nonsensical in educational imaginaries}

Another contribution of this study is the introduction of the nonsensical as a vital component of educational imaginaries. We need the nonsensical to make sense of sustainability. My analyses show that the nonsensical does play a role in the formation of sustainability and in the storytellings that make sustainability teachable. But a related question to ask is whether the nonsensical is teachable, as part of education's raison d'etre. My answer is both yes and no. Yes, if we are prepared to look beyond the boundaries of knowledge and meet the Other as an absolute alterity by accepting the unknown and the multiplicity of reality. And no, if by "knowledge" we are referring to something that is certain and stable. For Slavoj Žižek $(2008,46)$, the most difficult ethical task of today is to unlearn "the most basic coordinates of our immersion into our life-world: what usually serves as the resource of Wisdom (...) is now THE source of danger." He discusses the paradoxes in the fact that we cannot rely on either scientific knowledge or our common sense in deciding how to do things differently. Furthermore, the call for change entails a risk of changing for the worse, which might even "have the unintended consequence of triggering a catastrophe" $(2008,44)$. Turning towards the unknown is a risky strategy. Žižek's critique is in line with Sara Ahmed's (2010) analysis of unhappiness as a fear of something else. This argument can explain why most of us are so focused on investing in a future of happiness that is not radically different from today. Our investment in the certain by believing in happiness and progress "unavoidably locks us back into the structure of Western thinking, which postulates this idea of eternity that allows us to distinguish ourselves from nature" (Scanlan 2005). Introducing the nonsensical might essentially mean challenging education's raison d'etre, which can also be regarded as a strategy of re-politicization. As I have already pointed out, my notion of the nonsensical is not to be mistaken for something that does not make sense at all. The nonsensical in this study is about how we make use of things that are not only sensical and factual. In my opinion, educational research needs to find ways to grasp the nonsensical, ways that perhaps do not fit neatly into the categories of what we know today, and how we have learned to relate 
to each other. Attempts to relate differently are already taking place within posthumanities educational research (see e.g., Hagström 2014; Ceder 2015). When we cannot fit educational content, or that which suddenly makes itself relevant, into valuation models, we might really be onto what a sustainable way of relating to Others through education might mean. Really trying to take seriously the fact that more knowledge is not going to turn things around for humans, and trying to theorize other modes of relating to the world through education, are key contributions of this study.

\section{Education for the unknown}

Empirically, this study shows that subject positions of sustainability are formed hierarchically through notions of sameness rather than difference. This point was especially highlighted in Chapter 4 and Chapter 6 . This analysis has been possible through my use of a feminist understanding of how differentiation is made, and of how power and norms operate in ordering the world, with consequences for those inhabiting it. As Donna Haraway (1992, 297) critically observes, "transcendental naturalism (...) refuses a world full of cacophonous agencies and settles for a mirror image sameness that only pretends to difference." I now want to ask: How can sustainability be imagined in a way that includes the unknown Other? In Chapter 6, which focused on human-animal relations, the notion of sameness was operating by recognizing and violently caring for certain individual animals through possession and control. However, those species of animals that do not qualify as worthy of being preserved and displayed (such as domesticated slaughter animals) were not even regarded as animals, but reified as commodities. One important point of discussing human-animal relations in detail was to show that the boundaries of the relations are significant for the painful political, ontological, and ethical question of who gets to live and who dies through the sustainable imaginary in education. In Chapter 7 , I showed the limited possibility of grappling with the unknown in teacher instructors' handling of the future. The chapter opened up the question of the (difficult/impossible) relation between education and the unknown (that which cannot be captured and controlled), which I claim is an ethical question of recognizing the nonhuman world outside the realm of rational, calculable knowledge. I find the question of whether education can include the unknown Other to be central for the issue of whom education cares for. 
I have proclaimed a turn to the unknown elsewhere (Sjögren 2014b) by arguing for the necessity of mutual knowing - unknowing as a way to challenge conventional educational agendas of disciplining and raising the future. In many ways, the unknown goes against contemporary, modern ways of understanding the role of education. I hold that conventional understandings of education are problematic in relation to sustainability. These understandings display the contemporary impossibility of recognizing the agency of the nonhuman world. However, thinking in terms of the possibilities of the unknown is far from innocent as it runs the risk of reinstating nihilist arguments. The danger of unknowability is evident in examples from politicians from the far right, who tend to make a point of claiming racist, sexist, and other offensive things without appealing to either knowledge or facts. The unknown in the case of the far right might be seen as the perfect notion for appealing to affect rather than scientific sense and knowledge. The majority of climate change deniers in Sweden, for instance, are conservative men who have invested greatly in an industrial modernity rationale, but who are skeptical of the results presented by climate scientists (Anshelm and Hultman 2014). However, the relativist, anti-scientific claims of the conservatives and far right supporters tend to start out from an unaccountable and anthropocentric point of view in which the health and survival of nonhumans, and vulnerable groups of humanity, are ignored. The unknown in my sense of the word is a much more curious notion that aspires to open up to the more than human world. Therefore I maintain that unknowability is a possibility, but it is not a possibility without risk. The shifting positions of knowing and unknowing constitute a political matter on many levels.

Strategies for knowing and educating others make use of the idea that emancipation and societal change often happen through knowledge and knowing (Biesta 1998, 500). The kind of subject positions education makes possible depends to a large extent on which views of education are dominant in society. I hold that grappling with the unknown shows the importance of developing theoretical perspectives and practical strategies that make room for that which lies outside preconceived structures and categories. In order to imagine otherwise - more inclusively and less violently - educational theory and practice need to continue rethinking what education means, and whom it is for, outside the realm of the sameness and the idea of humanity as separated from the nonhuman world. Altogether, a common politically and ethically important focus for posthumanities is the questioning of humans at the center 
of knowledge production (Braidotti 2013). This is a particularly interesting and challenging quest for educational research's conventional focus on the educable subject, built on Enlightenment ideals of what humanism is (Pedersen 2010b). In other words, education needs to continue to open up for understanding and working with education in a non-anthropocentric way. In order to open up the possibility of imagining otherwise and further including the unknown, education for sustainability needs to move away from a relationship to the Other characterized by sameness, which grants subjectivity only to very specific (human) beings. I consider this study to be a contribution to posthumanities educational studies through my focus on sustainability education. Previous studies I encountered in my review on posthumanities educational research tended to focus on methodological issues, for example (see e.g., Mazzei 2013; Johansson 2014). Just like imagining nature outside the zoo - an institution that holds certain beings in captivity in order to foster knowledge about and care for particular species - education could strive to operate outside the boundaries of the ordered and the known. This is also why I introduced the concept of the nonsensical, to grasp both discursive formations and something else. Striving to include the unknown as a risky yet somewhat necessary project can be regarded as a strategy of re-politicization. In fact, as argued by Val Plumwood $(2002,4)$ and others, knowing can be destructively associated with the mind rather than the body with the risk of neglecting and ignoring corporeal and affective ways of being both in and of the world. More sustainable ways of relating to Others may not be a question of knowing more about them, but rather about finding ways of relating to the unexpected and nonsensical aspects of life.

\section{Images and the imaginary}

The images I used as stimulus material in the focus groups arguably helped in re-politicizing what sustainability could be. The images, with their richness in meaning, were important for opening up the discussions to the contradictory and conflictual aspects of contemporary meaning-making about sustainability. Some of the images, especially the pig image, subjected the participants to something cruel and nasty which - arguably - is ethically questionable. Subjecting someone to images of Other (human) suffering has been discussed as both dehumanizing and eye-opening (see e.g., Sontag 2013). Publishing pictures of dead refugee children fleeing from the Syrian war has recently been criticized and defended with exactly these arguments. Even 
though I can agree that there are problems with publishing and displaying images of Others' suffering, which "we" see from a distance, I will maintain that the cause in this case justified doing so: the image of dead pigs worked to address the seemingly unproblematic question about whom sustainability in education cares for, by displaying a practice behind the norm of eating meat. Looking back at the focus groups, there are images that I would have chosen differently or would remove if I were to do the interviews again. I would also choose fewer images so that the discussions could have been more focused. Nevertheless, with my assumption about knowledge as situated and embedded, the images did offer a way of displaying my situatedness, my gaze from somewhere, to the focus group participants. The participants criticized the images as too simplistic, dualistic, and anthropocentric, but most also acknowledged how the images were recognizable and well chosen. For anyone interested in studying an imaginary, I think images as a tool in interviews is a fruitful way of getting at that which goes beyond the rational, real, and knowledgeable.

\section{What now? The politics of imagining environmental change in education}

Overall, the analyses in this study showed that the sustainability imaginary for the most part is limited when it comes to imagining otherwise. Much of the collective imagining in the focus groups made use of the rational, the calculable, and the known. However, the teacher instructors were also visibly troubled by these understandings. The lack of visions and dreams can be understood as part of the post-political condition that has been ascribed to sustainability politics. Erik Swyngedouw $(2014,28)$ holds that nature is "necessarily radically imagined, scripted, and symbolically charged as Nature" to which a wide range of discursive formations and nonsensical fantasies are attached and, more importantly, emptied from visible conflicts and desires for a different world and future. However, the naturalized understandings of Otherness as a reduced version of the self will just not do as an image of thought in sustainability education that aims to care and educate for our common future.

I want to suggest that education can make itself meaningful in the sustainability domain only if it can be open to the unknown, the nonsensical, and the unhappy and mourning subject. On the one hand, these aspects can be seen 
as an abyss in the educational landscape with its raison d'etre of teaching the future generations certain knowledge areas and values. On the other hand, education always entails other aspects in the sense that an educational outcome, or becoming, can never be certain. In order for learning to take place, one has to take a leap into the unknown. This study, together with other related studies, shows that the unknown, the nonsensical, and the unhappy and mourning subject get very little space in educational practices (see e.g., Gyberg 2003; Ottander 2015). This suppression, or ignorance, of the unknown, the nonsensical, and the unhappy and mourning subject must be understood in the context of contemporary education as an arena that seeks the certain and the known through standardized models of evaluation, such as the PISA study mentioned in Chapter 7. How can sustainability issues, which indeed entail unknown matters, become teachable in an educational landscape that seeks certainty? This question relates to several aspects of education as a practice of disciplining and securing the future. What if the question were asked differently: Can education take the risk of opening up for the unknown, the nonsensical, and the unhappy and mourning subject as well as nonhuman dimensions with an outcome that we cannot know beforehand? In short, can education form future citizens as more than human entanglements? This seems to be a difficult, yet necessary, question to ask. The neoliberal influence on contemporary educational discursive formations must not be understated here. As argued by Chantal Mouffe (2005), the contemporary post-political condition makes it difficult to challenge the neoliberal hegemony in much of today's world. The current educational landscape in Sweden is characterized by a competitive market rationale in which the purpose of education becomes for the individual to perform well globally (Sjöberg 2011, 64). Furthermore, the hegemonic formations of the free and rational individual, which is a figure of thought that has become influential in so many different arenas globally and locally, such as education, health care, and environmental politics (see e.g., Bradley 2009; Henriksson 2014; Dahl 2014; Johansson Krafve 2015), form sustainability in education as a seemingly depoliticized project and a responsibility of the individual. Feminist researcher Emmy Dahl (2014) argues that responsibility for the environment becomes an individual moral obligation rather than a societal obligation. In the educational field, Malin Ideland and Claes Malmberg (2015) argue that education for sustainable development is well suited for the market economy's belief in 
the responsibilities and choices of the free subject. They write that "the political project of sustainable development becomes apolitical and impossible to resist" (Ideland and Malmberg 2015, 181). However, the elusive and uncomfortable aspects of teaching sustainability show that sustainability education as non-political is a figure of thought that is of little use when making sustainability teachable. Embracing the unknown, the nonsensical, and the unhappy and mourning subject in education is about demanding the impossible and about giving sustainability a fair chance in education. What we do not need is contemporary understandings of knowledge as static, separated from the knower, and easily managed and measured for comparison purposes. Rather, what sustainability education needs is a different ontology. An ontology, or ontologies rather, where more creatures and forces can come into being, and more of us can imagine environmental change otherwise through education. 


\section{References}

Adams, Carol J. 2010. The Sexual Politics of Meat: A Feminist-Vegetarian Critical Theory. New York: Continuum.

Ahmed, Sara. 2010. The Promise of Happiness. Durham: Duke University Press.

Alaimo, Stacy. 2000. Undomesticated Ground: Recasting Nature as Feminist Space. Ithaca: Cornell University Press.

Alaimo, Stacy. 2008. "Trans-Corporeal Feminism and the Ethical Space of Nature." In Material Feminisms, edited by Stacy Alaimo and Susan J. Hekman, 237-64. Bloomington: Indiana University Press.

Alaimo, Stacy. 2010. Bodily Natures: Science, Environment, and the Material Self. Bloomington: Indiana University Press.

Alaimo, Stacy. 2011. "Det nakna ordet: Den protesterande kroppens transkorporala etik," Tidskrift för genusvetenskap no. 4: 29-58.

Alaimo, Stacy. 2012. "Sustainable This, Sustainable That: New Materialisms, Posthumanism, and Unknown Futures." PMLA 127 (3): 558-64. doi:10.1632/pmla.2012.127.3.558.

Alvesson, Mats. 2013. The Triumph of Emptiness: Consumption, Higher Education, and Work Organization. Oxford: Oxford University Press.

Aman, Robert. 2014. Impossible Interculturality?: Education and the Colonial Difference in a Multicultural World. Linköping: Linköping University.

Anshelm, Jonas. 2012. Kampen om klimatet: Miljöpolitiska strider i Sverige 2006-2009. Storå: Pärspektiv. 
Anshelm, Jonas, and Martin Hultman. 2014. "A Green Fatwā? Climate Change as a Threat to the Masculinity of Industrial Modernity." NORMA 9 (2): 84-96. doi:10.1080/18902138.2014.908627.

Appadurai, Arjun. 1996. Modernity at Large: Cultural Dimensions of Globalization. Minneapolis: University of Minnesota Press.

Ball, Stephen J. 2008. The Education Debate. Bristol: Policy Press.

Barad, Karen. 2000. "Reconceiving Scientific Literacy as Agential Literacy, or Learning How to Intra-Act Responsibly within the World." In Doing Science + Culture, edited by Roddey Reid and Sharon Traweek. New York: Routledge.

Barad, Karen. 2003. "Posthumanist Performativity: Toward an Understanding of How Matter Comes to Matter.” Signs 28 (3): 801-31.

Beck, Ulrich. 1992. Risk Society: Towards a New Modernity. Translated by Mark Ritter. London: Sage.

Bennett, Jane. 2010. Vibrant Matter: A Political Ecology of Things. Durham, NC: Duke University Press.

Bernstein, M. Jay. 2008. “In Praise of Pure Violence (Matisse's War).” In The Life and Death of Images: Ethics and Aesthetics, edited by Diarmuid Costello and Dominic Willsdon, 37-55. London: Tate Publishing.

Bertilsson, Emil. 2009. "Lärarstudenterna. Förändringar i rekryteringen under perioden 1977-2007.” Praktiske grunde: Nordisk tidsskrift for kultur- og samfundsvidenskab no. 4: 19-42.

Biesta, Gert. 1998. "Say You Want a Revolution... Suggestions for the Impossible Future of Critical Pedagogy." Educational Theory 48 (4): 499-510. doi:10.1111/j.1741-5446.1998.00499.x.

Biesta, Gert. 2006a. Beyond Learning: Democratic Education for a Human Future. Boulder: Paradigm Publishers.

Biesta, Gert. 2006b. Bortom lärandet: Demokratisk utbildning för en mänsklig framtid. Translated by Gunnar Sandin. Lund: Studentlitteratur. 
Bird Rose, Deborah, Thom van Dooren, Matthew Chrulew, Stuart Cooke, Matthew Kearnes, and Emily O’Gorman. 2012. “Thinking through the Environment, Unsettling the Humanities." Environmental Humanities, vol. 1: 1-5.

Birke, Lynda. 2012. "Unnamed Others: How Can Thinking about 'Animals' Matter to Feminist Theorizing?” NORA - Nordic Journal of Feminist and Gender Research 20 (2): 148-57. doi:10.1080/08038740.2012.674059.

Björneloo, Inger. 2007. Innebörder av hållbar utveckling: En studie av lärares utsagor om undervisning. Göteborg: Göteborg University.

Björneloo, Inger. 2008. Hållbar utveckling: Att undervisa utifrån helheter och sammanhang. Stockholm: Liber.

Blühdorn, Ingolfur. 2013. “The Governance of Unsustainability: Ecology and Democracy after the Post-Democratic Turn.” Environmental Politics 22 (1): 16-36. doi:10.1080/09644016.2013.755005.

Bodén, Linnea. 2013. "Seeing Red? The Agency of Computer Software in the Production and Management of Students' School Absences." International Journal of Qualitative Studies in Education 26 (9): 1117-31. doi:10.1080/09518398.2013.816887.

Bonnett, Michael. 2002. "Education for Sustainability as a Frame of Mind." Environmental Education Research 8 (1): 9-20. doi:10.1080/13504620120109619.

Bradley, Karin. 2009. Just Environments: Politicising Sustainable Urban Development. Stockholm: KTH Royal Institute of Technology.

Braidotti, Rosi. 2013. The Posthuman. Cambridge: Polity.

Britzman, Deborah P. 2010. The Very Thought of Education: Psychoanalysis and the Impossible Professions. New York: State University of New York Press.

Brons, Lajos. 2015. “Othering, an Analysis.” Transcience 6 (1): 69-90.

Brown, Lester Russell. 2008. PLAN B 3.0: Uppdrag: Rädda Jorden! Stockholm: Addera.

Brown, Lester Russell. 2009. Plan B 4.0: Mobilizing to Save Civilization. New York: Norton. 
Bryld, Mette, and Nina Lykke. 2000. Cosmodolphins: Feminist Cultural Studies of Technology, Animals and the Sacred. London: Zed.

Bryman, Alan. 2016. Social Research Methods. 5th ed. Oxford: Oxford University Press.

Buber, Martin. 1970. I and Thou. Translated by Walter Kaufmann. New York: Simon \& Schuster.

Buchanan, John. 2012. "Sustainability Education and Teacher Education: Finding a Natural Habitat?" Australian Journal of Environmental Education 28 (2).

Bursjöö, Ingela. 2011. "How Student Teachers Form Their Educational Practice in Relation to Sustainable Development." Utbildning \& Demokrati 20 (1): 59-78.

Bursjöö, Ingela. 2014. Utbildning för hållbar utveckling från en lärarhorisont: Sammanhang, kompetenser och samarbete. Göteborg: Göteborg University.

Butler, Judith. 2011. Osäkra liv: Sörjandets och våldets makt. Translated by Sarah Clyne Sundberg. Hägersten: Tankekraft.

Cakici, Baki. 2013. "Sustainability Through Surveillance: ICT Discourses in Design Documents". Surveillance \& Society 11 (1/2): 77-89.

Calvo, Erika. 2008. “'Most Farmers Prefer Blondes': The Dynamics of Anthroparchy in Animals' Becoming Meat." Journal for Critical Animal Studies VI (1): 32-45.

Campbell, Coral, and Ian Robottom. 2008. "What's in a Name? Environmental Education and Education for Sustainable Development as Slogans." In Environmental Education: Identity, Politics and Citizenship, edited by Edgar González-Haudiano and Michael A. Peters, 195-206. Rotterdam: Sense Publishers.

Ceder, Simon. 2015. Cutting Through Water: Towards a Posthuman Theory of Educational Relationality. Lund: Lund University.

Ceulemans, Carlijne, Maarten Simons, and Elke Struyf. 2012. "Professional Standards for Teachers: How Do They 'Work'? An Experiment in Tracing 
Standardisation In-The-Making in Teacher Education." Pedagogy, Culture \& Society 20 (1): 29-47. doi:10.1080/14681366.2012.649414.

Collins-Figueroa, Marceline. 2012. "Biodiversity and Education for Sustainable Development in Teacher Education Programmes of Four Jamaican Educational Institutions." Journal of Education for Sustainable Development 6 (2): 253-67. doi:10.1177/0973408212475257.

Dahl, Emmy. 2014. Om miljöproblemen hänger på mig: Individer förhandlar sitt ansvar för miljön. Göteborg: Makadam.

Dahlbeck, Johan. 2014. "Svensk förskola mellan universell moral och rationell ontologi." Pedagogisk forskning i Sverige 19 (2-3): 173-92.

Dahlgren, Madeleine Abrandt, and Gunilla Öberg. 2001. "Questioning to Learn and Learning to Question: Structure and Function of Problem-Based Learning Scenarios in Environmental Science Education." Higher Education 41 (3): 263-82. doi:10.1023/A:1004138810465.

Danaher, Geoff, Tony Schirato, and Jen Webb. 2000. Understanding Foucault. London: Sage.

Dawney, Leila. 2011. "Social Imaginaries and Therapeutic Self-Work: The Ethics of the Embodied Imagination." The Sociological Review 59 (3): 535-52. doi:10.1111/j.1467-954X.2011.02015.x.

Dawson, Graham. 1994. Soldier Heroes: British Adventure, Empire, and the Imagining of Masculinities. London: Routledge.

Derrida, Jacques. 2008. The Animal That Therefore I Am. Translated by MarieLouise Mallet and David Wills. New York: Fordham University Press.

Dibley, Ben, and Brett Neilson. 2010. "Climate Crisis and the Actuarial Imaginary: 'The War on Global Warming.” New Formations 69 (1): 144-59. doi:10.3898/NEWF.69.08.2010.

Fenwick, Tara, and Paolo Landri. 2012. "Materialities, Textures and Pedagogies: Socio-Material Assemblages in Education." Pedagogy, Culture \& Society 20 (1): 1-7. doi:10.1080/14681366.2012.649421.

Fisher, Mark. 2009. Capitalist Realism: Is There No Alternative? Oxford: O Books. 
Fiske, John. 1990. Introduction to Communication Studies. London: Routledge. Fletcher, Robert. 2015. "Nature Is a Nice Place to Save but I Wouldn't Want to Live There: Environmental Education and the Ecotourist Gaze." Environmental Education Research 21 (3): 338-50. doi:10.1080/13504622.2014.993930.

Foucault, Michel. 1972. The Archaeology of Knowledge and the Discourse on Language. New York: Pantheon books.

Foucault, Michel. 1990. The History of Sexuality. Vol. 1, The Will to Knowledge. Harmondsworth: Penguin.

Foucault, Michel. 2004. Övervakning och straff: Fängelsets födelse. 4th ed. Lund: Arkiv förlag.

Gabrys, Jennifer, and Kathryn Yusoff. 2012. "Arts, Sciences and Climate Change: Practices and Politics at the Threshold." Science as Culture 21 (1): 124. doi:10.1080/09505431.2010.550139.

Gapminder. 2015. "Unveiling the Beauty of Statistics for a Fact Based World View." Accessed December 7 2015. http://www.gapminder.org/.

Gayford, Chris. 2001. "Education for Sustainability: An Approach to the Professional Development of Teachers." European Journal of Teacher Education 24 (3): 313-27. doi:10.1080/02619760220128879.

González-Haudiano, Edgar, and Michael A. Peters, eds. 2008. Environmental Education: Identity, Politics and Citizenship. Rotterdam: Sense publishers.

Gough, Stephen, and William Scott. 2008. Higher Education and Sustainable Development: Paradox and Possibility. New York: Routledge.

Government Proposition 2009/10:89. 2009. "Bäst i klassen - En ny lärarutbildning (2009/10:89)." Stockholm: Utbildningsdepartementet.

Gyberg, Per. 2003. Energi som kunskapsområde: Om praktik och diskurser $i$ skolan. Linköping: Linköping University.

Gyberg, Per. 2009. “Teknikens janusansikte.” In Världens gång - teknikens utveckling: Om samspelet mellan teknik, människa och samhälle, edited by Jonas Hallström and Per Gyberg, 177-87. Lund: Studentlitteratur. 
Gålmark, Lisa. 2005. Skönheter och odjur: En feministisk kritik av djurmänniska-relationen. Göteborg: Makadam.

Hagström, Erica. 2014. "En pedagogisk relation mellan människa och häst. På väg mot en pedagogisk filosofisk utforskning av mellanrummet." Pedagogisk forskning i Sverige 19 (2-3): 132-52.

Haraway, Donna. 1988. "Situated Knowledges: The Science Question in Feminism and the Privilege of Partial Perspective." Feminist Studies 14 (3): 57599.

Haraway, Donna. 1992. "The Promises of Monsters: A Regenerative Politics for Inappropriate/d Others." In Cultural Studies, edited by Lawrence Grossberg, Cary Nelson, and Paula A. Treichler, 295-337. New York: Routledge.

Haraway, Donna. 2003. The Companion Species Manifesto: Dogs, People and Significant Otherness. Chicago: Prickly Paradigm.

Haraway, Donna. 2008a. "Otherworldly Conversations: Terran Topics, Local Terms." In Material Feminisms, edited by Stacy Alaimo and Susan J. Hekman, 157-87. Bloomington: Indiana University Press.

Haraway, Donna. 2008b. When Species Meet. Minneapolis: University of Minnesota Press.

Haraway, Donna. 2015. "Anthropocene, Capitalocene, Plantationocene, Chthulucene: Making Kin." Environmental Humanities vol. 6: 159-65.

Hargreaves, Andy. 2003. Teaching in the Knowledge Society: Education in the Age of Insecurity. Maidenhead: Open University.

Hasslöf, Helen. 2015. The Educational Challenge in "Education for Sustainable Development": Qualification, Social Change and the Political. Malmö: Malmö University.

Hedlin, Maria, and Magnus Åberg. 2011. "Lärarutbildningen, jämställdhet och genus." Växjö: Linnæus University.

Hedrén, Johan. 2002. "Naturen som hot mot det moderna - några ideologikritiska reflektioner." In Naturen som brytpunkt: Om miljöfrågans mystifieringar, konflikter och motsägelser, edited by Johan Hedrén, 298-333. Eslöv: Brutus Östlings bokförlag Symposion. 
Hedrén, Johan, and Björn-Ola Linnér. 2009. "Utopian Thought and Sustainable Development." Futures 41 (4): 197-200.

Henriksson, Malin. 2014. Att resa rätt är stort, att resa fritt är större: Kommunala planerares föreställningar om hållbara resor. Linköping: Linköping University.

Hinchliffe, Steve, Matthew B. Kearnes, Monica Degen, and Sarah Whatmore. 2005. "Urban Wild Things: A Cosmopolitical Experiment." Environment and Planning D: Society and Space 23 (5): 643-58. doi:10.1068/d351t.

Hird, Myra J. 2012. "Knowing Waste: Towards an Inhuman Epistemology." Social Epistemology 26 (3-4): 453-69. doi:10.1080/02691728.2012.727195.

Hjälmeskog, Karin. 2006. "Att lära sig bry sig om de nära - och de långt borta." Utbildning \& Demokrati 15 (1): 61-76.

Holmberg, Kristina, and Marie-Helene Zimmerman Nilsson. 2014. "Cyborger och rhizom i förskolans musikverksamhet. Posthumanistiska begrepp i rörelse.” Pedagogisk forskning i Sverige 19 (2-3): 193-212.

Holmberg, Tora. 2005. Vetenskap på gränsen. Lund: Arkiv.

Hopkins, Charles. 2012. "Twenty Years of Education for Sustainable Development." Journal of Education for Sustainable Development 6 (1): 1-4. doi:10.1177/097340821100600101.

Hultman, Karin, and Hillevi Lenz Taguchi. 2010. "Challenging Anthropocentric Analysis of Visual Data: A Relational Materialist Methodological Approach to Educational Research." International Journal of Qualitative Studies in Education (QSE) 23 (5): 525-42.

Ideland, Malin, and Claes Malmberg. 2014. “'Our Common World' Belongs to 'Us': Constructions of Otherness in Education for Sustainable Development." Critical Studies in Education 55 (3): 369-86. doi:10.1080/17508487.2014.936890.

Ideland, Malin, and Claes Malmberg. 2015. "Governing 'Eco-Certified Children' through Pastoral Power: Critical Perspectives on Education for Sustainable Development." Environmental Education Research 21 (2): 173-82. doi:10.1080/13504622.2013.879696. 
Irwin, Ruth. 2008. “'After Neoliberalism': Environmental Education to Education for Sustainability." In Environmental Education: Identity, Politics and Citizenship, edited by Edgar González-Haudiano and Michael A. Peters, 171-93. Rotterdam: Sense Publishers.

Jasanoff, Sheila, and Sang-Hyun Kim. 2009. "Containing the Atom: Sociotechnical Imaginaries and Nuclear Power in the United States and South Korea." Minerva 47 (2): 119-46. doi:10.1007/s11024-009-9124-4.

Jasanoff, Sheila, and Sang-Hyun Kim. 2013. "Sociotechnical Imaginaries and National Energy Policies." Science as Culture 22 (2): 189-96. doi:10.1080/09505431.2013.786990.

Jenni, Kathie. 2005. “The Power of the Visual." Animal Liberation Philosophy and Policy Journal III (1): 1-21.

Joelsson, Tanja. 2013. Space and Sensibility: Young Men's Risk-Taking with Motor Vehicles. Linköping: Linköping University.

Johansson Krafve, Linus. 2015. Valuation in Welfare Markets: The Rule Books, Whiteboards and Swivel Chairs of Care Choice Reform. Linköping: Linköping University.

Johansson, Lotta. 2014. "Röster och rörelse: Fokusgruppen som postkvalitativ metod." Pedagogisk forskning i Sverige 19 (2-3): 110-31.

Jonsson, Gunnar. 2007. Mångsynthet och mångfald: Om lärarstudenters förståelse av och undervisning för hållbar utveckling. Luleå: Luleå University of Technology.

Jänicke, Martin. 2008. "Ecological Modernisation: New Perspectives.” Journal of Cleaner Production 16 (5): 557-65. doi:10.1016/j.jclepro.2007.02.011.

Kahn, Richard. 2003. "Towards Ecopedadogy: Weaving a Broad-Based Pedagogy of Liberation for Animals, Nature, and the Oppressed People of the Earth." Journal for Critical Animal Studies. http://www.rabbitadvocacy.com/pdf_files/Nature\%20Liberation\%20Connection.pdf.

Kaijser, Anna. 2014. Who Is Marching for Pachamama?: An Intersectional Analysis of Environmental Struggles in Bolivia under the Government of Evo Morales. Lund: Lund University. 
Kitzinger, Jenny, and Rosaline S. Barbour. 1999. "Introduction: The Challenge and Promise of Focus Groups." In Developing Focus Group Research: Politics, Theory and Practice, edited by Rosaline S. Barbour and Jenny Kitzinger, 1-20. London: Sage.

Kopnina, Helen. 2012. "Education for Sustainable Development (ESD): The Turn Away from 'Environment' in Environmental Education?” Environmental Education Research 18 (5): 699-717. doi:10.1080/13504622.2012.658028.

Kopnina, Helen. 2013. “Forsaking Nature? Contesting 'Biodiversity' Through Competing Discourses of Sustainability." Journal of Education for Sustainable Development 7 (1): 51-63. doi:10.1177/0973408213495606.

Kvale, Steinar, and Svend Brinkmann. 2009. Den kvalitativa forskningsintervjun. Translated by Sven-Erik Torhell. Lund: Studentlitteratur.

Levinas, Emmanuel, and Philippe Nemo. 1985. Ethics and Infinity. Pittsburgh: Duquesne University Press.

Lgr11. 2011. "Läroplan för grundskolan, förskoleklassen och fritidshemmen [Curriculum for the Compulsory School, Preschool Class and the Recreation Centre] (Lgr 11)." Stockholm: Skolverket.

Lidskog, Rolf, and Ingemar Elander. 2012. "Sweden and the Baltic Sea Pipeline: Between Ecology and Economy." Marine Policy 36 (2): 333-38. doi:10.1016/j.marpol.2011.06.006.

Lidskog, Rolf, and Göran Sundqvist. 2011. Miljösociologi. Lund: Studentlitteratur.

Lilja, Peter. 2010. "Globalisering, utbildningsreformer och nya förutsättningar för läraryrket.” In Från storslagna visioner till professionell bedömning - om barndom, utbildning och styrning, 206-20. Malmö: Malmö University.

Lindén, Lisa. 2013. “'What Do Eva and Anna Have to Do with Cervical Cancer?' Constructing Adolescent Girl Subjectivities in Swedish Gardasil Advertisements." Girlhood Studies 6 (2): 83-100. doi:10.3167/ghs.2013.060207.

Lindgren, Anne-Li. 2013. "Visuell analys av föreställningar om barn och natur." Barn, no. 2: 7-22. 
Linell, Per. 1994. Transkription av tal och samtal: Teori och praktik. Linköping: Linköping University.

Lorimer, Jamie. 2007. "Nonhuman Charisma." Environment and Planning D: Society and Space 25 (5): 911-32. doi:10.1068/d71j.

Lorimer, Jamie. 2009. "Natures, Charismatic." In International Encyclopaedia of Human Geography, edited by Rob Kitchin and Nigel Thrift, 324-30. Oxford: Elsevier.

Lotz-Sisitka, Heila. 2010. "Changing Social Imaginaries, Multiplicities and 'One Sole World': Reading Scandinavian Environmental and Sustainability Education Research Papers with Badiou and Taylor at Hand." Environmental Education Research 16 (1): 133-42. doi:10.1080/13504620903504081.

Lundegård, Iann. 2007. På väg mot pluralism: Elever i situerade samtal kring hållbar utveckling. Stockholm: HLS Förlag.

Lundh, Anna, and Åsa Ruling. 2008. "Lärarutbildningen och utbildning för hållbar utveckling." PM. Stockholm: Swedish National Agency for Higher Education.

Lundqvist, Eva, Roger Säljö, and Leif Östman. 2013. Scientific Literacy: Teori och praktik. Malmö: Gleerups.

Lykke, Nina. 2009. "Non-Innocent Intersections of Feminism and Environmentalism." Kvinder, køn og forskning 18 (3-4): 36-44.

Lykke, Nina. 2010. Feminist Studies: A Guide to Intersectional Theory, Methodology and Writing. London: Routledge.

MacGregor, Sherilyn. 2009. "A Stranger Silence Still: The Need for Feminist Social Research on Climate Change." The Sociological Review 57 (October): 124-40. doi:10.1111/j.1467-954X.2010.01889.x.

MacGregor, Sherilyn. 2013. "Only Resist: Feminist Ecological Citizenship and the Post-Politics of Climate Change." Hypatia 29 (3): 617-633. doi:10.1111/hypa.12065.

Marcus, George E. 1995. Technoscientific Imaginaries: Conversations, Profiles and Memoirs. Chicago: University of Chicago Press. 
Marino, Lori, Gay Bradshaw, and Randy Malamud. 2009. "The Captivity Industry: The Reality of Zoos and Aquariums." Best Friends Magazine March/April, 25-27.

Marková, Ivana, Per Linell, Michèle Grossen, and Anne Salazar Orvig. 2007. Dialogue in Focus Groups: Exploring in Socially Shared Knowledge. London: Equinox Publishing.

Martin, Ken, Denise Summers, and Harriet Sjerps-Jones. 2007. "Sustainability and Teacher Education." Journal of Further and Higher Education 31 (4): 351-62. doi:10.1080/03098770701625738.

Mazzei, Lisa A. 2013. "A Voice without Organs: Interviewing in Posthumanist Research.” International Journal of Qualitative Studies in Education 26 (6): 732 40. doi:10.1080/09518398.2013.788761.

McKenzie, Marcia, Andrew Bieler, and Rebecca McNeil. 2015. "Education Policy Mobility: Reimagining Sustainability in Neoliberal Times." Environmental Education Research 21 (3): 319-37. doi:10.1080/13504622.2014.993934.

Mckeown, Rosalyn. 2012. "Teacher Education 1992 and 2012 Reflecting on 20 Years." Journal of Education for Sustainable Development 6 (1): 37-41. doi:10.1177/097340821100600109.

Mies, Maria, and Vandana Shiva. 1993. Ecofeminism. London: Zed Books.

Mills, Reece, and Louisa Tomas. 2013. "Integrating Education for Sustainability in Pre-Service Teacher Education." Australian Journal of Environmental Education 29: 1-12.

Mirzoeff, Nicholas. 2009. An Introduction to Visual Culture. London: Routledge.

Mitchell, W. J. T. 2005. What Do Pictures Want?: The Lives and Loves of Images. Chicago: University of Chicago Press.

Mol, Annemarie. 1999. "Ontological Politics: A Word and Some Questions." In Actor Network Theory and After, edited by John Law and John Hassard, 7489. Oxford: Blackwell.

Mouffe, Chantal. 2005. On the Political. London: Routledge. 
Naturvårdsverket. 2013. "Köttkonsumtionens klimatpåverkan: Drivkrafter och styrmedel." Storå: Naturvårdsverkets rapport 6456. http://www.naturvardsverket.se/Documents/publikationer6400/978-91620-6456-3.pdf.

Neimanis, Astrida. 2013. "Feminist Subjectivity, Watered." Feminist Review 103 (1): 23-41. doi:10.1057/fr.2012.25.

Neimanis, Astrida, Cecilia Åsberg, and Johan Hedrén. 2015. “Four Problems, Four Directions for Environmental Humanities: Toward Critical Posthumanities for the Anthropocene." Ethics \& the Environment 20 (1): 67-97.

Oakley, Jan. 2011. "Animality and Environmental Education: Toward an Interspecies Paradigm." Canadian Journal of Environmental Education (CJEE) 16 (0): 8-13.

O'Neill, Saffron J., and Nicholas Smith. 2014. "Climate Change and Visual Imagery." Wiley Interdisciplinary Reviews: Climate Change 5 (1): 73-87. doi:10.1002/wcc.249.

Oppermann, Serpil. 2013. "Feminist Ecocriticism: A Posthumanist Direction in Ecocritical Trajectory." In International Perspectives in Feminist Ecocriticism, edited by Greta Gaard, Simon C. Estok, and Serpil Oppermann. London and New Work: Routledge.

Ottander, Katarina. 2015. Gymnasieelevers diskussioner utifrån hållbar utveckling: Meningsskapande, naturkunskapande, demokratiskapande. Umeå: Umeå University.

Ottestad, Ann Merete, and Nina Rossholt. 2014. "Affektive tilstander; Bevegelser i kropp og boks.” Pedagogisk forskning i Sverige 19 (2-3): 153-72.

Pedersen, Helena. 2007. The School and the Animal Other: An Ethnography of Human-Animal Relations in Education. Göteborg: Göteborg University.

Pedersen, Helena. 2010a. "Education Policymaking for Social Change: A Post-Humanist Intervention." Policy Futures in Education 8 (6): 683-96. doi:10.2304/pfie.2010.8.6.682. 
Pedersen, Helena. 2010b. "Is 'the Posthuman' Educable? On the Convergence of Educational Philosophy, Animal Studies, and Posthumanist Theory." Discourse: Studies in the Cultural Politics of Education 31 (2): 237-50.

Pedersen, Helena. 2013. "Follow the Judas Sheep: Materializing Post-Qualitative Methodology in Zooethnographic Space." International Journal of Qualitative Studies in Education 26 (6): 717-31. doi:10.1080/09518398.2013.788760.

Pedersen, Helena. 2014. "Posthumanistisk pedagogisk forskning." Pedagogisk forskning i Sverige 19 (2-3): 83-89.

Peirce, Charles S. 1955. Philosophical Writings of Peirce. Edited by Justus Buchler. Dover: Dover publications.

Plumwood, Val. 1993. Feminism and the Mastery of Nature. London: Routledge.

Plumwood, Val. 2002. Environmental Culture: The Ecological Crisis of Reason. London: Routledge.

Popkewitz, Thomas S. 2008. Cosmopolitanism and the Age of School Reform: Science, Education, and Making Society by Making the Child. New York: Routledge.

Postma, Dirk. 2012. "Education as Sociomaterial Critique." Pedagogy, Culture \& Society 20 (1): 137-56. doi:10.1080/14681366.2012.649419.

Rosiek, Jerry Lee. 2013. "Pragmatism and Post-Qualitative Futures." International Journal of Qualitative Studies in Education 26 (6): 692-705. doi:10.1080/09518398.2013.788758.

Rossiter, Penny. 2002. "Imagining Responsibility: Who Are 'We' Anyway?" Continuum 16 (1): 81-94. doi:10.1080/10304310220120993.

Ryan, Gery W., and H. Russell Bernard. 2003. "Techniques to Identify Themes." Field Methods 15 (1): 85-109. doi:10.1177/1525822X02239569.

Säfström, Carl Anders. 2011. "Equality and the Poetics of Teaching." In Heterogeneity. General Didactics Meets the Stranger, edited by Tobias Werler, 6782. Münster: Vaxmann Verlag. 
Samuelsson, Anna. 2008. I naturens teater: Kultur- och miljösociologiska analyser av naturhistoriska utställningar och filmer. Uppsala: Uppsala University.

Scanlan, John. 2005. On Garbage. London: Reaktion.

SFS 1992:1434. "Svensk författningssamling 1992:1434 Högskolelag." Stockholm: Utbildningsdepartementet.

SFS 1993:100. "Svensk författningssamling 1993:100. Högskoleförordningen.” Stockholm: Utbildningsdepartementet.

Shallcross, Tony, and John Robinson. 2007. "Is a Decade of Teacher Education for Sustainable Development Essential for Survival?" Journal of Education for Teaching 33 (2): 137-47. doi:10.1080/02607470701259382.

Sjöberg, Lena. 2009. "Skolan och den 'goda' utbildningen: För ett konkurrenskraftigt Europa.” In Utbildning \& Demokrati 18 (1): 33-58.

Sjöberg, Lena. 2010. "Lärarprofessionalism på glid. Performativ förskjutning av statlig och lärarfacklig utbildningspolicy." Pedagogisk forskning i Sverige 15 (1): 18-32.

Sjöberg, Lena. 2011. Bäst i klassen?: Lärare och elever i svenska och europeiska policytexter. Göteborg: Göteborg University.

Sjögren, Hanna. 2014a. "Den politisk-etiska potentialen hos djurmänniskorelationer i lärarutbildares samtal om hållbar utveckling." Pedagogisk forskning i Sverige 19 (2-3): 90-109.

Sjögren, Hanna. 2014b. "Educable Futures?: Managing Epistemological Uncertainties in Sustainability Education," Resilience: A Journal of the Environmental Humanities, 1 (2).

Sjögren, Hanna, Per Gyberg, and Malin Henriksson. 2015. "Human-animal Relations beyond the Zoo: The Quest for a More Inclusive Sustainability Education." Pedagogy, Culture \& Society 23 (4): 597-615. doi:10.1080/14681366.2015.1081969.

Skill, Karin. 2008. (Re)Creating Ecological Action Space: Householders' Activities for Sustainable Development in Sweden. Linköping: Linköping University. 
Skolverket. 2002. Hållbar utveckling i skolan: Miljöundervisning och utbildning för hålbar utveckling i svensk skola. Stockholm: Statens skolverk.

Solot, Dorian, and Arnold Arluke. 1997. "Learning the Scientist's Role: Animal Dissection in Middle School." Journal of Contemporary Ethnography 26 (1): 28-54. doi:10.1177/089124197026001002.

Sontag, Susan. 2013. Regarding the Pain of Others. New York: Picador.

Sørensen, Estrid. 2007. "STS Goes to School: Spatial Imaginaries of Technology, Knowledge and Presence.” Outlines. Critical Practice Studies 9 (2): 15-27.

SOU 2004:104. "Att lära för hållbar utveckling: Betänkande av kommittén för utbildning för hållbar utveckling (SOU 2004:104).” Stockholm: Utbildningsdepartementet.

SOU 2008:109. "En hållbar lärarutbildning. Betänkande av utredningen om en ny lärarutbildning (SOU 2008:109).” Stockholm: Utbildningsdepartementet.

Stoetzler, Marcel, and Nira Yuval-Davis. 2002. "Standpoint Theory, Situated Knowledge and the Situated Imagination.” Feminist Theory 3 (3): 315-33. doi:10.1177/146470002762492024.

Swyngedouw, Erik. 2003. "The Non-Political Politics of Climate Change." ACME: An International E-Journal for Critical Geographies 12 (1): 1-8.

Swyngedouw, Erik. 2010. "Apocalypse Forever? Post-Political Populism and the Spectre of Climate Change.” Theory, Culture \& Society 27 (2-3): 213-32. doi:10.1177/0263276409358728.

Swyngedouw, Erik. 2014. "Anthropocentric Politicization: From the Politics of the Environment to Politicizing Environments." In Green Utopianism: Perspectives, Politics and Micro-Practices, edited by Karin Bradley and Johan Hedrén, 23-37. New York: Routledge.

Taylor, Charles. 2002. "Modern Social Imaginaries." Public Culture 14 (1): $91-$ 124.

Tidholm, Po. 2012. Norrland: Essäer och reportage. Luleå: Teg Publishing. 
Todd, Sharon. 2003. Learning from the Other: Levinas, Psychoanalysis, and Ethical Possibilities in Education. SUNY Series, Second Thoughts. Albany: State University of New York Press.

Todd, Sharon. 2008. Att lära av den Andre: Levinas, psykoanalys och etiska möjligheter i undervisning och utbildning. Translated by Gunnar Sandin. Lund: Studentlitteratur.

Törrönen, Jukka. 2002. "Semiotic Theory on Qualitative Interviewing Using Stimulus Texts." Qualitative Research 2 (3): 343-62. doi:10.1177/146879410200200304.

Tuana, Nancy, and Shannon Sullivan. 2006. "Introduction: Feminist Epistemologies of Ignorance." Hypatia 21 (3): vii - ix.

Udovic, Ana. 2012. "När egot tar examen [When the Ego Graduates]." Dagens Nyheter, November 4. http://www.dn.se/livsstil/nar-egot-tar-examen/.

UNCED (United Nations Conference on Environment and Development). 1993. “Agenda 21: The United Nation's Conference on Environment and Development." Accessed 21 March 2016. http://www.unep.org/Documents.Multilingual/Default.asp?documentid=52.

UNECE (United Nations Economic Commission for Europe). 2005. "UNECE Strategy for Education for Sustainable Development." Accessed 21 March $2016 . \quad$ http://www.unece.org/fileadmin/DAM/env/documents/2005/cep/ac.13/cep.ac.13.2005.3.rev.

UNESCO (United Nations Educational, Scientific and Cultural Organization). 2013. "Education for Sustainable Development (ESD)." Accessed 16 December 2013. http://www.unesco.org/new/en/education/themes/leadingthe-international-agenda/education-for-sustainable-development/.

UNESCO (United Nations Educational, Scientific and Cultural Organization). 2014. "UN Decade of Education for Sustainable Development (20052014) Final Report: Shaping the Future We Want.” Paris: UNESCO.

UNESCO Institute for Statistics, and Education for All Global Monitoring Report. 2015. "A Growing Number of Children and Adolescents Are Out of 
School as Aid Fails to Meet the Mark." Policy Paper 22/Fact Sheet 31. Accessed 21 March 2016. http://unesdoc.unesco.org/images/0023/002336/233610e.pdf

Utbildningsdepartementet. 2002. “Agenda 21 för utbildning för hållbar utveckling. Östersjöområdet - Baltic 21 Education - Antagen av utbildningsministrarna vid möte på Haga slott den 24-25 januari 2002, Stockholm." Stockholm: Utbildningsdepartementet.

WCED (World Commission on Environment and Development). 1987. "Our Common Future: Report of the World Commission on Environment and Development: Our Common Future." Accessed 21 March 2016. http://www.un-documents.net/our-common-future.pdf

Webb, Graeme. 2013. “'Occupying' Our Social Imagination: The Necessity of Utopian Discourses in an Anti-Utopian Age." Perspectives on Global Development and Technology 12 (1-2): 152-61. doi:10.1163/15691497-12341248.

Whatmore, Sarah. 2002. Hybrid Geographies: Natures, Cultures, Spaces. London: Sage.

Wibaeus. 2008. "Vem historia, för vem? Ett historiedidaktiskt perspektiv på mångfald." In Uppdrag mångfald: Lärarutbildning i omvandling, edited by Marie Carlson and Annika Rabo, 125-60. Umeå: Borea.

Wibeck, Victoria. 2002. "Genmat i fokus: Analyser av fokusgruppssamtal om genförändrade livsmedel.” Linköping: Linköping University.

Wibeck, Victoria. 2010. Fokusgrupper: Om fokuserade gruppintervjuer som undersökningsmetod. Lund: Studentlitteratur.

Wibeck, Victoria, Madeleine Abrandt Dahlgren, and Gunilla Öberg. 2007. "Learning in Focus Groups an Analytical Dimension for Enhancing Focus Group Research.” Qualitative Research 7 (2): 249-67. doi:10.1177/1468794107076023.

Wickenberg, Per, ed. 2004. Learning to Change Our World?: Swedish Research on Education \& Sustainable Development. Lund: Studentlitteratur.

Wilkinson, Sue. 1999. "How Useful Are Focus Groups in Feminst Research?" In Developing Focus Group Research: Politics, Theory and Practice, edited by Rosaline S. Barbour and Jenny Kitzinger, 64-78. London: Sage. 
Willis, Susan. 1999. “Looking at the Zoo.” The South Atlantic Quarterly 98 (4): 669-87.

Wolfe, Cary. 2008. "Learning from Temple Grandin, Or, Animal Studies, Disability Studies, and Who Comes after the Subject." New Formations, no. 64: 110-24.

Yusoff, Kathryn, and Jennifer Gabrys. 2011. "Climate Change and the Imagination." Wiley Interdisciplinary Reviews: Climate Change 2 (4): 516-34. doi:10.1002/wcc.117.

Žižek, Slavoj. 2008. "Ecology as the New Opium for the Masses.” In Sustainabilities, edited by Paco Barragán, 42-47. New York City: Charta Books Ltd.

Žižek, Slavoj. 2010. Living in the End Times. London: Verso.

Åberg, Magnus. 2008. Lärardrömmar: Om makt, mångfald och konstruktioner av lärarsubjekt. Göteborg: Mara.

Åsberg, Cecilia. 2005. Genetiska föreställningar: Mellan genus och gener i populär/vetenskapens visuella kulturer. Linköping: Linköping University.

Åsberg, Cecilia. 2012. "Läskunnighet bortom humaniorans bekvämlighetszoner. En inledning.” In Posthumanistiska nyckeltexter, edited by Cecilia Åsberg, Martin Hultman, and Francis Lee, 7-21. Lund: Studentlitteratur.

Åsberg, Cecilia. 2013. “The Timely Ethics of Posthumanist Gender Studies.” Feministische Studien 31 (1): 7-12.

Åsberg, Cecilia, and Astrida Neimanis. 2016. "Environmental Humanities in Feminist Arts and Sciences." GEXcel Research Fields. Accessed February 10. http://www.gexcel.org/posthumanities_with_a_difference.html.

Öhman, Johan. 2006. Den etiska tendensen i utbildning för hållbar utveckling: meningsskapande i ett genomlevandeperspektiv. Örebro: Örebro University.

Öhman, Johan. ed. 2008. Values and Democracy in Education for Sustainable Development: Contributions from Swedish Research. Malmö: Liber.

Öhman, Johan. 2011. “Theme: The Swedish Environmental and Sustainability Education Research.” Utbildning \& Demokrati 20 (1): 3-12. 
Öhman, May-Britt. 2016. “Techno Visions of a Sámi Cyborg: Reclaiming Sámi Body-, Land-and Waterscapes after a Century of Colonial Exploitations in Sábme." In Illdisciplined Gender: Engaging Questions of Nature/culture and Transgressive Encounters, edited by Jacob Bull and Margaretha Fahlgren, 6398. Cham: Springer. 


\section{Appendix A}

\section{Links to images used as stimulus material in the focus groups}

North-South (3 out of 4 images available online)

- bit.ly/northsouth1

- bit.ly/northsouth2

- bit.ly/northsouth3

Individual-Collective (Responsibility) (1 out of 2 images available online)

- bit.ly/individualcollective

Nature-Culture (2 out of 2 images available online)

- $\quad$ bit.ly/natureculture1

- $\quad$ bit.ly/natureculture2

Global-Local (2 out of 2 images available online)

- $\quad$ bit.ly/globallocal1

- $\quad$ bit.ly/globallocal2

Policy-Practice (2 out of 3 images available online)

- bit.ly/politicspractice1

- $\quad$ bit.ly/politicspractice2

Rich-Poor (3 out of 3 images available online)

- bit.ly/richpoor1

- bit.ly/richpoor2 
- $\quad$ bit.ly/richpoor3

Doomsday-Future Optimism (2 out of 2 images available online)

- bit.ly/doomsdayfutureoptimism1

- bit.ly/doomsdayfutureoptimism2

Technological Optimism-Skepticism (2 out of 2 images available online)

- bit.ly/technologicaloptimismskepticism1

- bit.ly/technologicaloptimismskepticism2

Human-Machine-Animal (2 out of 3 images available online)

- bit.ly/humanmachineanimal1

- bit.ly/humanmachineanimal2 